\title{
AN INVESTIGATION OF ATTENTIONAL DEMAND IN A SIMULATED DRIVING ENVIRONMENT
}

by

\author{
Catherine Courage
}

A thesis submitted in conformity with the requirements for the degree of Master of Applied Science

Graduate Department of Mechanical and Industrial Engineering University of Toronto

(c) Copyright by Catherine Courage 2000 
Acquisitions and Bibliographic Services

395 Wellington Street Ottawa ON K1A ONA Canada
Bibliothèque nationale du Canada

Acquisitions et services bibliographiques

395. ne Wellington Ottawa ON K1A ONA Canada
The author has granted a nonexclusive licence allowing the National Library of Canada to reproduce, loan, distribute or sell copies of this thesis in microform, paper or electronic formats.

The author retains ownership of the copyright in this thesis. Neither the thesis nor substantial extracts from it may be printed or otherwise reproduced without the author's permission.
L'auteur a accordé une licence non exclusive permettant à la Bibliothèque nationale du Canada de reproduire, prêter, distribuer ou vendre des copies de cette thèse sous la forme de microfiche/film, de reproduction sur papier ou sur format électronique.

L'auteur conserve la propriété du droit d'auteur qui protège cette thèse. Ni la thèse ni des extraits substantiels de celle-ci ne doivent être imprimés ou autrement reproduits sans son autorisation. 


\title{
An Investigation of Attentional Demand in a Simulated Driving Environment
}

\author{
Catherine Courage \\ Master of Applied Science, 2000 \\ Graduate Department of Mechanical and Industrial Engineering \\ University of Toronto
}

\begin{abstract}
Driver's attention is a dynamic process which is dependent on the demands of the driving task, the environment, and the driver's internal state. The primary objective of this study was to examine how attentional demand changes as a function of vehicle speed, road curvature and lane width and to establish baseline quantitative measures of attentional demand for these variables. A corollary objective was to determine whether results obtained from a low fidelity driving simulator would correspond with results obtained from an on-the-road study. Attentional demand was measured in a driving simulator using visual occlusion. It was calculated as the percent of the driving time that the visual occlusion glasses were open. Results revealed that attentional demand increases as speed increases and as lane width decreases, and is greater for curved as compared to straight roads. In addition, behavioural validity was found between the low fidelity simulator and on-the-road experimental results.
\end{abstract}




\section{ACKNOWLEDGEMENTS}

There are a number of individuals without whom this thesis would not have been possible. Firstly, I would like to thank my supervisor, Paul Milgram for his continuous support, advice and encouragement over the course of the past two years. In addition, I must extend my thanks to Alison Smiley of Human Factors North for initiating the present study and for her guidance and recommendations. I would also like to thank Z Parseghian and Ted Rosenthal of Systems Technology Inc. for guiding me through numerous programming challenges. Finally, I would like to express my gratitude to John Senders and again to Paul Milgram and Alison Smiley for serving on my thesis committee and providing me with their valuable time and feedback. 


\section{TABLE OF CONTENTS}

1.0 INTRODUCTION

PAGE \#

1.1 THE DRIVING TASK

1.2 MEASURES OF MENTAL WORKLOAD 7

1.3 VISUAL OCCLUSION AS A MEASURE OF WORKLOAD 9

1.4 THE USE OF SIMULATORS IN THE STUDY OF DRIVING BEHAVIOUR

1.5 THE PRESENT STUDY

1.6 LIST OF EXPERIMENTAL HYPOTHESES

$\begin{array}{ll}\text { 1.6.1 Experiment } 1 \text { Hypotheses } & 19\end{array}$

1.6.2 Experiment 2 Hypotheses 20

$\begin{array}{ll}2.0 \mathrm{METHOD} & 21\end{array}$

2.1 SUBJECTS $\quad 21$

2.2 APPARATUS 21

2.3 EXPERIMENTAL DESIGN 22

2.4 PROCEDURE $\quad 26$

$\begin{array}{ll}3.0 \text { RESULTS } & 29\end{array}$

3.1 EXPERIMENT $1 \quad 29$

3.1.1 Standard deviation of lane position $\quad 29$

3.1.2 Time between button presses $\quad 30$

3.1.3 Percent of time with the glasses open 33

3.1.4 Comparison between current simulator study and on-the-road study 35 (Milgram et al., 1982).

3.1.5 Mean number of meters between glasses openings 37

3.1.6 Individual Subject Results 38

3.2 EXPERIMENT 2

3.2.1 Time between button presses (or glasses openings) 40

3.2.2 Percent of time with the glasses open 45

3.2.3 Differences between sexes $\quad 51$

3.2.4 Mean standard deviation of lane position (SDLP) 53 
4.0 DISCUSSION 60

4. 1 EXPERIMENT 1

60

4.2 EXPERIMENT 2

65

5.0 CONCLUSION

6.0 REFERENCES

7.0 APPENDICIES 


\section{LIST OF TABLES}

PAGE \#

Table 1. Standard deviation and mean standard deviation of lane position

(SDLP) for 3 speeds and 2 viewing conditions $(n=10)$.

Table 2. Results from the planned comparisons for the time between button presses.

Table 3. Results from the planned comparisons for the percent of time with the glasses open.

Table 4. Mean number of meters between looks at the road.

Table 5. ANOVA results for the time between button presses for the within subjects variables (speed, lane width, curvature) $(n=10)$.

Table 6. ANOVA results for the time between button presses for the between subjects variable sex $(n=10)$.

Table 7. Mean time between button presses for each lane width.

Table 8. Planned comparison results for each lane width for the time between button presses $(n=10)$.

Table 9. ANOVA results for the percent of time with glasses open for the within subjects variables (speed, lane width, curvature) $(n=10)$.

Table 10. ANOVA results for the percent of time with glasses open for the between subjects variable sex $(n=10)$.

Table 11. Mean (\%) and standard deviation (sd) of the percent of time with the glasses open for each lane width $(n=10)$.

Table 12. Planned comparison results for each lane width for the percent of time with the glasses open $(n=10)$. Shaded rows represent $p<.05$.

Table 13. Mean standard deviation of lane position and standard deviation for males and females across all Experiment 2 scenarios $(n=10)$.

Table 14. Mean standard deviation of lane position and standard deviation for males and females for the baseline scenario $(n=10)$.

Table 15. Results from the ANOVA for standard deviation of lane position across all Experiment 2 conditions. 
Table 16. Statistical comparison results for each lane width for the standard deviation of lane position. Shaded regions represent $p<.05$.

Table 17. Mean number of meters between looks at the road. 


\section{LIST OF FIGURES}

PAGE \#

Figure 1. A simplified block diagram of driver functions in the driver-vehicleroad system (Shinar, 1978).

Figure 2. The interaction between driving performance and environmental demands (Blumenthal, 1968).

Figure 3. Systems Technology Inc. low-cost driving simulator (image provided by $\mathrm{STI}$ )

Figure 4. PLATO shuttering spectacles (image provided by Translucent Technologies Inc.)

Figure 5. Mean standard deviation of lane position ( $+/$ - the standard deviation) for each speed and each viewing condition $(n=10)$.

Figure 6. Mean standard deviation of lane position for males and females (+/standard deviation) $(n=10)$.

Figure 7. Mean time between button presses (sec) $(+/$ - the standard deviation) for the $20 \mathrm{~km} / \mathrm{h}, 60 \mathrm{~km} / \mathrm{h}$ and $100 \mathrm{~km} / \mathrm{h}$ straight road scenarios $(n=10)$.

Figure 8. Mean time between button presses (sec) ( $+/$ - the standard deviation) for males and females for the straight road scenarios $(n=10)$.

Figure 9. Mean percent of time with the glasses open (+/- the standard deviation for the $20 \mathrm{~km} / \mathrm{h}, 60 \mathrm{~km} / \mathrm{h}$ and $100 \mathrm{~km} / \mathrm{h}$ straight road scenarios $(n=10)$.

Figure 10. Mean percent of time with the glasses open (+/- the standard deviation) for males and females on the straight road scenarios $(n=10)$.

Figure 11. Mean time between button presses (sec) $(+l$ - the standard deviation) for the $20 \mathrm{~km} / \mathrm{h}, 60 \mathrm{~km} / \mathrm{h}$ and $100 \mathrm{~km} / \mathrm{h}$ straight on-the-road drives $(n=6)$ (Milgram et al., 1982).

Figure 12. Mean percent of time with the glasses open $(+/$ - the standard deviation) for the $20 \mathrm{~km} / \mathrm{h}, 60 \mathrm{~km} / \mathrm{h}$ and $100 \mathrm{~km} / \mathrm{h}$ straight on-the-road drives $(n=6)$.

Figure 13. Mean percent of time with glasses open for each subject $(n=10)$ (standard deviations not available). 
Figure 14. Mean time between button presses (+/- standard deviation) for the $100 \mathrm{~km} / \mathrm{h}$ and $60 \mathrm{~km} / \mathrm{h}$ scenarios $(n=10)$.

Figure 15. Mean time between button presses ( $+/$ - standard deviation) for the curved and straight road sections of the scenarios $(n=10)$.

Figure 16. Mean time between button presses ( $+/$ - standard deviation) for the each lane width $(9,10,11$, and $12 \mathrm{ft})(n=10)$.

Figure 17. Mean time between button presses $(+/-$ the standard deviation) for males and females $(n=10)$.

Figure 18. Mean time between button presses ( $+/-$ the standard deviation) for each lane width, speed and curvature treatment.

Figure 19. Mean percent of time with glasses open (+/- standard deviation) for the $100 \mathrm{~km} / \mathrm{h}$ and $60 \mathrm{~km} / \mathrm{h}$ scenarios $(n=10)$.

Figure 20. Mean percent of time with the glasses open (+/- standard deviation) for the curved and straight road sections of the scenarios $(n=10)$.

Figure 21. Mean percent of time with the glasses open (+/- the standard deviation) for each lane width $(9,10,11,12 \mathrm{ft})(\mathrm{n}=10)$.

Figure 22. Mean percent of time with the glasses open( $+/-$ the standard deviation) for males and females $(n=10)$.

Figure 23. Mean percent of time with glasses open for the variables sex and speed.

Figure 24. Mean percent of time with the glasses open $(+1-$ the standard deviation) for each lane width, speed and curvature treatment.

Figure 25. Mean standard deviation of lane position ( $+1-$ standard deviation) for males and females across all Experiment 2 scenarios $(n=10)$.

Figure 26. Mean standard deviation of lane position ( $+/$ - standard deviation) for males and females for the baseline scenario $(n=10)$.

Figure 27. Mean standard deviation of lane position (+/- standard deviation) for lane width across all Experiment 2 drives $(n=10)$.

Figure 28. Mean SDLP (+/- standard deviation) for the variables speed $(n=10)$.

Figure 29. Mean percent of time with glasses (+/-standard deviation) open, for individual subjects, for the variable speed. $(n=10)$. 
Figure 30. Mean percent of time with glasses (+1- standard deviation) open, for individual subjects, for the variable road curvature $(n=10)$.

Figure 31. Mean percent of time with glasses ( $+/$ - standard deviation) open, for individual subjects, for the variable lane width $(n=10)$. 


\section{LIST OF APPENDICIES}

PAGE \#

APPENDIX A

79

APPENDIX B

82

APPENDIX C

83 


\subsection{INTRODUCTION}

Driving is composed of three main elements: the vehicle, the road/environment and the driver (Dewar, 1992, 1993). Although reliable engineering models about vehicles and about the road/environment are available, practically applicable quantitative models of the third element, the automobile driver, are not as extensive. Those that have been proposed attempt to characterise the driver's responses while operating the vehicle. One example of models of driver behaviour comprises those which describe steering behaviour (Smiley, 1978; McRuer \& Klein, 1974). Other models examine the driver during operations that require previewing input prior to making an overt response. Such models are useful because they can aid in the study of the effects of preview on driving performance. Despite the fact that various models of driving behaviour have been developed, much remains to be understood. For example, to date there are few models which reliably describe lane keeping behaviour. Such models would be beneficial, in that they would allow researchers to gain an understanding of the impact of factors such as lane width and previewing on lane keeping.

The application of human factors to driving research is intended to address this gap and is thus important so that an understanding can be gained of the road user (driver, pedestrian, cyclist etc) and his/her interactions with the driving environment and vehicle. A good comprehension of human behaviour in relation to the road is essential, furthermore, so that roadways and vehicles can be designed, built, and maintained optimally, to create a driving environment which matches the capabilities and limitations of road users.

Although drivers' interactions with the road and vehicle have been researched for decades, they are still not well understood. Thus, it is critical that researchers strive to learn more through testing and evaluation. This thesis aims to contribute to this objective. In particular, it strives to further the current understanding of the mental workload imposed by driving and the methods of measuring workload. It also 
attempts to investigate the utility of low cost, low fidelity driving simulation. Before discussion of the current study, as background, the driving task, widespread methods of mental workload measurement and the use of simulation in lesting and evaluation environments will be discussed.

\subsection{THE DRIVING TASK}

Alexander and Lunenfeld (1975) have broken down the driving task into three main elements, each of which requires different kinds of information. These elements are: control, guidance and navigation. Control refers to the driver's keeping control of the vehicle on the road, in terms of speed and direction. This is accomplished through steering, braking and accelerating. The information used to accomplish this task mainly comes from the vehicle and its displays. Guidance refers to sustaining a safe path and speed and keeping the vehicle in its proper position with respect to other roadway elements (e.g., in the correct lane, correct headway, etc.). Guidance requires information from the road, such as traffic control devices, hazards, other vehicles and pedestrians. The third element, navigation, refers to planning and executing the journey from one location to another. Information for navigation comes from maps, landmarks, signs, etc.

Similarity exists between each of these three driving elements. To accomplish each, the driver acts as an information processor and must process visual and other sensory inputs from the driving environment and the vehicle. He/she then must decide the appropriate control actions, carry out these actions, and process and respond to new situations that arise. Figure 1 presents a simplified illustration of driver functions in the driver-vehicle-road system. The complexity of the driving task is unmistakable even when illustrated by a simplified model. 


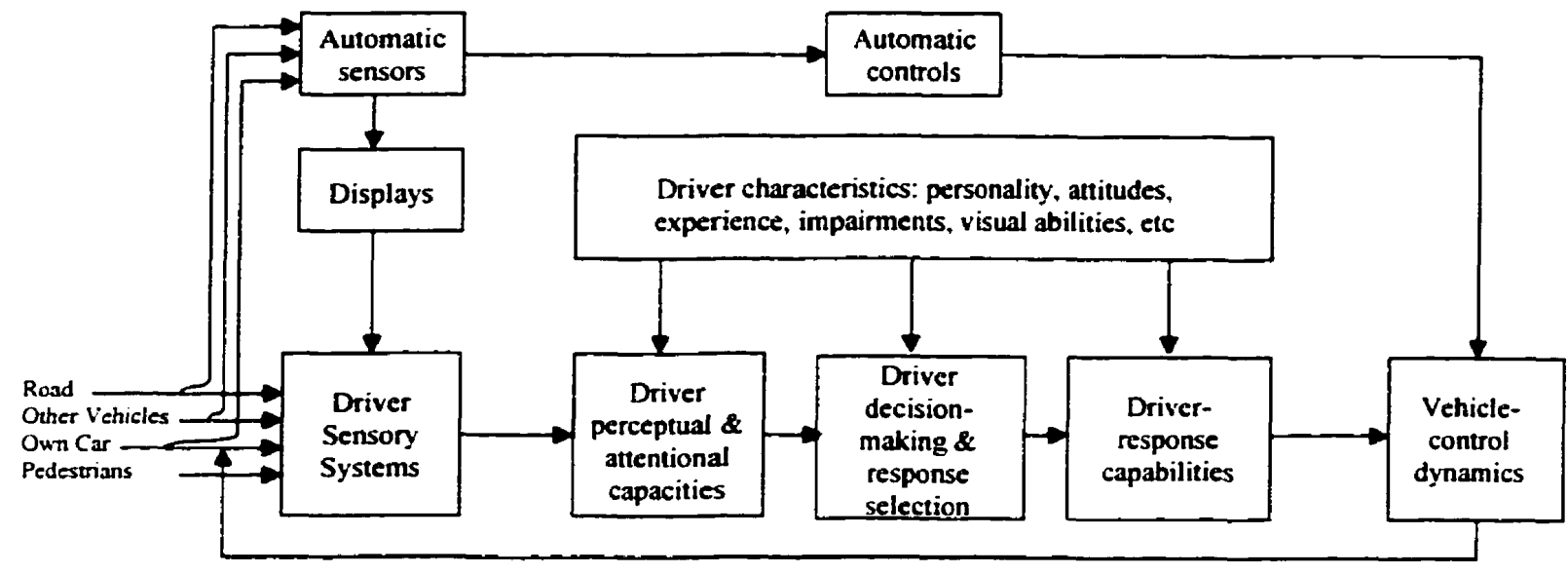

Figure 1. A simplified block diagram of driver functions in the driver-vehicle-road system (Shinar, 1978).

The above model illustrates the role(s) of the driver, the environment and the vehicle, as well as the relationship(s) that exist between them. The focus of the following discussion is on the role of the driver, as illustrated by this model. The driver receives a wealth of sensory information from both the environment and the vehicle. Much of the information that the driver receives has already been interpreted by the vehicle's electronic systems. These electronic systems are illustrated as the automatic sensors in Figure 1. They include instruments such as the speedometer and other dashboard displays. The automatic controls illustrated in Figure 1 also have a very important function in the driver-vehicle-road system. Just as the name indicates, these controls function to automatically control the car. They include such functions as the cruise control and automatic transmission. Both the automatic sensors and controls are very important, in that they alleviate some of the load imposed upon the driver.

The information the driver obtains from the vehicle's automatic sensors, controls and the environment is meaningless until processed by the brain into meaningful information. The driver then must make a decision concerning the appropriate response(s) to this information. Each of these three stages is impacted by the 
driver's characteristics, such as level of driving experience, mood, personality, and needs. When a response is made the vehicle's control dynamics respond to this action. For example, when the driver brakes, the car slows down. This process repeats itself continually while driving.

With experience, the majority of drivers' complex activities just described become automated and drivers are unaware of the multiple internal activities at work (Shinar, 1978). When drivers reach this stage, where processing is fast and effortless, it known as automatic processing. For inexperienced drivers the task of driving is much more demanding. Information processing and motor control are consciously controlled and resource-demanding (Wikman, Nieminen, \& Summala, 1998). This demanding processing is referred to as controlled processing.

In the current investigation the focus is on experienced drivers. Despite extensive experience, failure in any of the areas illustrated in Figure 1 can result in a system breakdown, which presents itself in the form of errors or accidents. Such failures within the system commonly occur within the drivers' information processing stages (e.g. perception, attention, decision making). The reason for such failures relates to the fact that the capacity of the human information processing system is limited. Thus, this system is susceptible to overload. To avoid information overload the driver is constantly faced with the need to decide what information to attend to and what information to ignore. Shinar (1978) summarised the driver's information processing task well. He stated that, "the driver can best be thought of as an information processing channel in which the central decision making component is rate limited, and the peripheral attentional and perceptual mechanisms function to select the most important cues to be processed by that central decision mechanism". As previously discussed, the demands of the information task may ease with experience, but information processing still remains susceptible to overload, even for the experienced driver. 
Experienced drivers are usually able to avoid accidents because their information processing capacity is greater than the information processing demands placed on them by the environment. However, when the information processing demands placed upon the driver by the environment become too great, performance declines and accidents can result. Figure 2 illustrates this interaction between driving performance and environmental demands.

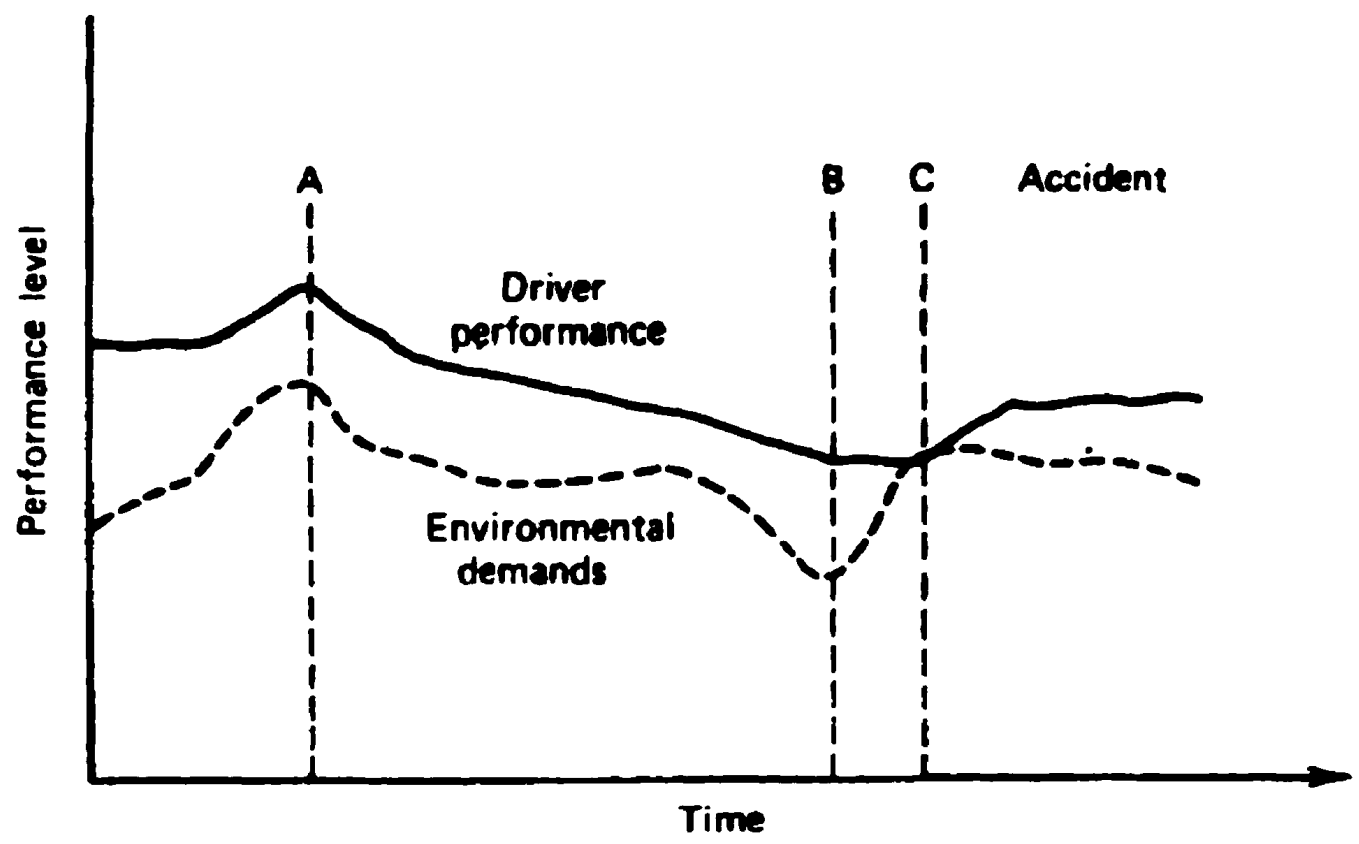

Figure 2. The interaction between driving performance and environmental demands (Blumenthal, 1968).

Point $C$ on the graph illustrates the scenario in which environmental demands exceed performance. Typically, this occurs when high demands are suddenly placed on an unprepared driver. Point $A$ illustrates the situation in which the environmental demands are high, but the driver is able to perform at a level, which exceeds these demands. For example, this may occur if the driver is on a busy freeway. He/she is 
aware of the demands of the situation, thus he/she focuses on the task. Point B illustrates the situation in which the environmental demands are low, thus drivers gradually adjusts his/her performance to a lower level, indicated by the gradual decline from $A$ to $B$, while still maintaining performance at a level sufficient to meet the demands of the environment (Blumenthal, 1968).

It is critical that researchers gain a strong understanding of the limits and capabilities of the information processing system. This area of study is important so that we can aid in reducing the number of accidents. Accident prevention via workload analysis is of particular importance today, due to the incorporation of advanced technology into the driving environment (Smiley, 1989). Today's drivers are increasingly diverting their attention away from the road and applying it to cellular phones, invehicle navigation systems, auto PC's and even televisions. Thus, the "driving experience" is no longer solely focused on the goal of transporting one's self safely from location A to location B. By incorporating new tasks and goals into the "driving experience" the workload placed on today's driver is potentially greater than ever. It is thus critical that sound methods and techniques for measuring workload be employed to study driver workload. This is so that researchers can gain an understanding of how such technology impacts the attention that drivers are paying to the roadway and so that regulations regarding the incorporation of technology into vehicles can be enforced if necessary.

Workload assessment techniques also have important implications for road designers. For example, with the use of a simulator, engineers can predict the hypothetical workload imposed by roads before they are even built. By doing so, they can ensure that roads that are to be built or reconstructed do not exceed the mental capabilities of drivers. Mental workload is also a very important area of study due to the growing number of elderly drivers on the road. It is important to understand the mental capabilities of this growing population of drivers. In the following section a review of the more common mental workload measurement 
techniques will be reviewed. This will be succeeded by a discussion of a less utilised method known as visual occlusion.

\subsection{MEASURES OF MENTAL WORKLOAD}

There are three categories of workload measurement techniques which are most commonly used. These categories of measurement are: physiological measures, subjective measures and performance-based measures (Wierwille \& Eggemeier, 1993). In this section each of the three measurement techniques and some of their advantages and/or disadvantages will be reviewed.

Physiological workload measures reflect the physiological consequences of dealing with demand. The assumption is that the more demanding the task, the greater the mental workload and the greater the level of physiological arousal. The most commonly employed physiological measures include heart rate variability, brain activity and eye-blink activity. Physiological workload measurements are advantageous, in that the data can be collected in a relatively unobtrusive manner. Typically, for the driver this simply involves the placement of electrodes on the body (Wierwille \& Eggemeier, 1993; Smiley, 1989). One must be aware, however, of the limitations of physiological measures when using them. Specifically, physiological measures reflect mainly the body's "defence response". In other words, they are responsive to novel situations and controlled information processing, but not necessarily to automatic information processing (de Waard, \& Brookhuis, 1997).

The second category of workload measurement is subjective measurement. Subjective measures of workload assume that the drivers' subjective estimate of workload increases as the difficulty of the task increases (Smiley, 1989). This information is typically collected via self-reports or questionnaires of mental workload or effort. Intrusiveness can be minimised if these questionnaires are administered after the driving task has been completed (de Waard \& Brookhuis, 1997). A disadvantage of this technique, on the other hand, is that the researcher is relying on 
the subjects' own perception of workload which can be impacted by the subject' sensitivity to such changes, as well as motivational factors.

The third category of common workload measurements is performance-based measurement. Performance-based measures of workload include two subcategories: primary task measurement and secondary task measurement. Primary task measurement examines the drivers' performance on one or many of the elements of the driving task (e.g., standard deviation of lane position, standard deviation of steering wheel movements, etc.). This method makes the assumption that, as the driving task becomes more difficult, the workload increases and the drivers' performance will decline. An advantage of this method is that there is no interference in the driving task. A limitation of this method of assessing workload, on the other hand, is that primary task measures, like physiological measures, can be insensitive to certain changes in workload. In the case of primary task measurement, this insensitivity stems from the fact that, when workload increases, drivers typically expend extra processing resources to meet the additional demand. The result is that the primary measures will not exhibit any changes, despite the increased workload (Wierwille. \& Eggemeier, 1993).

The second subcategory of performance-based measures of workload is secondary task measurement. This method involves having the driver perform a secondary task while carrying out the primary task (i.e., driving). Typical secondary tasks include performing mental arithmetic and discriminating between signals. The assumption here is that, as the driving task becomes more difficult, the workload increases and thus performance on the secondary task will decline (Smiley, 1989). A problem with secondary task measurement, however, is that the secondary task itself may interfere with the primary task, which can lead to intrusion. Intrusion occurs when drivers divert the allocation of their processing resources from the primary task to the secondary task (Wierwille \& Eggemeier, 1993). 


\subsection{VISUAL OCCLUSION AS A MEASURE OF WORKLOAD}

Visual occlusion is another method of measuring mental workload. This method focuses on the amount of attention required to drive under different circumstances. As previously discussed, attention has a major role in the information processing carried out by the driver (see Figure 1). The driver must continually choose what information to attend to and what to ignore, so that an overload of mental workload does not occur.

The visual occlusion method of attention assessment is based on the assumption that a driver is able to safely control an automobile while viewing the roadway ahead only when he/she needs to update information for guidance and control purposes. This procedure allows the experimenter to produce an estimate of the mean sampling rate, and thereby an estimate of the visual information requirements, for different road environments. This measure has been referred to as attentional demand (Senders, Kristofferson, Levison, Dietrich \& Ward, 1967). The complement of this measure ( $100 \%$ minus attentional demand) gives a measure of the percent of spare visual capacity (Fitzpatrick, Wooldridge, Tsimhoni, Collins, Green, Bauer, Parma, Koppa, Harwood, Anderson, Krammes, \& Poggioli, 1999).

In 1967, Senders et al. first used the visual occlusion method to assess their uncertainty model of attentional demand in an experiment with an actual automobile on a real roadway. Their model postulated a pattern of increasing uncertainty of the driver about the vehicle-roadway system between looks at the road. The theoretical supposition behind the model was that, "drivers drive to a limit that is determined by that point when the drivers' information processing capacity, either real or imagined, is matched by the information generation rate of the road, either real or estimated". 
The following equation describes the driver's uncertainty at the end of the occlusion interval:

$U\left(T_{d}\right)=H^{\cdot} D\left[1-e^{-(V / D+1 / F) T d]}+K_{n} V^{2}\left(T_{d}\right)^{3 / 2}<=U_{c}\right.$

where

$H^{\cdot} D\left[1-e^{-(N / D+1 / F) T d}=\right.$ the amount of information in storage at the end of the occlusion interval

$H=$ the information density of the road

$\mathrm{D}=$ the weighting constant (miles)

$V=$ vehicle velocity (miles/sec)

$F=$ the time constant (sec) for the rate of forgetting

$T_{d}=$ the time at the end of the occlusion interval

$K_{n}=a$ constant (which includes the power spectral density and other scaling factors) $V^{2}\left(T_{d}\right)^{3 / 2}=$ the driver's uncertainty concerning the lateral displacement of the vehicle $U_{c}=$ the driver's criterion level (bits)

Experimentally, Senders et al. (1967) measured drivers' attentional demand using a visual occlusion device consisting of a pneumatically driven visor mounted on a football heimet, which provided drivers with a half second glance of the roadway whenever the subject drivers felt it was necessary. It was found that, as the velocity of the vehicle increased, so did the attentional demand. That is, the greater the speed at which the automobile travelled, the more often drivers looked at the road. These data from the visual occlusion study verified the adequacy of the driver uncertainty model.

In 1980, Milgram, Godthelp and Blaauw performed an extensive set of on-the-road baseline experiments, following up on Senders et al.'s original research (Milgram et al., 1982). Their findings were independently replicated by Mourant \& Ge (1997) who tested subjects in a driving simulator. The authors of that study found that a 
greater attentional demand was required for curved as opposed to straight roads and for traffic versus no traffic scenarios. More recently, still using visual occlusion techniques, it was found in another on-the-road experiment that visual demand for curves is linearly related to degree of curvature and that in curved sections there is a tendency to fixate on one edge of the road (Fitzpatrick et al., 1999).

Relatively speaking, in comparison to other methods of workload measurement, visual occlusion has been used only very rarely. Nevertheless, the visual occlusion method holds great promise for workload assessment, due to the simplicity of the method and the robustness of the data. Consequently, it is important that studies be carried out to emphasise the power and validity of this technique. That is, in order for visual occlusion, or any other workload assessment method, to be valued for use in testing and evaluation, it is important that it be proven sensitive to a range of workload manipulations across a variety of experiments (Wierwille \& Eggemeier, 1993). It is also important that experimental results can be replicated to ensure the reliability of the method.

As a part of the present study, Milgram et al.'s (1982) on-the-road visual occlusion study (discussed in further detail in Section 1.5) was replicated for this purpose, using a low fidelity Systems Technology Inc. (STI) driving simulator. A corollary objective of the present study was to determine if the results collected using this simulator would correspond with earlier results obtained in a real automobile. That is, it is important to replicate the results of on-the-road studies to ensure the behavioural validity of such simulation tools. In the next section the issue of simulation and validity are explored in greater detail.

\subsection{THE USE OF SIMULATORS IN THE STUDY OF DRIVING BEHAVIOUR}

Today simulator studies have a major role in driving research. Simulation is very appealing, in that it can provide a safe, convenient and comprehensive environment for conducting research (Allen, Rosenthal, \& Aponso, 1998). Not all simulators are 
created equal, however. Distinctions can be made between low fidelity, mid fidelity and high fidelity simulators. Simulators which consist of a PC, monitor(s), and a simple cab with controls are considered low fidelity. Mid fidelity simulators, are more advanced, in that they typically include advanced imaging techniques, a large projection screen, a realistic cab and often have a motion base. Simulators which are considered high fidelity typically have a 360-degree field of view and an advanced moving base (Kaptein, Theeuwes, \& van der Horst, 1996). The Systems Technology Inc. simulator used in the current study would be considered a low fidelity simulator. It is PC driven and consists of three monitors, a steering wheel, brake and accelerator pedals and driving seat. It is not mounted on a motion base.

The use of driving simulators for research is advantageous in a number of ways. Some of these advantages include: the potential to create cost savings, the ability to investigate dangerous or rare situations, and the provision of experimental control. Each of these advantages is discussed in further detail below.

The use of a driving simulator can provide substantial cost savings. In particular, it can be used for the investigation of the effects of prototype roadway elements on driving behaviour. Typically, new ideas in road design are far too expensive to build for the sole sake of testing. However, through the use of simulation, highway and road designers can have the opportunity to test new roadway designs before they are built. Cost savings can also be experienced by researchers who wants to study behaviour on existing roadways. On-the-road studies are very expensive to carry out so, by simulating the current road conditions of interest, substantial savings can be made (Kaptein, et al., 1996).

In addition to cost savings, driving simulation is advantageous in that it allows researchers to study conditions which may be potentially dangerous. For example, an experimenter interested in crash avoidance behaviour could put subjects in simulated situations where they have to avoid a collision(s). This aspect of simulation has very important implications for studying how in-vehicle technology 
affects the driver. This is a growing area of research, as it is critical that we have an understanding of how this technology impacts driving behaviour. Simulation is advantageous for such research, in that it allows experimenters to study how such technology impacts mental workload and it allows them to do this in a risk-free manner. Simulation also allows researchers to study conditions which may be rare, and thus difficult to reproduce under real roadway conditions. For example, they can create specific types of traffic behaviour or particular weather patterns (Kaptein et al., 1996; Allen et al, 1998).

Another advantage of using simulators to studying driving behaviour is the experimental control simulation affords. Using a simulator researchers can carry out an examination of driving behaviour in a controlled environment, thus increasing the internal validity of the study. They can control specific factors of interest and eliminate unwanted influences, such as traffic fluctuations and weather changes, whereas on-the-road tests must deal with the unpredictability of the environment. Such unpredictability can result in different testing conditions for different subjects, a problem which can be eliminated with simulation (Kaptein et al., 1996; Gianutsos, 1994).

Simulators have numerous advantages, as we have just discussed, but these must be exploited with caution. This is because the value of a simulator is contingent upon its capability to elicit the same sort of responses from the driver that he/she would make in analogous situations on the real road (Rolfe, Hammerton-Frase, Poulter and Smith, 1970). In other words, the validity of the data produced by simulators is a major concern. Most simulator studies discuss the face validity of the simulator they are using (i.e., how the simulator physically resembles a vehicle and the driving environment), but they typically fail to discuss the behavioural validity (Blaauw, 1982). Unfortunately, without behavioural validity, the practical value of research carried out on a simulator is uncertain. 
It is critical that researchers ensure that the simulator they are using produce behaviourally valid responses to the specific driving task they are examining. The first step in accomplishing this involves the researcher ensuring that the capabilities or qualities of the simulator match the particular driving task. For example, if examining the drivers' response to traffic signs or hazards, it is important to use a driving simulator with high resolution. Similarly, if tracking is being examined, it is critical that the simulator can create dynamics comparable to an on-the-road driving situation.

A quantitative method of studying the behavioural correspondence between simulators and on-the-road studies involves applying the same experimental design to on-the-road and simulated driving environments. Subjects' performances in each test environment are then compared. If the results are not statistically different, that is, if the absolute size of the effect is the same for both the on-the-road and simulator conditions, the simulator is said to have absolute validity. If the absolute values differ, but the direction and ranking of the effect is the same, then the simulator is said to have relative validity (Blaauw, 1982; Kaptein et al., 1996).

With so many inexpensive low fidelity driving simulators available on the market, such as the Systems Technology Inc. simulator and Elemental Driving simulator (EDS) (Gianutsos, 1994)., simulator research is becoming more and more widespread. It is critical, however, that researchers consider the validity of their particular simulator before commencing their study. One of the goals of the present study is to examine the validity of a particular low cost, low fidelity simulator, manufactured by Systems Technology Inc. (www.systemstech.com), which is used by many driving behaviour researchers. The validity of this simulator will be tested by replicating an earlier on-the-road study carried out by Milgram et al. (1982). If validity does exist, it will also be of interest to determine if it is absolute or relative. 


\subsection{THE PRESENT STUDY}

Three main objectives were involved in the present set of experiments. These objectives included:

1. to investigate the behavioural validity of a low cost, low fidelity driving simulator

2. to provide support for visual occlusion as a measure of attentional demand

3. to investigate how speed, curvature of the road and lane width affect the level of attentional demand in a simulated driving environment

To accomplish the first objective of investigating the behavioural validity of a low cost, low fidelity driving simulator, an on-the-road visual occlusion study carried out by Milgram et al. (1982) was replicated. The replication study was carried out in a low cost, low fidelity Systems Technology Inc. driving simulator, to determine if the same results could be obtained. It was also of interest to determine whether the results, if replicated, would be replicated with absolute or relative validity. In Milgram et al.'s study, experienced drivers wore a visual occlusion device, consisting of an electric motor driven visor mounted on a bicycle helmet, while driving down a straight stretch of unused road. The helmet was normally closed, thus occluding the drivers' view of the road. However, they were able to look at the road by triggering a switch, which caused the visor to open and provided them with a 0.5 sec glimpse of the roadway.

In Milgram et al's study, drivers were instructed to "drive safely and look at the road as often as necessary". The percentage of the time that the subjects spent looking at the road was calculated, as the attentional demand for that particular condition. In addition, the time between opening requests was examined. This parameter was also important to investigate, because it revealed the rate at which the drivers sampled different driving conditions. In their experiment Milgram et al. assessed how drivers' attentional demand varied with speed as their primary independent variable. Specifically, they examined $20,40,60,80,100$ and $120 \mathrm{~km} / \mathrm{h}$ speed conditions. It was found that, as speed increased, so did the attentional demand and sampling rate measures. 
In the present driving simulator study, Milgram et al.'s (1982) first experimental design was replicated, with simulated driving scenarios programmed to reproduce the same driving conditions as in the 1982 study. In the present Experiment 1, as in Milgram et al.'s study, drivers wore visual occlusion goggles and were instructed "to drive safely and to look at the road as often as necessary". Each "look" provided them with a $0.5 \mathrm{sec}$ glimpse of the road. Three of the speeds examined by Milgram et al. were investigated in the present study: $20 \mathrm{~km} / \mathrm{h}, 60 \mathrm{~km} / \mathrm{h}, 100 \mathrm{~km} / \mathrm{h}$. Based on pilot testing it was anticipated that the same pattern of results would be obtained, that is, as the speed increased, so would the measures of attentional demand. Due to the obvious differences between low-fidelity simulation and a real on-the-road experiment, it was not expected that absolute validity would be achieved; however, due to the robustness of the visual occlusion technique, it was hypothesised that relative validity would be found.

The second experimental objective of the present study was to provide support for visual occlusion as a measure of attentional demand. Specifically, the experimenters wanted to demonstrate the transferability, reliability, diagnosticity, and sensitivity of visual occlusion as a measure of attentional demand. Transferability refers to the capability of a technique to be used in a variety of operational situations (Wierwille \& Eggemeier, 1993). Experiment 1, as outlined above, was a replication of an on-theroad study in a simulator. If the results are replicated, as hypothesised, it will help demonstrate the transferability of visual occlusion from simulator to on-the-road studies. It is also important that experimental results can be replicated to ensure the reliability of the method. Experiment 1 was thus also replicated within the present study for this purpose.

Diagnosticity, in this case, refers to the ability of the visual occlusion method to attribute changes in attentional demand to identifiable aspects of the driver's task. Sensitivity refers to the degree to which visual occlusion can distinguish differences in the level of workload imposed on the driver (Wierwille \& Eggemeier, 1993). In the 
present experiment an attempt was made to exemplify diagnosticity and sensitivity in both experiments 1 and 2 . Variables such as speed (examined in experiments 1 and 2), road curvature (examined in experiment 2 ) and lane width (experiment 2 ) were manipulated. It was hypothesised that the changing workload created by the manipulation of these variables would be demonstrated by the changing level of attentional demand. In addition, it was hypothesised that the changes in workload would be able to be attributed to the specific variables. The specific hypotheses with regard to each of these variables will be discussed in the next section, along with a detailed discussion of Experiment 2.

The third objective of the present study was to investigate how speed, curvature of the road and lane width affect attentional demand while driving. Attentional demand across different speeds and/or road curvatures has been examined by other researchers. In particular, it has been found that as speed increases so does attentional demand (Senders et al., 1967; Milgram et al., 1982; Mourant \& Ge, 1997; Fitzpatrick et al., 1999). With regards to road curvature, it has been found that more attentional demand is required for curved roads as opposed to straight roads and that attentional demand for curves is linearly related to curvature (Mourant $\& \mathrm{Ge}$, 1997; Fitzpatrick et al., 1999).

In the second experiment of the present simulator study, visual occlusion was used to measure attentional demand imposed by a range of driving conditions. Specifically, attentional demand was investigated across the speeds $60 \mathrm{~km} / \mathrm{h}$ and $100 \mathrm{~km} / \mathrm{h}$, for both straight and curved segments (radius of curvature $=1.52 \mathrm{~km}$ ) of road. Based on previous findings, it was hypothesised that as speed increased so would the attentional demand (Senders, et al., 1967; Milgram et al., 1982). It was also hypothesised that greater attentional demand would be required for the curved sections of road as compared to the straight segments of road.

A third variable, lane width, was also examined in the experiment. Although no published research regarding attentional demand as a function of lane width was 
found, this is a very important area of research, particularly because traffic engineers often try to squeeze more lanes onto pre-existing roads/highways, to cope with the growing volume of traffic. This is typically accomplished by decreasing the width of individual lanes (Heimbach, Cribbins, \& Chang, 1983). Other traffic engineers narrow the roadway for the purpose of slowing down driving speeds. Some studies have shown that narrowing lane widths is advantageous, because it does indeed have the ability to slow drivers down (van der Horst \& Hoekstra, 1994). Narrowing lane widths can also have major negative implications. Specifically, it has been found that roads with narrower lane widths have a higher percentage of accidents (Zegeer, Huang, Stewart, \& Williams, 1998; Heimbach, Cribbins, \& Chang, 1983). It seems clear, therefore, that more research investigating the impact of lane widths must be conducted. In the present study, the examination of attentional demand across different lane widths was fuelled by the limited research in this very important area, since understanding the mental demand which a lane width imposes drivers should have very useful implications. Because it is important that the drivers' mental capabilities not be overloaded, an awareness of the attentional demand created by different road conditions can help avoid this.

In the second experiment of the present study the attentional demand of 9, 10, 11 and 12 foot road widths was investigated using visual occlusion. These particular lane widths were chosen after examination of the lane widths deemed acceptable by the Ontario Ministry of Transportation's Geometric Design Standards for Ontario Highways. Specifically, the guidelines for $2-l a n e, 60$ and $100 \mathrm{~km} / \mathrm{h}$ rural roadways were examined. These guidelines gave a lane width range between 9.8 and $12.3 \mathrm{ft}$ as acceptable ( 3.0 and $3.5 \mathrm{~m}$ respectively). It was hypothesised that, as the lane width decreased, the attentional demand would increase. As previously mentioned, in addition to lane width, the different speeds and road curvature were also examined, because it was also of interest to determine if interactions would exist among these three variables. 
Finally, it is expected that results of this research will be potentially useful for assisting in the design of roadways, with respect to factors such as road width and signage density. In addition, although it is beyond the scope of the present study, the data collected from these experiments could be used by researchers who develop mathematical models to construct a model of attentional demand. In the past, such models have been developed, for example, by Senders et al. (1967), Milgram et al (1982), and Wierwille, Hulse, Fischer, and Dingus (1988). As previously mentioned, such models can aid researchers in further understanding drivers' behaviour.

With regards to the investigation of the validity of the particular low fidelity simulator used here, the obvious advantage of demonstrating the validity of such a simulator is its potential for further driving behaviour research at relatively low cost and great flexibility.

\subsection{LIST OF EXPERIMENTAL HYPOTHESES}

The following section summarises the experimental hypotheses generated for the two experiments of the present study.

\subsubsection{Experiment 1 Hypotheses:}

Experiment 1 was a replication of an on-the-road study carried out by Milgram et al. (1982). In that study the relationship between speed and attentional demand was examined using visual occlusion. The aim of Experiment 1 of the present study was to replicate these results using a low cost, low fidelity simulator. To ensure that subjects were performing the visual occlusion task as instructed, subjects' lane position was measured with and without the visual occlusion glasses. The following hypotheses were generated for this experiment:

1. Subjects will perform the visual occlusion task as instructed. That is, the standard deviation of lane position will be the same for the glasses and no glasses driving conditions.

2. as driving speed increases so will the attentional demand 
3. relative validity will be found between the on-the-road and simulator studies for the measures of attentional demand

\subsubsection{Experiment 2 Hypotheses:}

Experiment 2 of the present study was designed to examine the relationships between attentional demand and the variables: speed, road curvature and lane width using visual occlusion. The following hypotheses were generated for this experiment:

1. as driving speed increases, the attentional demand will increase

2. greater attentional demand will be required for the curved segments of road as compared to the straight segments of road

3. as lane width decreases, attentional demand will increase 


\subsection{METHOD:}

\subsection{SUBJECTS}

Ten subjects, five males and five females, participated in this study. Each subject participated in both experiments. The mean subject age was 25 ( $s d=2.6$ ). All subjects held a valid driver's license at the time of testing and were licensed drivers for a mean of 7.8 years ( $(s d=2.5$ ). Subjects were recruited from the University of Toronto graduate and undergraduate student populations via postings on campus. Subjects had a mean of 4.5 years $(s d=1.1)$ post-secondary education. Each subject was paid $\$ 37$ at the end of testing for their 3 days of participation.

\subsection{APPARATUS}

Subjects were required to drive a variety of pre-programmed driving scenarios on a Systems Technology Inc. (STI) driving simulator. The STI simulator comprises three fifteen inch monitors which display the driving scene to the driver. In addition, the simulator includes a steering wheel, accelerator pedal, brake pedal and driving chair (see Figure 3). The required field of view for the STI simulator is $80^{\circ}$ horizontally and $47^{\circ}$ vertically.

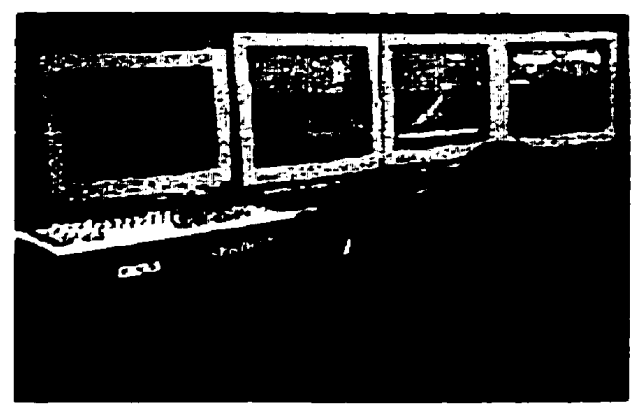

Figure 3. Systems Technology Inc. low-cost driving simulator (image provided by STI)

In addition to the simulator, a pair of PLATO shuttering spectacles (Milgram, 1987) provided by Translucent Technologies Inc. were used (see Figure 4). 


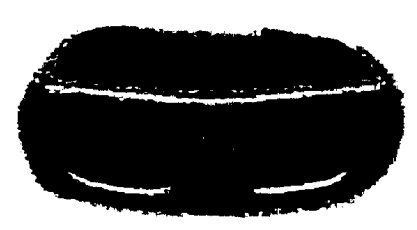

Figure 4. PLATO shuttering spectacles (photograph provided by Translucent Technologies Inc.)

The glasses provided the subjects with a horizontal field of view of 122 and a vertical field of view of 94 . This field of view was greater than the required field of view for the STI simulator (horizontal $=80^{\circ}$; vertical $=47^{\circ}$ ).

These spectacles allowed the experimenter to program the lenses to open and shut according to experimental requirements. The opening and closing times of the spectacles were rated at $1 \mathrm{~ms}$ and 3-5 ms respectively. The software package ToTaLcontrol (Translucent Technologies Inc.) was used to program the glasses, to allow for a $0.5 \mathrm{~s}$ view of the scene each time the subjects activated the switch. The switch was incorporated into the simulator's turn signal activator, located beneath the left side of the steering wheel. Using this apparatus it was possible for the glasses to be open for $100 \%$ of the drive. In order for this to be accomplished, however, the button would have to be pressed while the glasses were still open (which would also have been rather fatiguing for the subject).

\subsection{EXPERIMENTAL DESIGN}

Two experiments were carried out. Each experiment required subjects to drive preprogrammed driving scenarios. There were a number of variables which remained 
constant for all driving scenarios ${ }^{1}$. For example, the car driven was $6 \mathrm{ft}(183 \mathrm{~cm})$ wide and its hood and the speedometer could always be seen while driving. Also, all roads were flat with 2 lanes (one in either direction) which were separated by a dashed line. The shoulder of the road was $.333 \mathrm{ft}(10 \mathrm{~cm})$ on each side. The driving scene consisted of a blue sky with clouds, with grass on both sides of the road, and contained randomly placed trees and fixed mountains in the background. An external disturbance function, simulating wind gusts was incorporated into each scenario. The wind gusts, which impacted the entirety of each scenario, were created by summing a group of sine waves together to produce a complex wind pattern. The wind caused the vehicle to drift, which in turn forced the subjects to continually attempt to maintain the vehicle's heading angle by controlling the steering. All scenarios were between 2.2 and 3.5 minutes in length, but no data were collected for the first 10 seconds of each run. This allowed the driver to adjust to the speed of the scenario. When data collection commenced, all variables were recorded five times per second for the duration of each scenario.

Each experiment required subjects to drive some or all of its scenarios while wearing the shutter glasses. The subjects' task was to drive safely and to look at the road (i.e. open the shutter glasses) whenever they felt it was necessary. The shutter glasses were triggered by engaging a switch, which was activated when the turn indicator was momentarily pressed down (i.e., when a left turn indication was made). Experiment 1 was a $2 \times 3 \times 2$ mixed factorial design. The two sexes (male and female) along with three levels of speed were examined $(20 \mathrm{~km} / \mathrm{h}(18.22 \mathrm{ft} / \mathrm{sec}) 60 \mathrm{~km} / \mathrm{h}$ $(54.67 \mathrm{ft} / \mathrm{sec})$ and $100 \mathrm{~km} / \mathrm{h}(91.11 \mathrm{ft} / \mathrm{sec}))$, in combination with two levels of viewing condition (with or without shutter spectacles/glasses) to yield a total of 12 treatments. With the exception of sex all variables were within subjects. The variable speed was examined by setting the speed of the simulation at a constant for each scenario (either $20 \mathrm{~km} / \mathrm{h}$ or $60 \mathrm{~km} / \mathrm{h}$ or $100 \mathrm{~km} / \mathrm{h}$ ). By setting the speed at a constant it was as though the driver was using cruise control (i.e., no braking or accelerating

\footnotetext{
' It is important to note that the STI simulator is programmed in feet. Thus, throughout the methods section measurements are at times given in feet.
} 
was required, only steering). The variable, viewing condition, vas examined by having the subject drive either with or without the glasses. Each of the 6 scenarios driven for Experiment 1 involved straight road driving and each was, equal in duration (130 seconds long). The scenarios were equal in duration, because, when pilot experiments were run using equal distance, it was found that the $20 \mathrm{~km} / \mathrm{h}$ scenario was far too long; that is, subjects found the combination of the slow speed and long duration to be very taxing. The distances driven for the $20 \mathrm{~km} / \mathrm{h}, 60 \mathrm{~km} / \mathrm{h}$ and $100 \mathrm{~km} / \mathrm{h}$ scenarios were $0.39 \mathrm{~km}, 1.17 \mathrm{~km}$ and $1.94 \mathrm{~km}$, respectively.

Three dependent variables were examined in Experiment 1. Firstly, the standard deviation of the lane position was examined. This variable was recorded as a presumed measure of whether a difference in primary driving performance existed across the three speeds when the drivers were wearing the glasses versus when they were not. This information was critical to ensure that drivers were performing equally well with and without the glasses on while driving, in light of their instruction "to drive safely". In addition, the time between button presses (or request to open the glasses) and the percent of time with the glasses open were examined. Obviously, however, these dependent variable were examined for the glasses conditions only. It is important not to confuse the time between button presses as a measure of the time between looks. Time between button presses includes the $0.5 \mathrm{sec}$ that the glasses were open. To obtain the mean time between looks - that is, the mean time between the end of the previous look and the beginning of the next one $-0.5 \mathrm{sec}$ would have to be subtracted from the mean time between button presses. It is also necessary to note that the two dependent measures are essentially the same. It was felt that it was important to represent the data both ways, as it allows readers to see the data from two different perspectives. The mean percent of time with glasses open gives an overall measure of the attentional demand of individual runs, while the mean time between glasses opening reflects the mean sampling rate adopted by subjects for particular conditions. 
Experiment 2 was a $2 \times 2 \times 2 \times 4$, mixed factorial design, with the factors being sex, speed, road curvature and lane width. With the exception of sex all variables were within subjects. The two sexes (male and female), two speeds (60 km/h and 100 $\mathrm{km} / \mathrm{h}$ ), two road curvatures (straight and curved), and four lane widths ( $9 \mathrm{ft}, 10 \mathrm{ft}, 11$ $\mathrm{ft}$ and $12 \mathrm{ft}$ ) were examined, to yield a total of 32 treatments. Each scenario comprised only one speed and one lane width but had both straight and curved road types. Thus a total of 8 scenarios ( 4 lane widths $\times 2$ speeds) were driven by the subjects. Like Experiment 1, speed was controlled by setting it at a constant for each scenario (either $60 \mathrm{~km} / \mathrm{h}$ or $100 \mathrm{~km} / \mathrm{h}$ ). Each scenario had 6 curves (3 to the right and 3 to the left). Each curve was $230 \mathrm{~m}(750 \mathrm{ft})$ in length and had a radius of curvature of $1520 \mathrm{~m}$ (5000 ft), a value which falls within the Transportation Association of Canada's manual of guidelines for road design. All curves were separated by $0.33 \mathrm{~km}$ straightaways.

Unlike Experiment 1, the scenarios for Experiment 2 were not equal in duration, instead they were equal in length. Each of the 8 scenarios that the subjects drove were a total of $3.61 \mathrm{~km}$ in length. The $100 \mathrm{~km} / \mathrm{h}$ scenarios took $130 \mathrm{sec}$ to complete, while the $60 \mathrm{~km} / \mathrm{h}$ scenarios took 217 seconds to complete. The reason why the scenarios were equal in length rather than duration (like Experiment 1) was due to the fact that it was deemed necessary for comparison purposes that subjects drive curves of equal length and radius of curvature for all conditions. In order for this to be possible for both speeds, scenarios of equal duration could not be used, thus the scenarios were designed to be equal in length.

In Experiment 2, two dependent variables were examined. Specifically, the time between button presses (or requests to open the glasses) and the percent of time with the glasses open were examined. Subjects wore the glasses for all Experiment 2 scenarios. 
For both experiments, each treatment scenario was driven by the subjects only once during the data collection day. In addition, the ordering of the presentation of the scenarios was counterbalanced across subjects to eliminate the effects of practice.

\subsection{PROCEDURE}

The experiments took approximately 3 hours per subject, comprising 3 one hour sessions over a week. Days 1 and 2 were training days and on Day 3 data were collected. (See Appendix A for schedule.) The two training days were a critical component of the experiment. They allowed the subjects to become familiar and comfortable with both the simulator and the glasses.

To begin Day 1 of training, the subjects were given detailed instructions about their responsibilities and the requirements of the experiment and were asked to sign a consent form (See Appendix B). Next the subjects completed a demographic questionnaire (See Appendix $\mathrm{C}$ ). After completion of the questionnaire subjects drove a baseline training drive, which took approximately 3 minutes to complete. The baseline scenario used was adopted from a drive developed and used for research carried out by the Southern California Research Institute and Human Factors North (Moskowitz, Burns, Fiorentino, Smiley, \& Zador, 1999). The purpose of the baseline training scenario run was to provide the experimenter with a measure of the subjects' ability to drive the simulator without any prior training. The subjects used the accelerator, brake and steering wheel for the baseline scenario, in contrast to the subsequent experimental runs, which required steering control only. For this and all other scenarios, subjects were asked to obey all rules of the road and drive as they normally would in a real automobile.

Following the baseline run the subjects began training for Experiment 1 by driving the $60 \mathrm{~km} / \mathrm{h}$ scenario without the glasses. (See Appendix A - Day 1 training.) This scenario, like all of the scenarios for Experiment 1, was 130 seconds in length and had a constant speed, i.e., subjects were not required to accelerate or brake. Next, they drove two more scenarios, $60 \mathrm{~km} / \mathrm{h}$ and $100 \mathrm{~km} / \mathrm{h}$ scenarios respectively, but 
this time with glasses. The latter of these two scenarios was repeated until criterion, or until it had been driven three times. Criterion was reached when the driver was able to stay in his/her lane (i.e. without exceeding the lane boundaries), for the duration of the scenario. It was originally planned that, if any drivers were unable to reach criterion after three runs, they would be given ten dollars and would be disqualified from the experiment. This situation did not occur, however, as all drivers successfully met criterion. This completed training for Experiment 1 and the subjects were given a 10 minute break at this point.

After the break subjects began training for Experiment 2. Subjects wore the glasses for all the training stages of this experiment. They were required to drive four scenarios. (See Appendix A - Day 1 training.) All scenarios for Experiment 2 had a constant speed, that is, subjects were not required to accelerate or brake. Each scenario comprised only one speed and one lane width but had both straight and curved road types. Once again, subjects were asked to obey all rules of the road and drive as they normally would for this and all other scenarios that they would drive. It was also emphasised to subjects that this was not an experiment in risktaking. The latter of the four scenarios driven was repeated until criterion, or until it had been driven six times. Criterion was reached when the driver was able to stay in his/her lane for the duration of the scenario. Once again, it was planned that, if any drivers were unable to reach criterion at this stage in training, they would be given ten dollars and would be disqualified from the experiment. Again, this situation did not occur as all drivers successfully met criterion. This completed training for Day 1.

Days 2 and 3 of the experiment were identical in terms of the scenarios that were driven. They differed in that Day 2 was a second day of training while on Day 3 data were collected. (See Appendix A - Day 2 \& Day 3.) Each day began with Experiment 1 scenarios. The Experiment 1 scenarios were initiated by having the subjects drive one warm up scenario at $100 \mathrm{~km} / \mathrm{h}$ with the glasses. Data were not collected for this run on either day. The subjects were then required to drive six more scenarios, with the ordering of these scenarios randomised for each subject on both 
days. For three of the scenarios the subjects wore the glasses and for three they did not. This completed the driving for Experiment 1. Subjects were then given a ten minute break before proceeding to the Experiment 2 scenarios.

The driving of the Experiment 2 scenarios began with two warm up drives at 100 $\mathrm{km} / \mathrm{h}$ with glasses. Data were not collected for these runs on either Day 2 or 3 . The subjects were then required to drive eight more scenarios, all with glasses. The ordering of these scenarios was randomised for each subject on both days. The subjects were given a five minute break half way through Experiment 2. Upon completion of all trials (approximate total time: 3 hours over 3 days), the subjects were paid $\$ 37$ for their participation in the experiment. 


\subsection{RESULTS:}

\subsection{EXPERIMENT 1}

Experiment 1 was a $2 \times 3 \times 2$, mixed factorial design. The two sexes (males and females) along with three levels of speed were examined $(20 \mathrm{~km} / \mathrm{h}, 60 \mathrm{~km} / \mathrm{h}$ and $100 \mathrm{~km} / \mathrm{h}$ ) in combination with two levels of viewing condition (with and without shutter glasses) to yield a total of 12 treatments. All scenarios driven for Experiment 1 involved straight road driving.

\subsubsection{Standard deviation of lane position}

A repeated measures analysis of variance (ANOVA) was performed on the standard deviation of lane position collected for each treatment. As hypothesised (see Introduction, section 1.6 for list of experimental hypotheses), no significant main effects or interactions were found for speed $(f(2,16)=2.84, p>.05)$ or viewing condition $(f(1,8)=1.51, p>.05)$. Figure 5 and Table 1 illustrate the mean standard deviation of lane position data for each treatment.

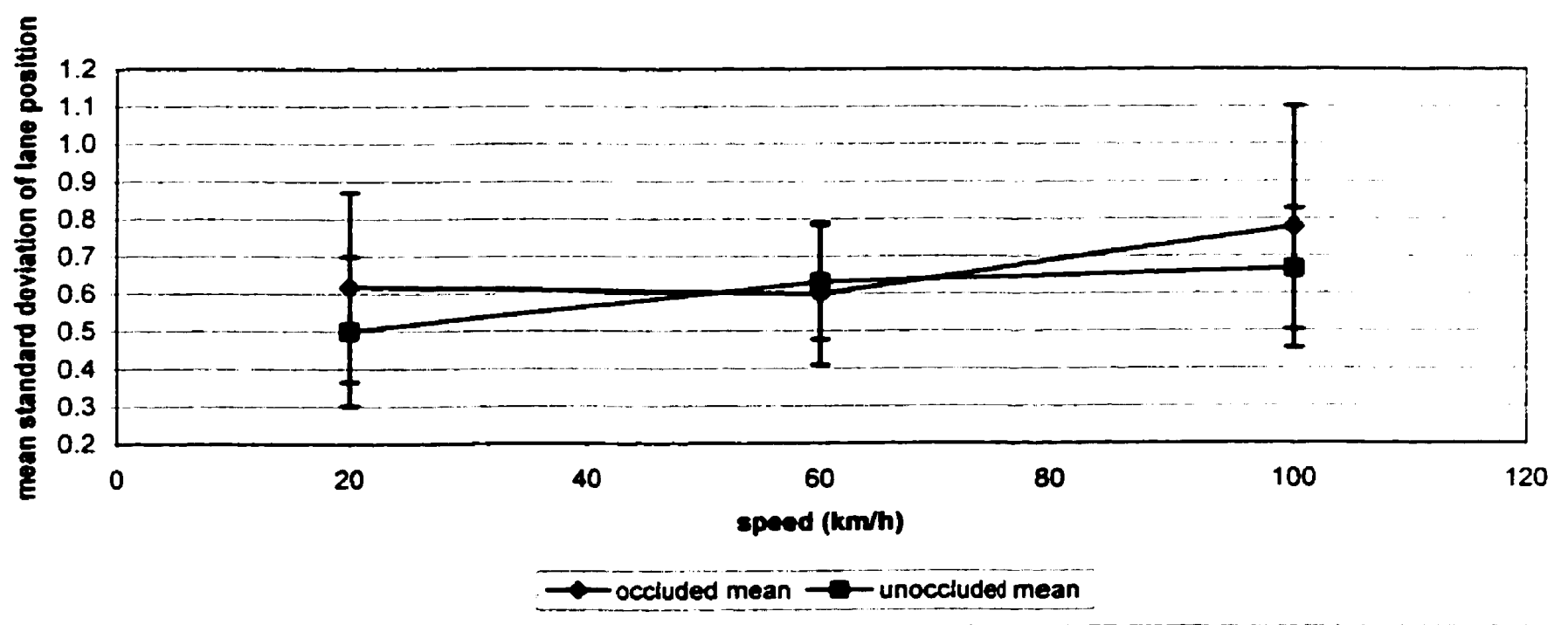

Figure 5. Mean standard deviation of lane position (+l- the standard deviation) for each speed and each viewing condition $(n=10)$. 


\begin{tabular}{|c|c|c|c|c}
\hline & \multicolumn{2}{|c|}{ mean SDLP } & \multicolumn{2}{c}{ sd of SDLP } \\
\hline $\begin{array}{c}\text { speed } \\
(\mathbf{k m} / \mathbf{h})\end{array}$ & occluded condition & unoccluded condition & occluded condition & unoccluded condition \\
\hline 20 & 0.62 & & & \\
\hline 60 & 0.60 & 0.50 & 0.25 & 0.20 \\
\hline 100 & 0.78 & 0.63 & 0.19 & 0.15 \\
\hline
\end{tabular}

Table 1. Standard deviation and mean standard deviation of lane position (SDLP) for 3 speeds and 2 viewing conditions $(n=10)$.

In addition, no significant main effects $(f(1,8)=1.06, p>.05)$ or interactions were found for sex ( $p<.05$ for all interactions). Figure 6 illustrates the mean standard deviation of lane position for both males $($ mean $=0.58$ ) and females $($ mean $=0.68$ ).

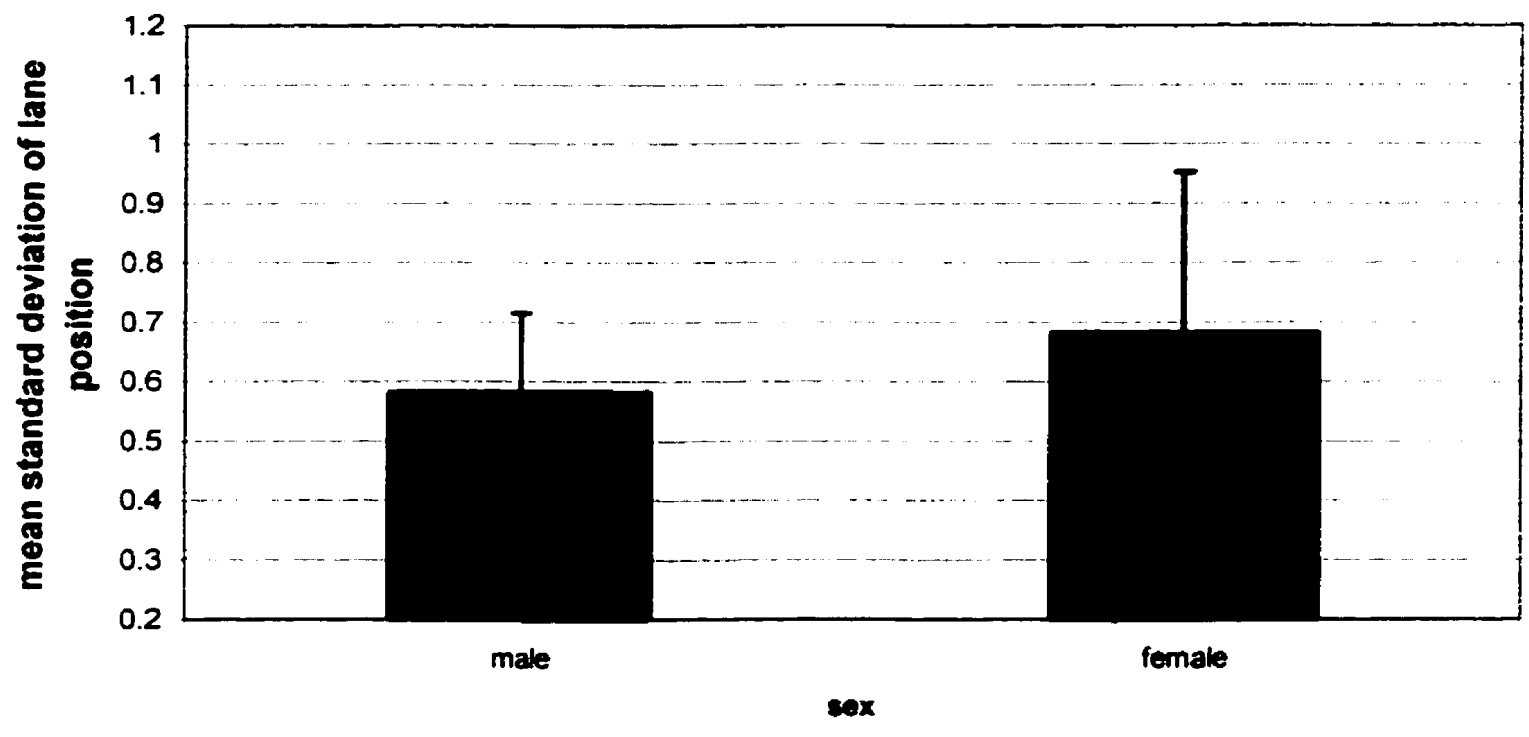

Figure 6. Mean standard deviation of lane position for males and females $(+1-$ standard deviation $)(n=10)$.

\subsubsection{Time between button presses}

A second ANOVA examined the mean time between button presses (i.e. time between requests for glasses to open) for each of the three speeds and for both sexes. As hypothesised, and illustrated in Figure 7, a significant main effect was found for speed (f $(2,16)=22.34, p<.05)$. Also as expected, the three planned 
comparisons revealed a significant difference between the mean times between button presses for each of the comparisons of speed. Table 2 presents the $t$ values for each of these planned comparisons.

\begin{tabular}{|c|c|c|c|c|c|c|}
\hline & $\begin{array}{c}\text { speeds } \\
(\mathbf{k m} / \mathbf{h})\end{array}$ & mean & Sd & t & df & $\begin{array}{c}\text { Sig. } \\
\text { Level }\end{array}$ \\
\hline Pair 1 & $20-60$ & 0.17 & 0.18 & 2.89 & 9 & 0.02 \\
\hline Pair 2 & $100-20$ & -0.39 & 0.26 & -4.79 & 9 & 0.00 \\
\hline Pair 3 & $100-60$ & 0.23 & 0.09 & -7.63 & 9 & 0.00 \\
\hline
\end{tabular}

Table 2. Results from the planned comparisons for the time between button presses. Shaded rows represent $p<.05$.

The results show that the time between button presses was significantly smaller for the $100 \mathrm{~km} / \mathrm{h}$ speed when compared to the 20 and $60 \mathrm{~km} / \mathrm{h}$ speeds. It was also found that the time between button presses was significantly smaller for the $60 \mathrm{~km} / \mathrm{h}$ speed when compared to the $20 \mathrm{~km} / \mathrm{h}$ speed.

Figure 7 shows the means for each speed. All means were greater than 0.5 seconds (the glasses opening duration), indicating that on average the button to open the glasses was pressed while the glasses were closed (i.e. on average subjects were able to drive safely without visual input for at least some period of time). 


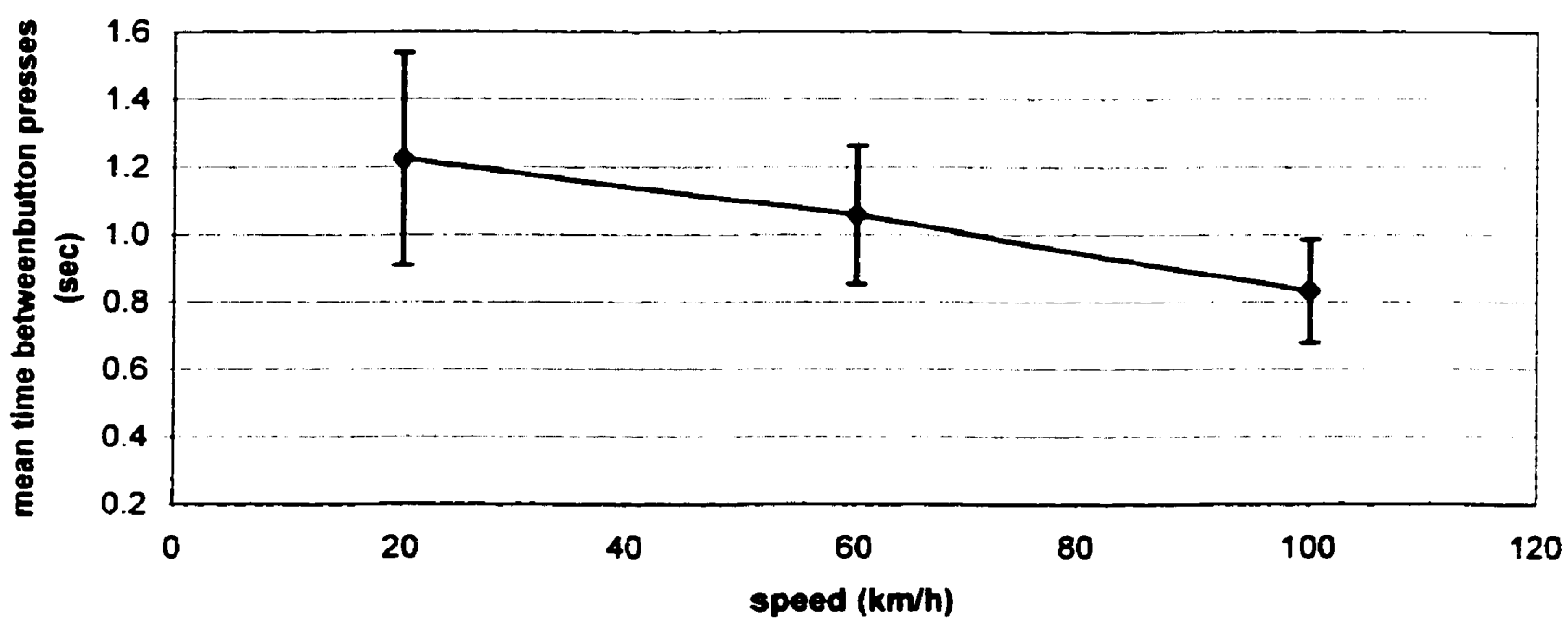

Figure 7. Mean time between button presses (sec) ( +1 - the standard deviation) for the $20 \mathrm{~km} / \mathrm{h}, 60 \mathrm{~km} / \mathrm{h}$ and $100 \mathrm{~km} / \mathrm{h}$ straight road scenarios $(n=10)$.

A significant main effect was not found for the variable, $\operatorname{sex}(f=(1,8) 3.87, p>.05)$. In addition, no interactions were found for this analysis. Figure 8 illustrates the means for times between presses for each sex.

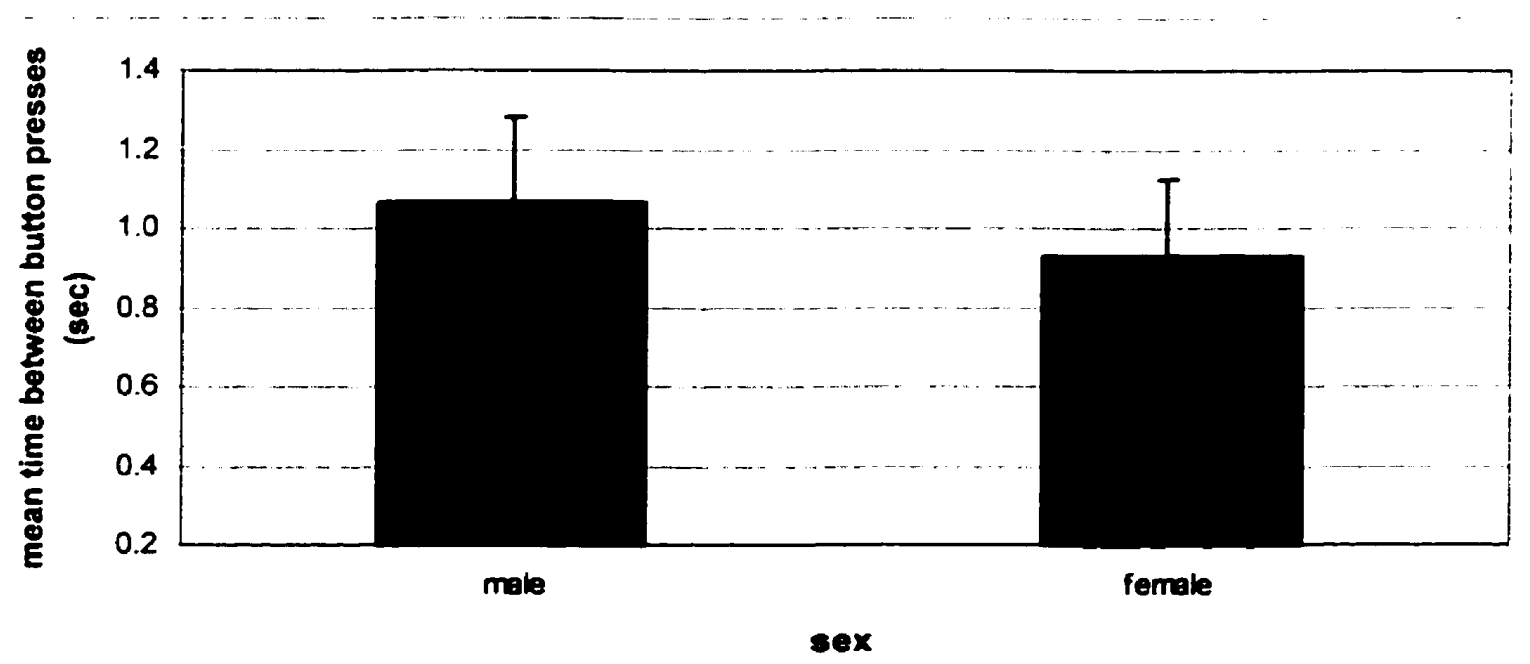

Figure 8. Mean time between button presses (sec) ( $+/$ - the standard deviation) for males and females for the straight road scenarios $(n=10)$. 


\subsubsection{Percent of time with the glasses open}

A third ANOVA was performed on the measure percent of time with glasses open.

As hypothesised, a significant main effect was found for speed $(f(2,16)=35.69$, $p<.05$ ). Also as expected, three planned comparisons revealed a significant difference between the percentages of time the glasses were open for each of the speeds. Table 3 illustrates the $t$ values for each of the comparisons.

\begin{tabular}{|c|c|c|c|c|c|c|}
\hline & $\begin{array}{l}\text { speed } \\
(\mathbf{k m} / \mathrm{h})\end{array}$ & mean & sd & t & df & $\begin{array}{l}\text { Sig. } \\
\text { Level }\end{array}$ \\
\hline Pair 1 & $20-60$ & $5: 8333$ & 52558 & -3.5008 & 9 & 0.01 \\
\hline Pair 2 & $100=20$ & $18: 9167$ & 95875 & $6: 3723$ & $\overline{9}$ & 0.00 \\
\hline Pair 3 & $100=60$ & 13.0833 & 4053 & 8.5510 & $\overline{8}$ & $0: 00$ \\
\hline
\end{tabular}

Table 3. Results from the planned comparisons for the percent of time with the glasses open. Shaded rows represent p<.05.

The percent of time with the glasses open was significantly larger for the $100 \mathrm{~km} / \mathrm{h}$ speed when compared to the 20 and $60 \mathrm{~km} / \mathrm{h}$ speeds. It was also found that the percent of time with the glasses open was significantly larger for the $60 \mathrm{~km} / \mathrm{h}$ speed when compared to the $20 \mathrm{~km} / \mathrm{h}$ speed. Figure 9 presents the means for each speed. 


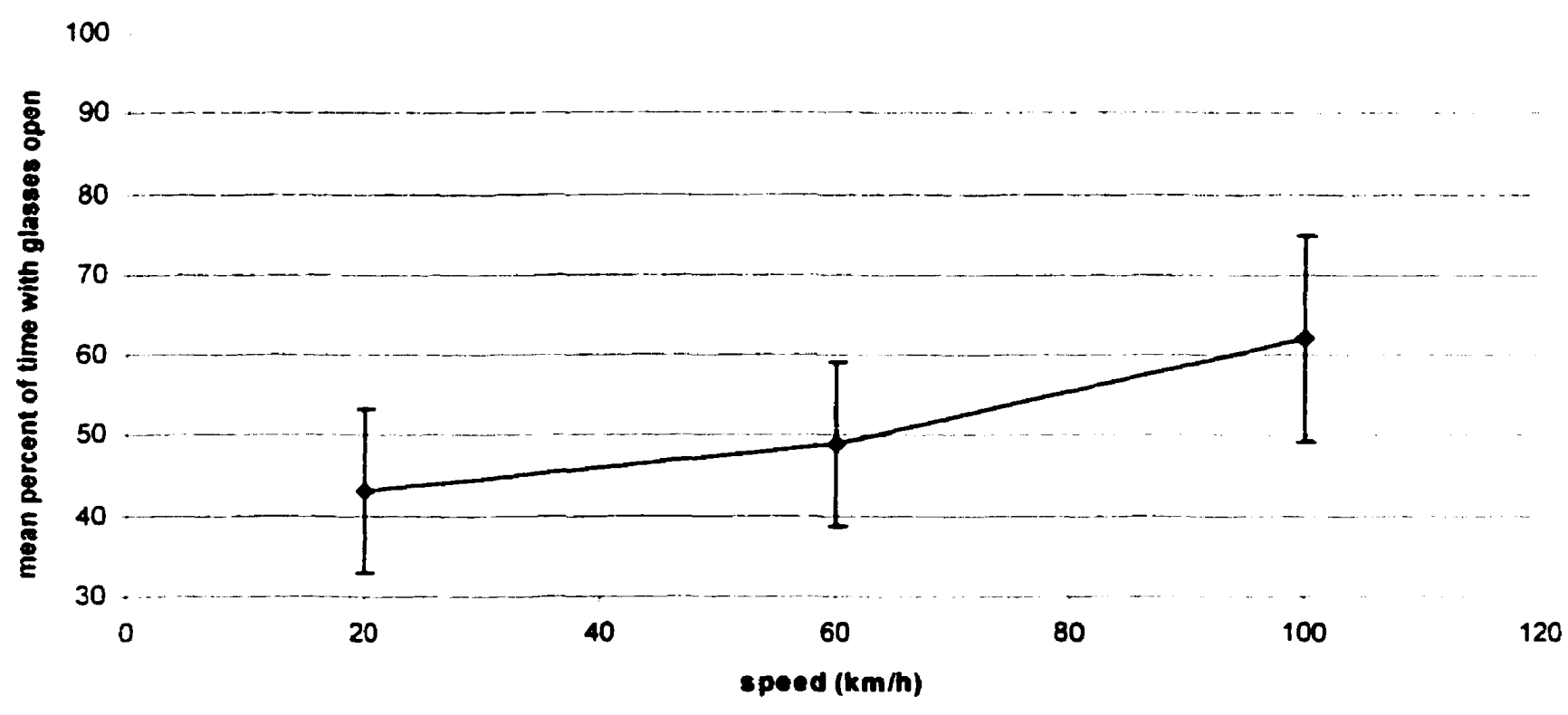

Figure 9. Mean percent of time with the glasses open (+/- the standard deviation for the $20 \mathrm{~km} / \mathrm{h}, 60 \mathrm{~km} / \mathrm{h}$ and $100 \mathrm{~km} / \mathrm{h}$ straight road scenarios $(n=10)$.

No interactions were found from the analysis of the mean percent of time with glasses open and there was also not a significant main effect for the variable, sex $(f(1,8)=3.5, p>.05)$. Figure 10 illustrates the means for percent of time with the glasses open for each sex. 


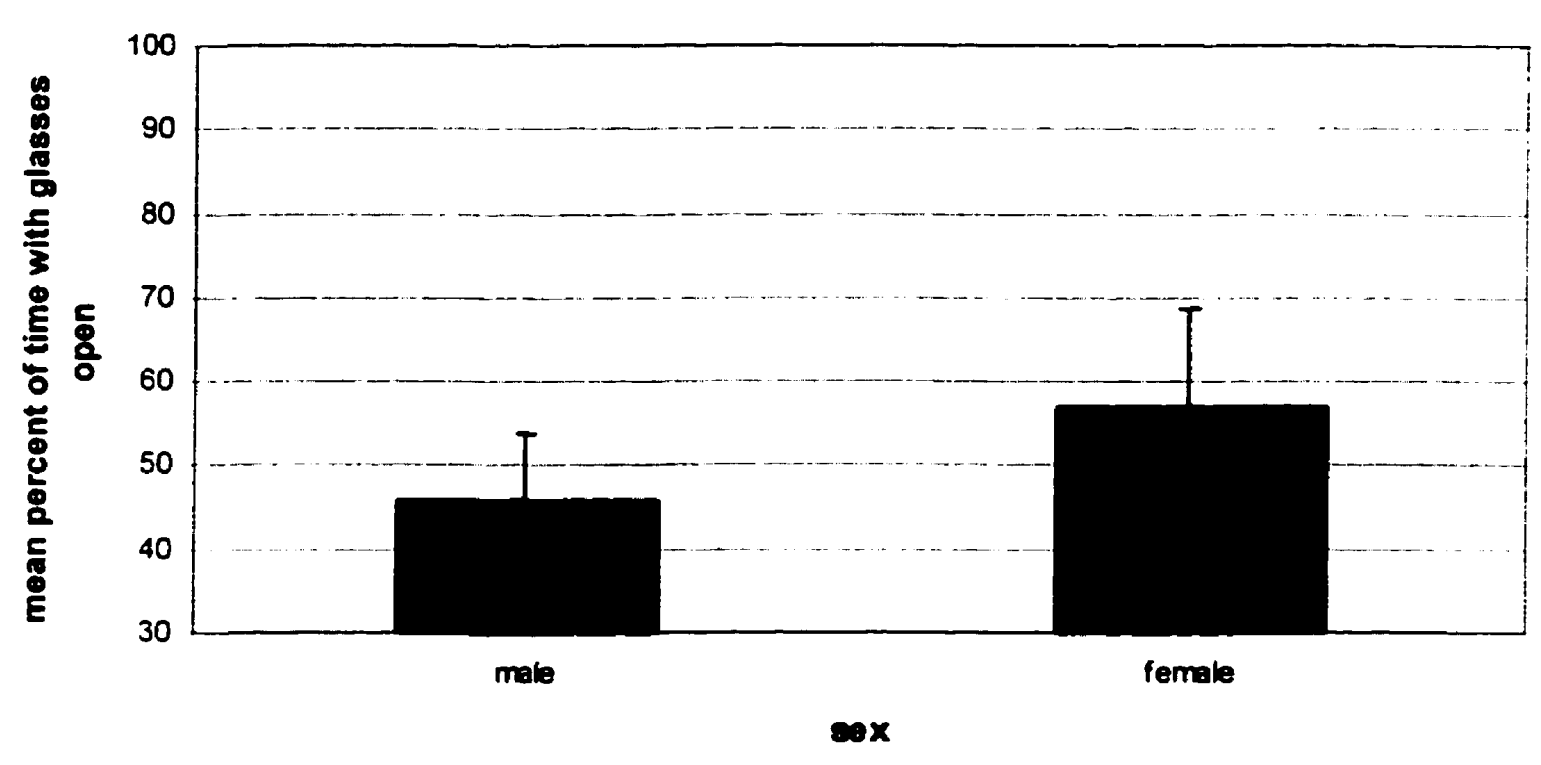

Figure 10. Mean percent of time with the glasses open ( $+/-$ the standard deviation) for males and females on the straight road scenarios $(n=10)$.

\subsubsection{Comparison between current simulator study and on-the-road study} (Milgram et al., 1982).

As hypothesised, the same trends were found for Milgram et al.'s on-the-road data and the present simulator study. Figure 11 presents the data for mean time between button presses for the on-the-road and simulator studies. 


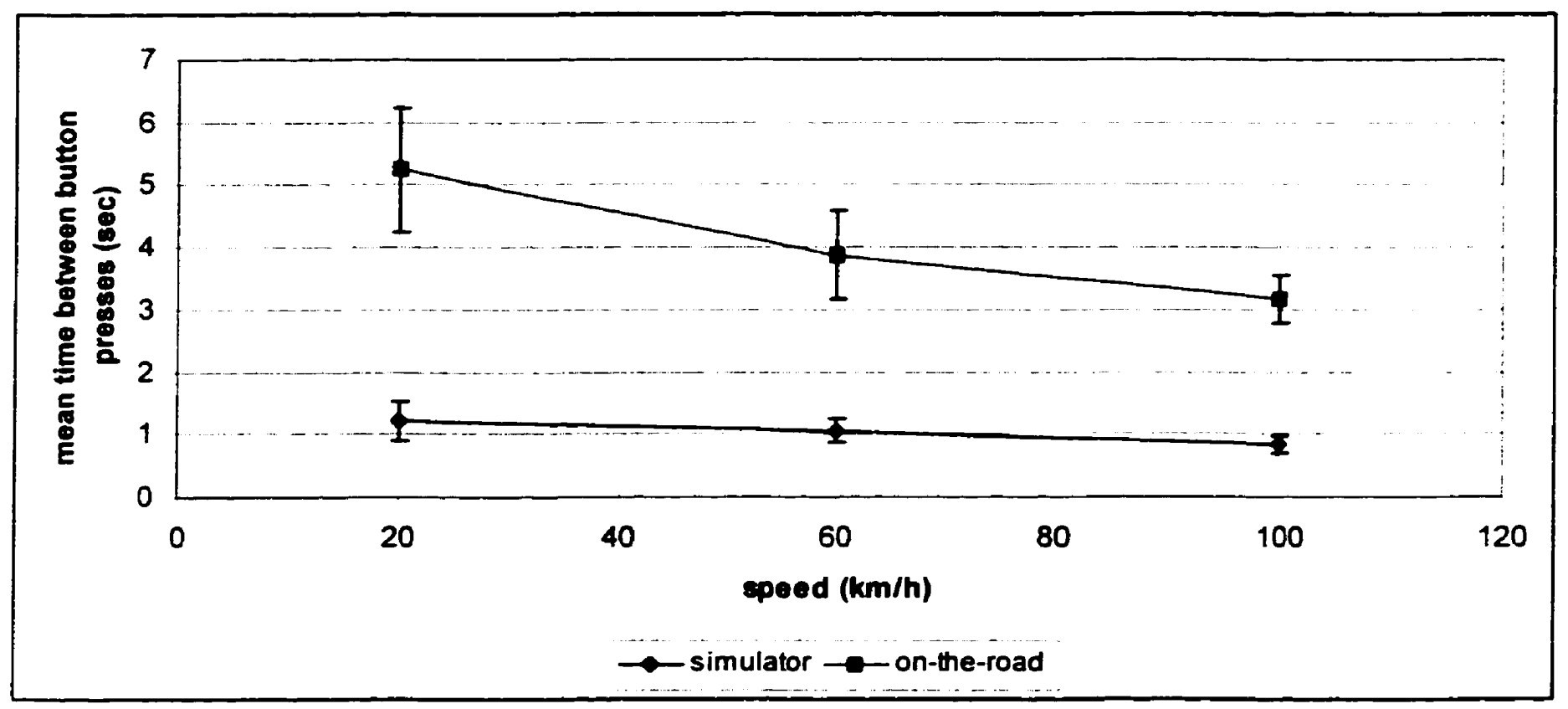

Figure 11. Mean time between button presses (sec) ( $+/$ - the standard deviation) for the $20 \mathrm{~km} / \mathrm{h}, 60 \mathrm{~km} / \mathrm{h}$ and $100 \mathrm{~km} / \mathrm{h}$ straight road simulator $(\mathrm{n}=10)$ and on-the-road drives ( $n=6)$ (Milgram et al., 1982).

In both studies the time between button presses increased as the speed decreased. Surprisingly, the absolute values for the on-the-road study were much greater for each of the three speeds; that is, subjects were waiting longer before taking a look at the driving scene.

When the mean percent of time with the glasses open was compared between the two studies the same trends were seen. Figure 12 presents the results of the on-theroad and simulator studies. 


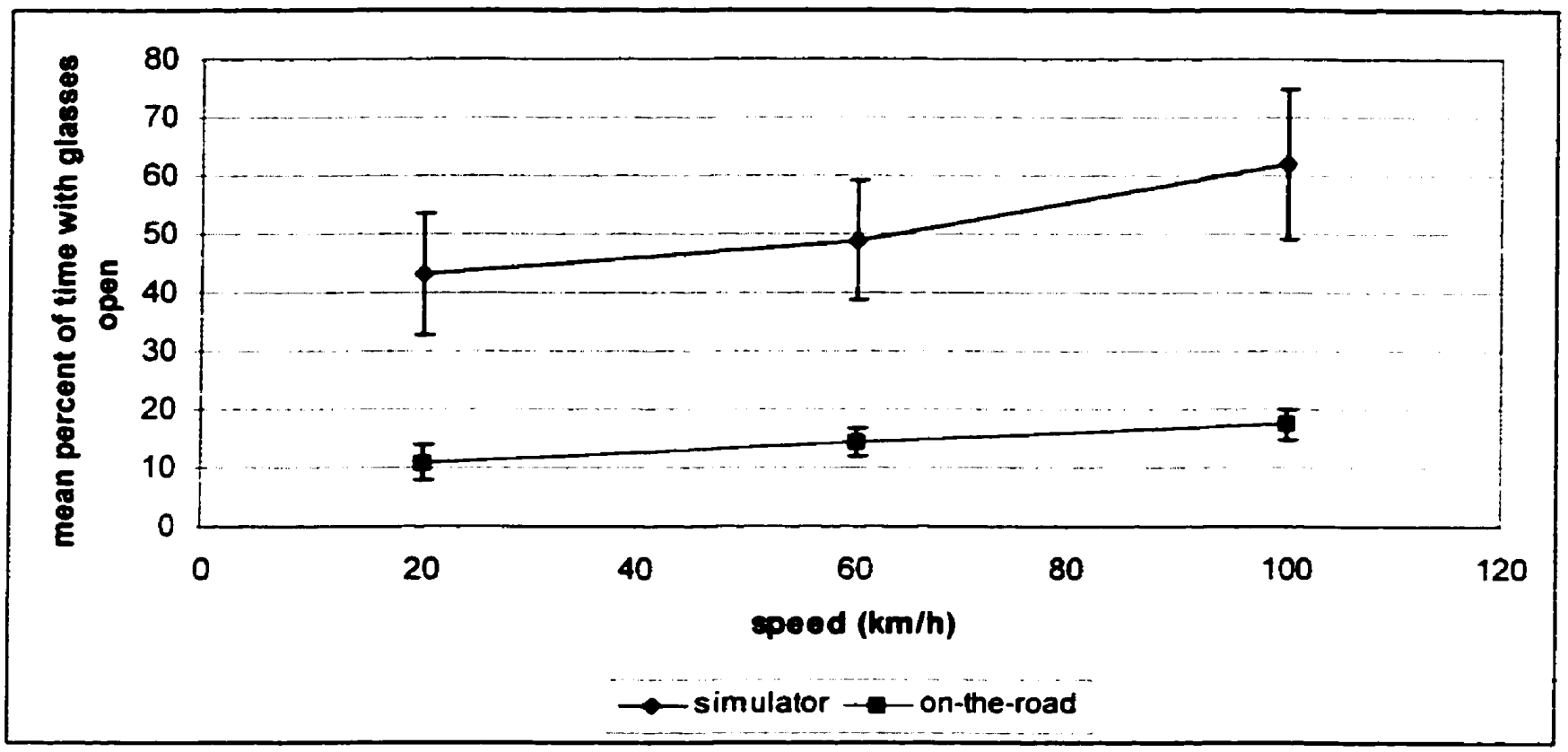

Figure 12. Mean percent of time with the glasses open ( $+/$ - the standard deviation) for the $20 \mathrm{~km} / \mathrm{h}, 60 \mathrm{~km} / \mathrm{h}$ and $100 \mathrm{~km} / \mathrm{h}$ straight road simulator $(n=10)$ and on-theroad drives $(n=6)$ (Milgram et al., 1982).

As expected, for both the on-the-road and simulator studies the drivers looked at the road for a greater percentage of time when the speed was greater. Surprisingly, the main difference between the two sets of results is that drivers looked at the road for a greater percentage of the time in the simulator study as compared to the on-theroad study.

\subsubsection{Mean number of meters between glasses openings}

As expected in Experiment 1 the results indicated that attentional demand increased with increasing speed (see Figure 7 and Figure 9). It was of further interest, however, to determine the mean number of meters between spectacle openings, since, if the number of meters were equal for each of the speeds, this would indicate that subjects adopted a criterion of looking at the road as a function of distance travelled. If this were the case, this could be a very good explanation as to why attentional demand increases with speed. Table 4 presents the results from this calculation. 


\begin{tabular}{|l|c|c|c|}
\hline Speed $(\mathrm{km} / \mathrm{h})$ & 20 & 60 & 100 \\
\hline $\begin{array}{l}\text { mean \# of meters } \\
\text { between looks }\end{array}$ & 4.02 & 9.3 & 9.3 \\
\hline
\end{tabular}

Table 4. Mean number of meters between looks at the road.

Interestingly, the mean number of metres between looks is equal for the 60 and 100 $\mathrm{km} / \mathrm{h}$ drives. Due to the fact the number of meters was not calculated as a dependent measure and that these calculations were made from the cumulative mean data, as opposed to from the raw data, statistical tests could not be performed on this mean number of meters between looks at the road.

\subsubsection{Individual Subject Results}

It was also determined that it would be of interest to graphically display the individual results for looking behaviour, to provide an indication of how subjects performed in comparison to one another. Specifically, mean percent of time with the glasses open data are presented for each subject in Figure 13. 


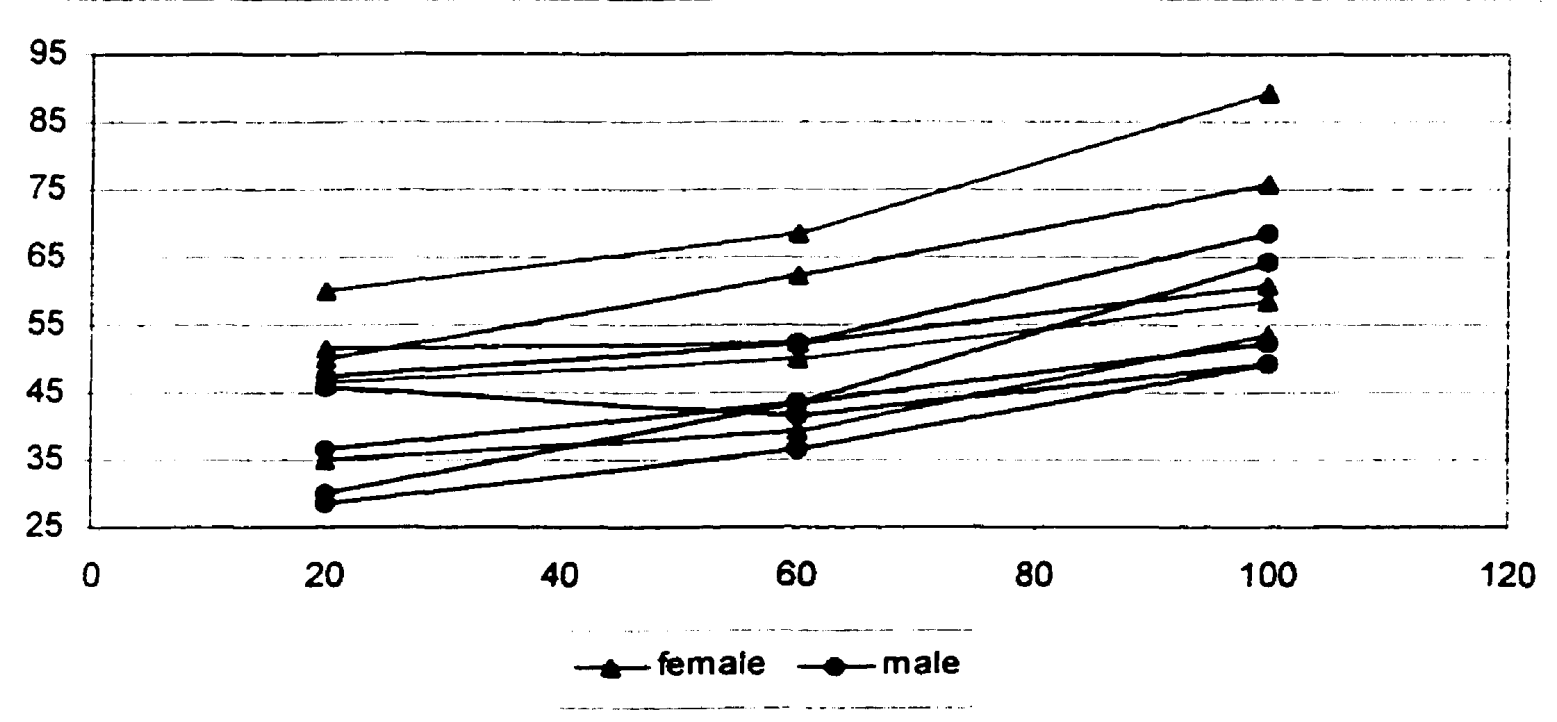

Figure 13. Mean percent of time with glasses open for each subject $(n=10)$ (standard deviations not available).

It is noteworthy that there is overlap across each of the subjects, with the exception of two females. That is, two of the five females are looking for what appears to be a substantially greater percentage of the drive when compared to the other eight subjects.

\subsection{EXPERIMENT 2}

Experiment 2 was a $2 \times 2 \times 2 \times 4$, mixed factorial design, with the variables sex, speed, road curvature and lane width examined. With the exception of sex, all variables were within subjects. The two sexes (male and female), two speeds $(60 \mathrm{~km} / \mathrm{h}(54.67$ $\mathrm{ft} / \mathrm{sec}$ ) and $100 \mathrm{~km} / \mathrm{h}(91.11 \mathrm{ft} / \mathrm{sec})$ ), two road curvatures (straight and curved), and four lane widths ( $9 \mathrm{ft}, 10 \mathrm{ft}, 11 \mathrm{ft}$ and $12 \mathrm{ft}$ ) were examined, to yield a total of 16 treatments ${ }^{2}$. Each curve was $230 \mathrm{~m}$ (750 ft) in length and had a radius of curvature of $1520 \mathrm{~m}(5000 \mathrm{ft})$.

\footnotetext{
${ }^{2}$ It is important to note that the STI simulator is programmed in feet. Thus, throughout the methods section measurements are at times given in feet.
} 


\subsubsection{Time between button presses (or glasses openings)}

A repeated measures ANOVA was performed on the data collected for time between button presses. Tables 5 and 6 show these results, for the within and between subjects variables respectively. Four significant main effects were found $(p<.05)$ and are highlighted in the tables.

\begin{tabular}{|c|c|c|c|c|c|}
\hline Variable & \begin{tabular}{|r|} 
Sum of \\
Squares \\
\end{tabular} & df & $\begin{array}{l}\text { Mean } \\
\text { Square }\end{array}$ & $\mathbf{F}$ & $\begin{array}{l}\text { Sig. } \\
\text { Level }\end{array}$ \\
\hline SPEED & 0.8 & $\bar{T}$ & osta & $23: 30$ & 0.00 \\
\hline SPEED * SEX & 0.10 & 1 & 0.10 & 3.69 & 0.09 \\
\hline Error(SPEED) & 0.22 & $\overline{8}$ & 0.03 & & \\
\hline CURVATURE & 1933 & I) & 783 & $100: 21$ & 0.00 \\
\hline CURVATURE * SEX & 0.02 & 1 & 0.02 & 1.82 & 0.21 \\
\hline Error(CURVATURE) & 0.11 & 8 & 0.01 & & \\
\hline LANE WIDTH & 0.15 & 3 & 0.05 & 5.50 & 0.01 \\
\hline LANE WIDTH * SEX & 0.04 & 3 & 0.01 & 1.45 & 0.25 \\
\hline Error(LANE WIDTH) & 0.22 & 24 & 0.01 & & \\
\hline SPEED * CURVATURE & 0.00 & 1 & 0.00 & 0.10 & 0.77 \\
\hline SPEED * CURVATURE * SEX & 0.00 & 1 & 0.00 & 1.37 & 0.28 \\
\hline Error(SPEED*CURVATURE) & 0.02 & 8 & 0.00 & & \\
\hline SPEED * LANE WIDTH & 0.01 & 3 & 0.00 & 1.42 & 0.26 \\
\hline SPEED * LANE WIDTH ${ }^{\bullet}$ SEX & 0.00 & 3 & 0.00 & 0.46 & 0.71 \\
\hline Error(SPEED*LANE_WIDTH) & 0.06 & 24 & 0.00 & & \\
\hline CURVATURE * LANE WIDTH & 0.00 & 3 & 0.00 & 0.07 & 0.98 \\
\hline CURVATURE * LANE WIDTH * SEX & 0.00 & 3 & 0.00 & 0.19 & 0.90 \\
\hline Error(CURVATURE*LANE_WIDTH) & 0.05 & 24 & 0.00 & & \\
\hline SPEED * CURVATURE • LANE WIDTH & 0.00 & 3 & 0.00 & 0.74 & 0.54 \\
\hline $\begin{array}{l}\text { SPEED * CURVATURE * LANE_WIDTH } \\
\text { SEX }\end{array}$ & 0.00 & $\overline{3}$ & 0.00 & 0.55 & 0.66 \\
\hline Error(SPEED*CURVATURE*LANE WIDTH) & 0.03 & 24 & 0.00 & & \\
\hline
\end{tabular}

Table 5. ANOVA results for the time between button presses for the within subjects variables (speed, lane width, curvature) $(n=10)$. Shaded areas represent $p<.05$. 


\begin{tabular}{|l|c|c|c|c|c|}
\hline Variable & $\begin{array}{c}\text { Sum of } \\
\text { Squares }\end{array}$ & df & $\begin{array}{c}\text { Mean } \\
\text { Square }\end{array}$ & F & $\begin{array}{c}\text { Sig. } \\
\text { Level }\end{array}$ \\
\hline Intercept & 110.18 & 1 & 110.18 & 581.78 & 0.00 \\
\hline SEX & 1155 & 1 & 115 & 7.63 & 0.02 \\
\hline Error & 1.52 & 8 & 0.19 & & \\
\hline
\end{tabular}

Table 6. ANOVA results for the time between button presses for the between subjects variable sex $(n=10)$. Shaded areas represent $p<.05$.

First of all, a main effect was found for the variable speed $(f(1,8)=23.30, p<.05)$. Specifically, as hypothesised, the time between button presses (or requests for glasses to open) was significantly smaller for the $100 \mathrm{~km} / \mathrm{h}$ scenarios (mean $=.77$ $\mathrm{sec}$ ) when compared to the $60 \mathrm{~km} / \mathrm{h}$ scenarios (mean $=.89 \mathrm{sec}$ ). Figure 14 shows these means.

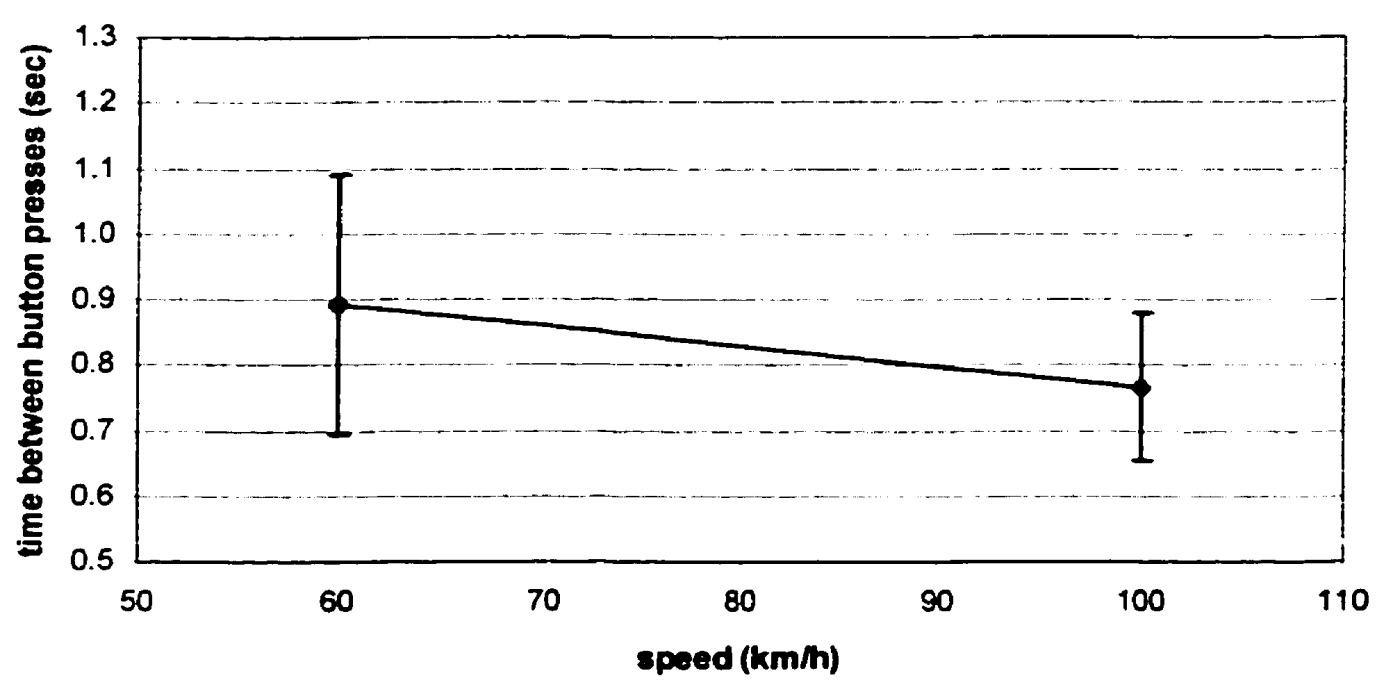

Figure 14. Mean time between button presses (+l- standard deviation) for the 100 $\mathrm{km} / \mathrm{h}$ and $60 \mathrm{~km} / \mathrm{h}$ scenarios $(n=10)$.

A second main effect was found for the variable curvature $(f(1,8)=100.21, p<.05)$. Specifically, as hypothesised, the time between button presses (or glasses openings) was significantly smaller for the curved road portions of the scenarios 
(mean $=0.74 \mathrm{sec}$ ) when compared to the straight portions (mean $=0.92 \mathrm{sec})$. Figure 15 shows these means.

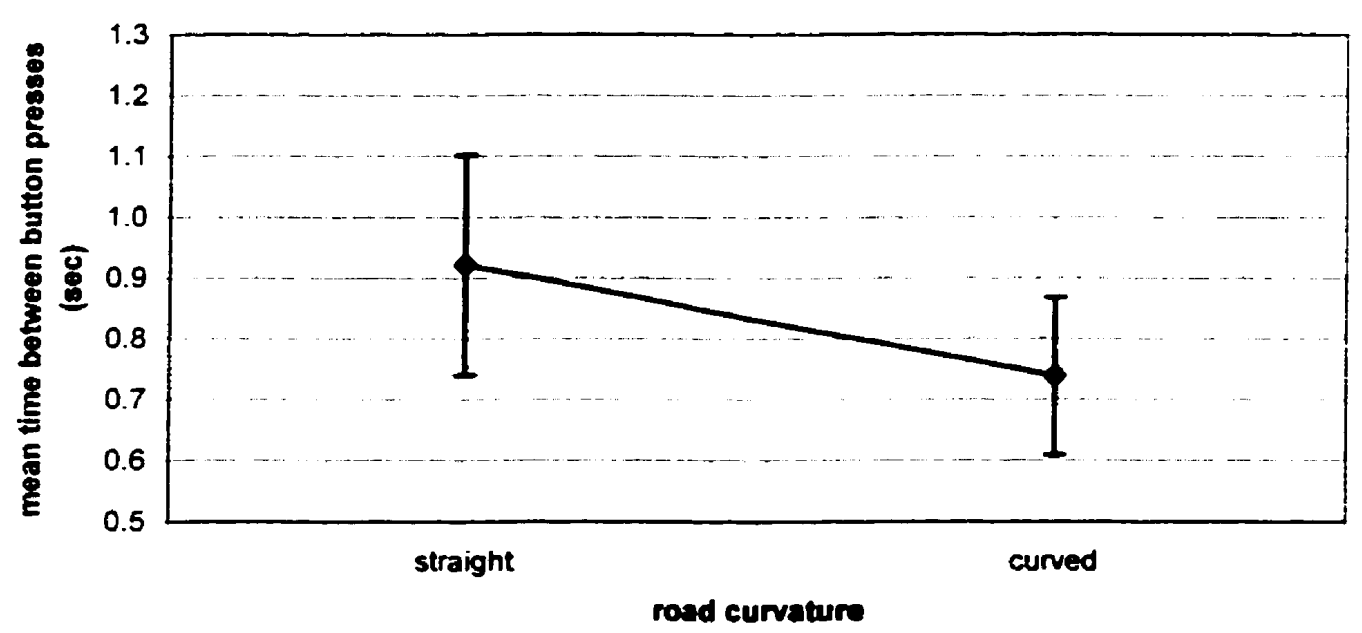

Figure 15. Mean time between button presses ( $+/$ - standard deviation) for the curved and straight road sections of the scenarios $(n=10)$. Each curve was $230 \mathrm{~m}$ long and had a radius of curvature of $1520 \mathrm{~m}$.

In addition, as expected, a third significant main effect was found for the variable lane width $(f(3,24)=5.50, p<.05)$. Specifically, as hypothesised, the time between button presses (or glasses openings) became increasingly larger as the lane width increased. Figure 16 and Table 7 present the mean data. 


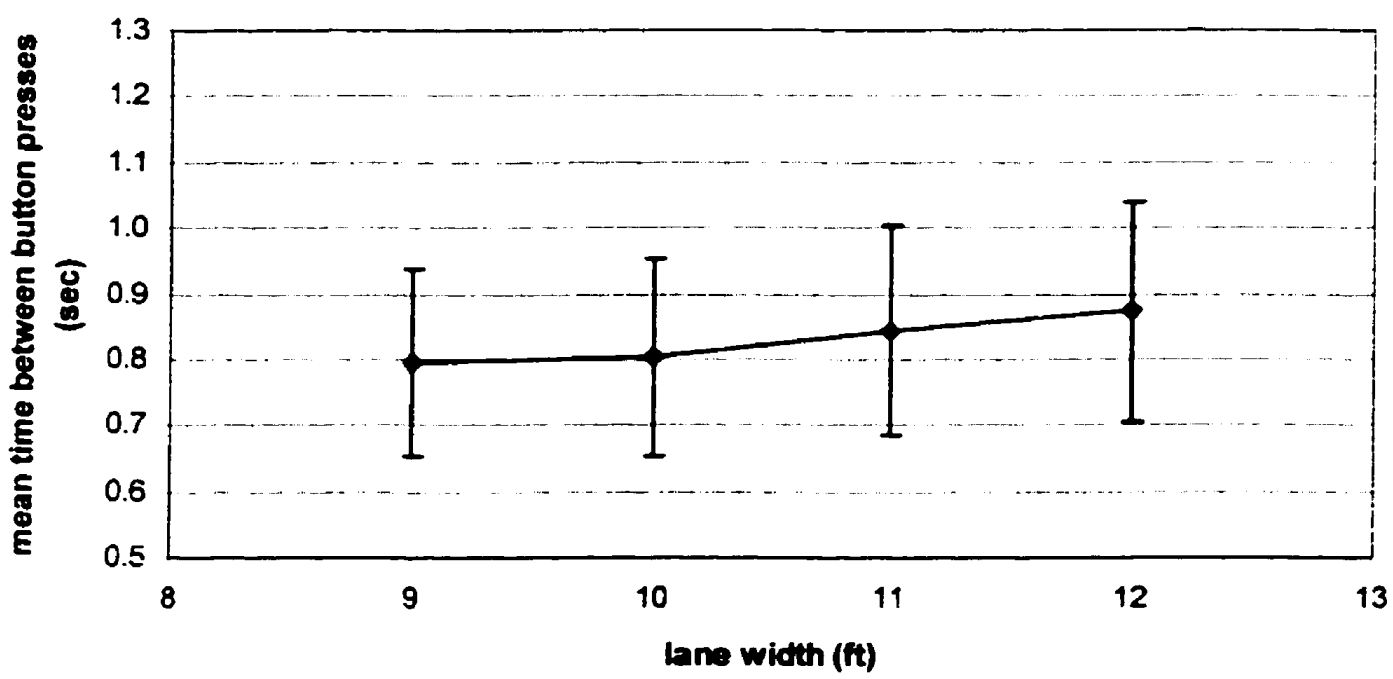

Figure 16. Mean time between button presses (+/-standard deviation) for the each lane width $(9,10,11$, and $12 \mathrm{ft})(\mathrm{n}=10)$.

\begin{tabular}{|c|c|c|}
\hline lane width (ft) & Mean (sec) & sd \\
\hline 9 & 0.80 & 0.15 \\
\hline 10 & 0.81 & 0.15 \\
\hline 11 & 0.85 & 0.16 \\
\hline 12 & 0.87 & 0.17 \\
\hline
\end{tabular}

Table 7. Mean time between button presses for each lane width.

Planned comparisons revealed differences in the times between button presses across the lane widths (see Table 8). Specifically, as the lane width became larger the subjects waited a significantly longer time from the time that the glasses last closed before requesting again that they be opened. The only significant difference not found was for the time between button presses for the 9 and $10 \mathrm{ft}$ lane widths. 


\begin{tabular}{|c|c|c|c|c|c|c|}
\hline & $\begin{array}{l}\text { lane widths } \\
\text { (ft) }\end{array}$ & Mean & SD & $t$ & df & $\begin{array}{l}\text { Sig. } \\
\text { Level) }\end{array}$ \\
\hline Pair 1 & $9 \& 10$ & 0.01 & 0.10 & 0.52 & 39 & 0.61 \\
\hline Pair 2 & 8411 & 0805 & 007 & 629 & 39 & 0.00 \\
\hline Pair 3 & 9012 & 008 & $0: 03$ & 6212 & 39 & 0.00 \\
\hline Pair 4 & Toxist & 808 & 0.009 & $22^{2}$ & 39 & 0.02 \\
\hline Pair 5 & 10 E2 & 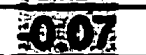 & 007 & 503 & 39 & 0.00 \\
\hline Pair: 6 & 14012 & 003 & $0 \% 8$ & 221 & 30 & 0.03 \\
\hline
\end{tabular}

Table 8. Planned comparison results for each lane width for the time between button presses $(n=10)$. Shaded areas represent $p<.05$.

The fourth and final significant main effect was found for the variable, sex.

Specifically it was found that the time between button presses was longer for males $($ mean $=0.73 \mathrm{sec})$ when compared to females $($ mean $=0.92 \mathrm{sec})(f(1,8)=7.63$, $p<.05)$. Figure 17 presents the data means.

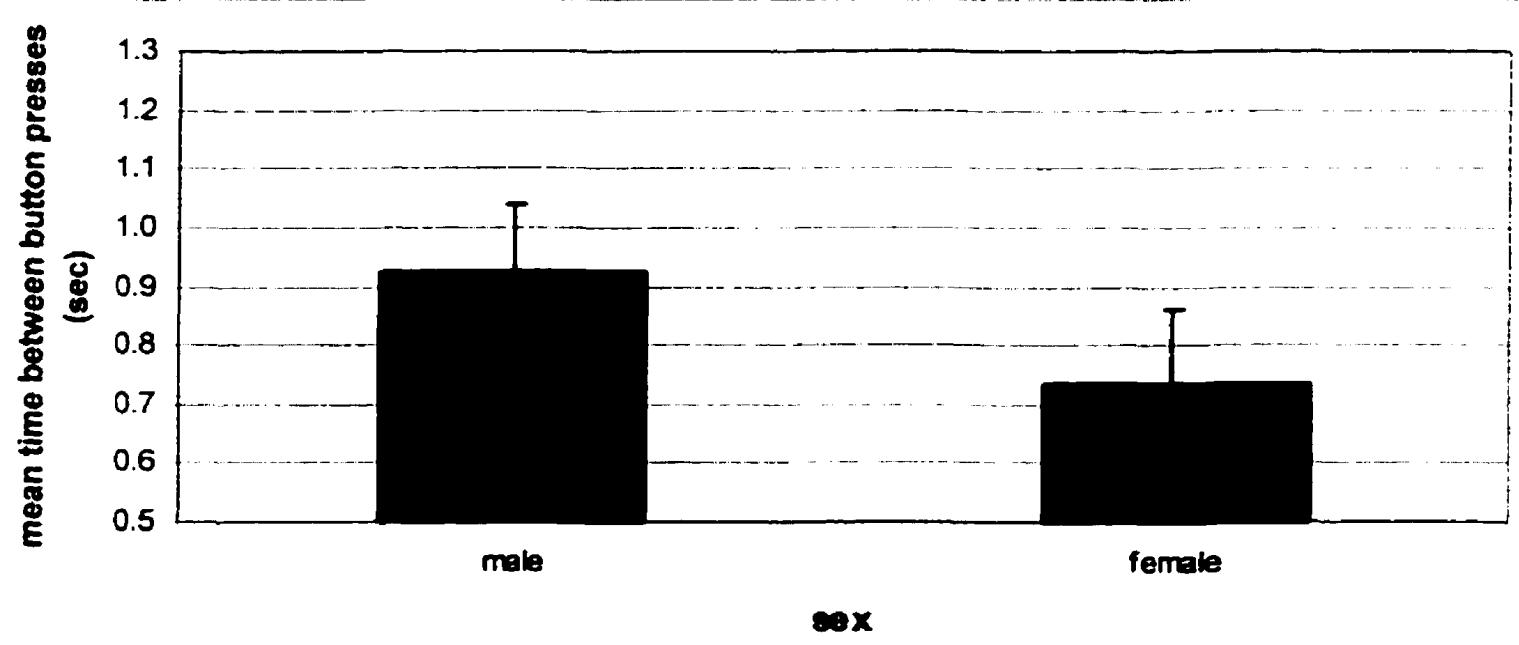

Figure 17. Mean time between button presses $(+1-$ the standard deviation) for males and females $(n=10)$.

No significant interactions were found for the time between button presses data (see Figure 18). 


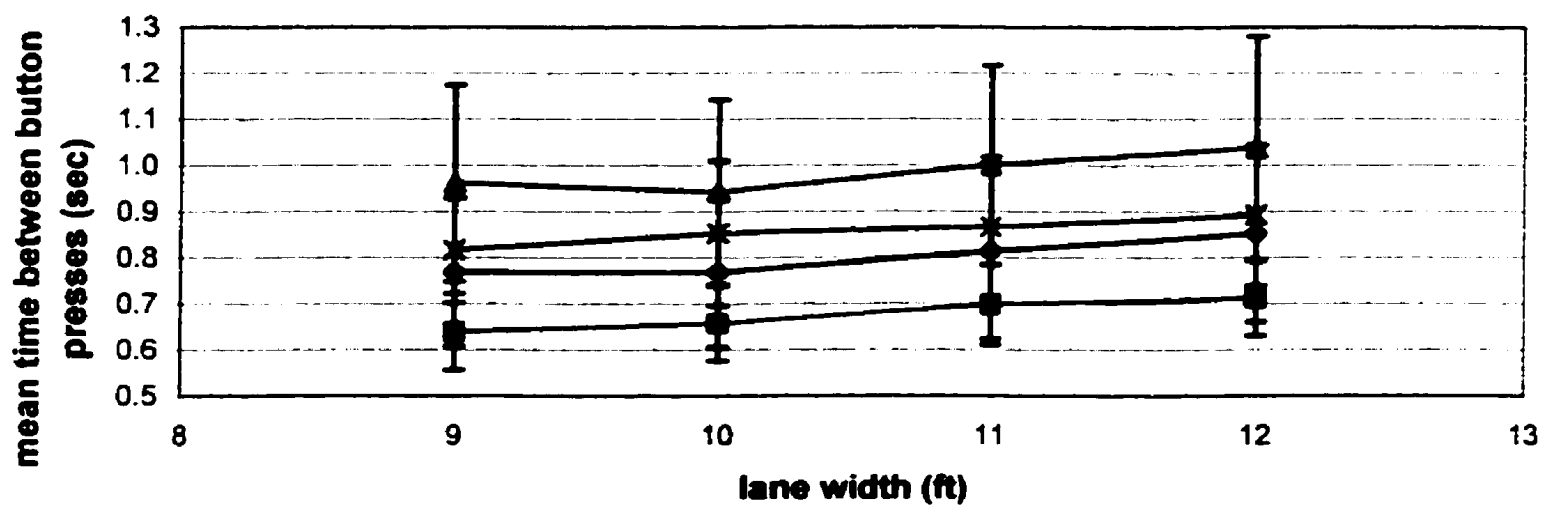

- curved $60=$-curved $100-$ - straight $60 \rightarrow$-straight 100

Figure 18. Mean time between button presses ( $+/-$ the standard deviation) for each lane width, speed and curvature treatment.

\subsubsection{Percent of time with the glasses open}

A repeated measures ANOVA was performed on the data collected for percent of time with glasses open. Tables 9 and 10 show these results and highlight the significant effects for the within and between subject comparisons respectively $(p<.05)$. Once again, four significant main effects were found. 


\begin{tabular}{|c|c|c|c|c|c|}
\hline Variable & $\begin{array}{l}\text { Sum of } \\
\text { Squares }\end{array}$ & df & $\begin{array}{l}\text { Mean } \\
\text { Square }\end{array}$ & $\bar{F}$ & $\begin{array}{l}\text { Sig. } \\
\text { Level }\end{array}$ \\
\hline CURVATURE & $7516 \% 1$ & 1 & 751621 & 23975 & 0.00 \\
\hline CURVATURE・SEX & 47.02 & 1 & 47.02 & 1.47 & 0.26 \\
\hline Error(CURVATURE) & 256.15 & 8 & 32.02 & & \\
\hline SPEED & $2023 \% 7$ & 1 & $2693: 17$ & 35.98 & 0.00 \\
\hline SPEED * SEX & 246.34 & 1 & 246.34 & 3.38 & 0.10 \\
\hline Error(SPEED) & 583.33 & 8 & 72.92 & & \\
\hline LANE WIDTH & 839810 & 3 & 27270 & $6: 68$ & 0.00 \\
\hline LANE WIDTH* SEX & 218.39 & 3 & 72.80 & 1.74 & 0.19 \\
\hline Error(LANE WIDTH) & 1005.62 & 24 & 41.90 & & \\
\hline CURVATURE・SPEED & 78.08 & 1 & 78.08 & 2.78 & 0.13 \\
\hline CURVATURE・SPEED・SEX & 70.20 & $T$ & 70.20 & 2.49 & 0.15 \\
\hline Error(CURVATURE*SPEED) & 225.13 & 8 & 28.14 & & \\
\hline CURVATUR・ LANE WIDTH & 60.14 & 3 & 20.05 & 2.86 & 0.06 \\
\hline CURVATURE * LANE WIDTH * SEX & 10.89 & 3 & 3.63 & 0.52 & 0.67 \\
\hline Error(CURVATUR*LANE WIDTH) & 168.22 & 24 & 7.01 & & \\
\hline SPEED・LANE WIDTH & 37.58 & 3 & 12.53 & 1.10 & 0.37 \\
\hline SPEED • LANE WIDTH * SEX & 15.07 & 3 & 5.02 & 0.44 & 0.72 \\
\hline Error(SPEED*LANE WIDTH) & 272.40 & 24 & 11.35 & & \\
\hline CURVATURE • SPEED * LANE WIDTH & 15.06 & 3 & 5.02 & 1.02 & 0.67 \\
\hline $\begin{array}{l}\text { CURVATURE・SPEED } \\
\text { - SEX }\end{array}$ & 9.57 & 3 & 3.19 & 0.65 & 0.59 \\
\hline $\begin{array}{l}\text { Error(CURVATURE*SPEED*LANE } \\
\text { WIDTH) }\end{array}$ & 117.72 & 24 & 4.91 & & \\
\hline
\end{tabular}

Table 9. ANOVA results for the percent of time with glasses open for the within subjects variables (speed, lane width, curvature) $(n=10)$. Shaded rows represent $p<.05$.

\begin{tabular}{|l|c|c|c|c|c|}
\hline Variable & $\begin{array}{c}\text { Sum of } \\
\text { Squares }\end{array}$ & df & $\begin{array}{c}\text { Mean } \\
\text { Square }\end{array}$ & F & Sig. \\
\hline Intercept & 644419.17 & 1 & 644419.17 & 543.53 & 0.00 \\
\hline SEX & $8090 \% 67$ & 1 & $8005.87_{i}$ & 7326 & 0.03 \\
\hline Error & 9484.96 & 8 & 1185.62 & & \\
\hline
\end{tabular}

Table 10. ANOVA results for the percent of time with glasses open for the between subjects variable sex $(n=10)$. Shaded rows represent $p<.05$.

First of all, a main effect was found for the variable speed $(f(1,8)=35.98, p<.05)$. Specifically, as hypothesised, the percent of time with the glasses open was 
significantly larger for the $100 \mathrm{~km} / \mathrm{h}$ scenarios (mean $=72.70 \%$ ) when compared to the $20 \mathrm{~km} / \mathrm{h}$ scenarios (mean $=59.41 \%$ ). Figure 19 presents these means.

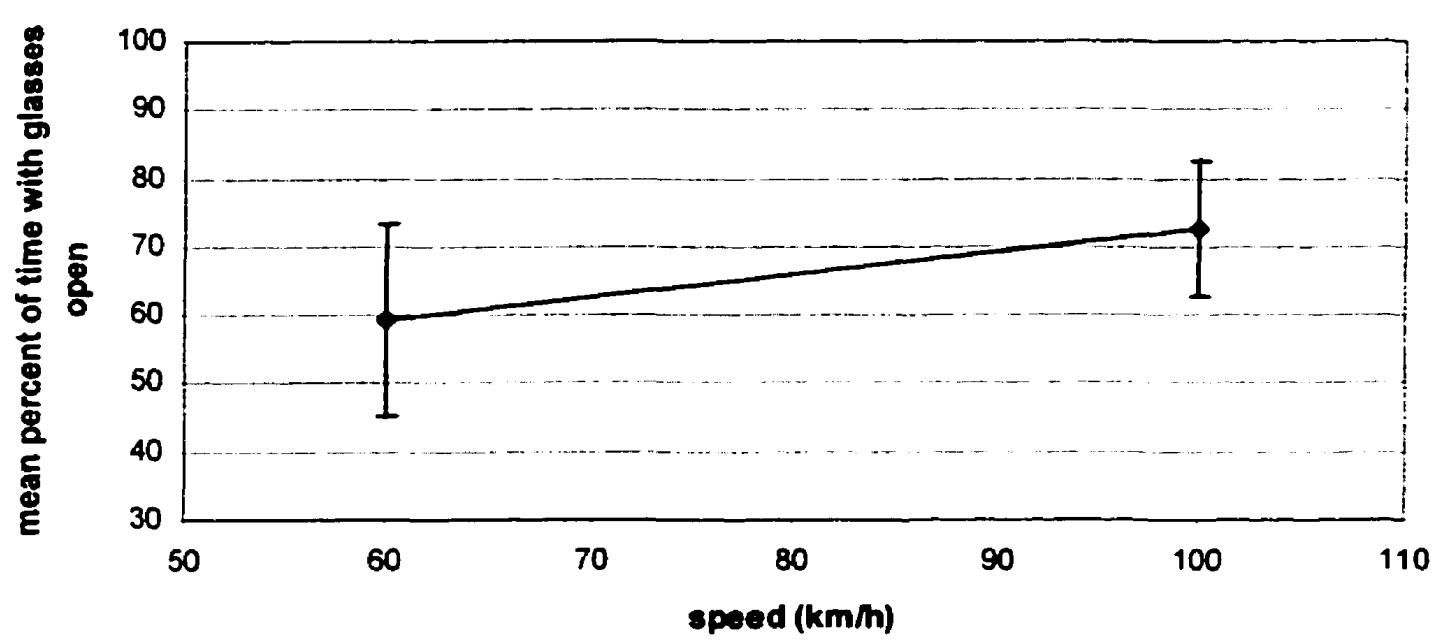

Figure 19. Mean percent of time with glasses open ( $+/$ - standard deviation) for the $100 \mathrm{~km} / \mathrm{h}$ and $60 \mathrm{~km} / \mathrm{h}$ scenarios $(n=10)$.

A second main effect was found for the variable curvature $(f=234.75, p<.05)$. Specifically, as hypothesised, the mean percent of time with the glasses open was significantly larger for the curved portions of the scenarios (mean $=67.20 \%$ ) when compared to the straight portions of the scenarios (mean $=56.61 \%$ ). Figure 20 presents the data means. 


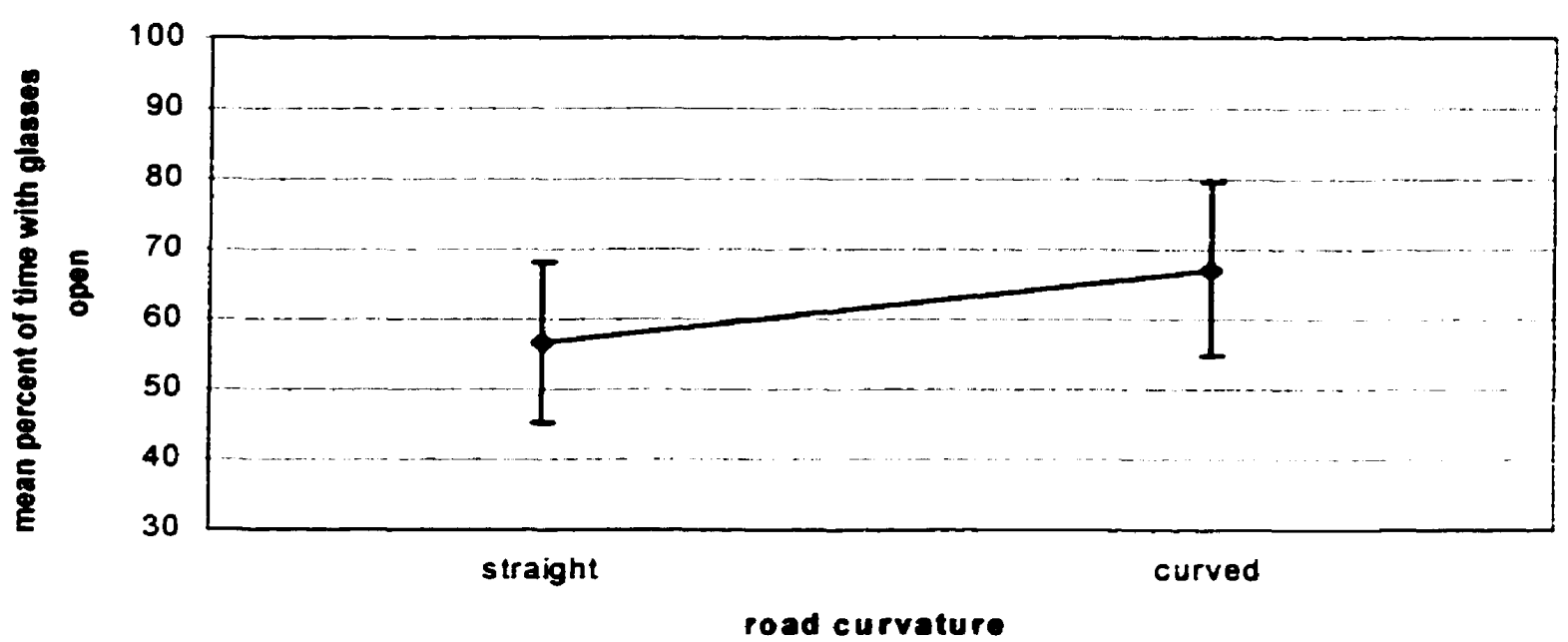

Figure 20. Mean percent of time with the glasses open ( $+/$ - standard deviation) for the curved and straight road sections of the scenarios $(n=10)$.

Secondly, as expected, a significant main effect was also found for the variable lane width $(f(3,24)=6.68, p<.01)$. Specifically, as hypothesised, the mean percent of time with the glasses open was larger for the smaller lane widths. Figure 21 and Table 11 present the data means and standard deviations.

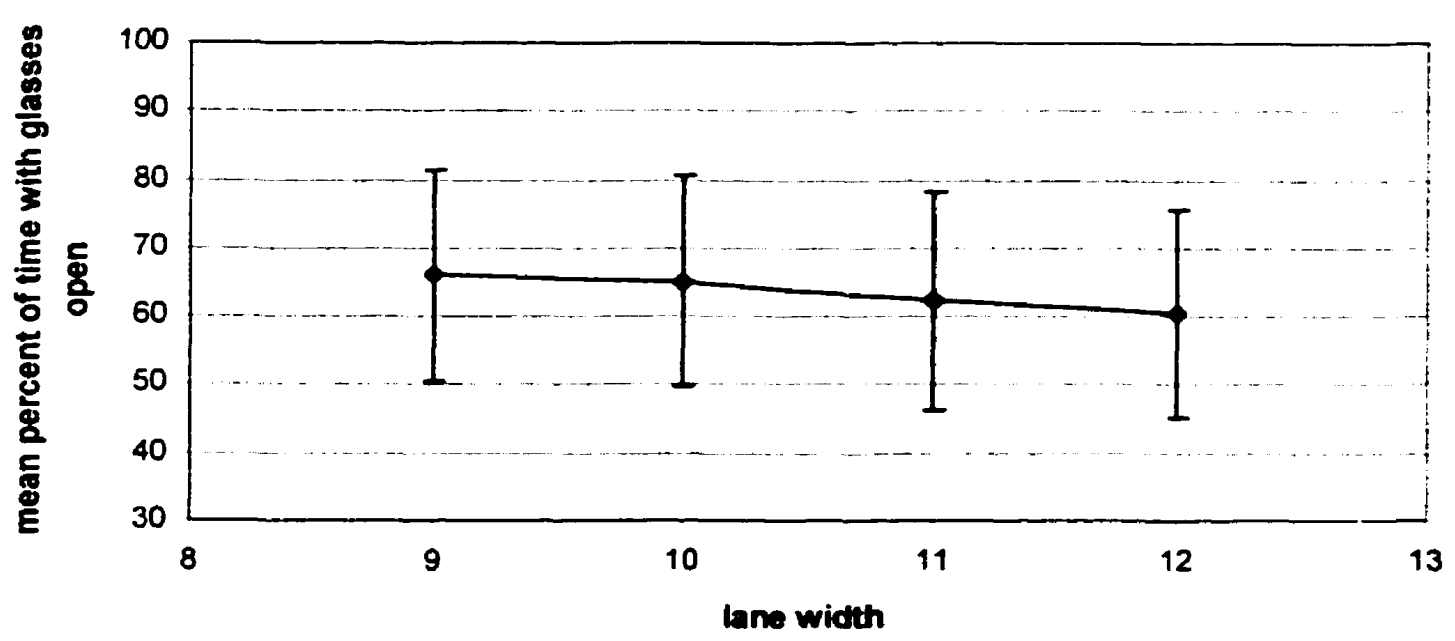

Figure 21. Mean percent of time with the glasses open ( $+/$ the standard deviation) for each lane width $(9,10,11,12 \mathrm{ft})(n=10)$. 


\begin{tabular}{|c|c|c|}
\hline lane width (ft) & Mean (\%) & sd \\
\hline 9 & 66.05 & 15.37 \\
\hline 10 & 65.18 & 15.44 \\
\hline 11 & 62.34 & 15.80 \\
\hline 12 & 60.28 & 15.21 \\
\hline
\end{tabular}

Table 11. Mean (\%) and standard deviation (sd) of the percent of time with the glasses open for each lane width $(n=10)$.

Planned comparisons revealed a number of significant differences between the lane widths (see Table 12). Specifically, as the lane width became larger the subjects had the glasses open for a significantly smaller portion of the time. A significant difference was not found in the percent of time with the glasses open for the 9 and $10 \mathrm{ft}$ lane widths.

\begin{tabular}{|c|c|c|c|c|c|c|}
\hline & \begin{tabular}{|c|}
$\operatorname{lan} \theta$ \\
widths $(f t)$
\end{tabular} & Mean & SD & $t$ & df & $\begin{array}{l}\text { Sig. } \\
\text { Level }\end{array}$ \\
\hline Pair 1 & $9 \& 10$ & -0.87 & 7.64 & -0.72 & 39 & 0.50 \\
\hline Pair 2 & 8\&11 & 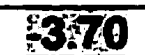 & 464 & 505 & 39 & 0.00 \\
\hline Pair 3 & 9812 & 3576 & $5: 23$ & 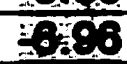 & 39 & 0.00 \\
\hline Pair 4 & 108414 & 2893 & 6.78 & 28 & 39 & 0.01 \\
\hline Pair 5 & 10812 & 569 & 5.04 & 6.14 & 39 & 0.00 \\
\hline Pair 6 & $118: 12$ & 2.06 & 4.40 & 2.86 & 39 & 0.01 \\
\hline
\end{tabular}

Table 12. Planned comparison results for each lane width for the percent of time with the glasses open $(n=10)$. Shaded rows represent $p<.05$.

Finally, a fourth significant main effect was found for the variable, sex. Specifically it was found that the percent of time with the glasses open was significantly shorter for males $($ mean $=56.75 \%)$ when compared to females $($ mean $=68.78 \%)(f(1,8)=7.26$, $p<.05)$. Figure 22 illustrates these means. 


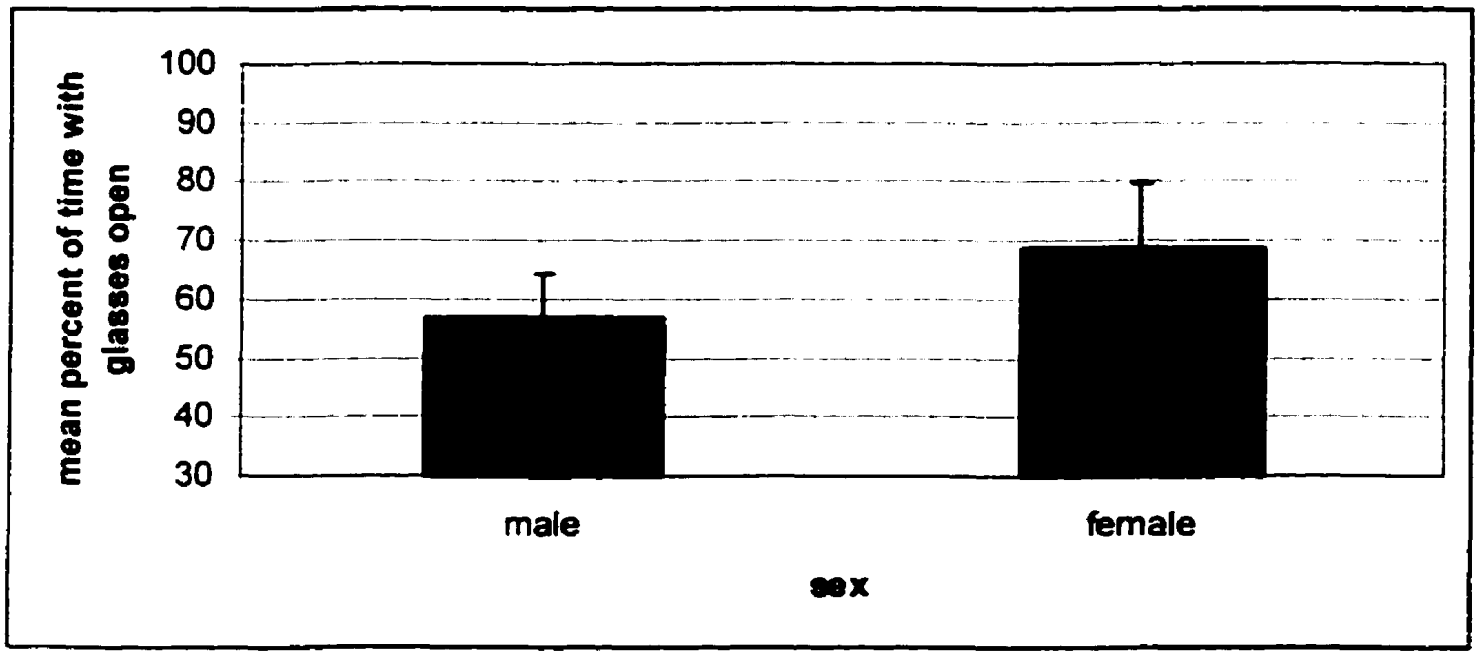

Figure 22. Mean percent of time with the glasses open ( $+/$ the standard deviation) for males and females $(n=10)$.

It is noteworthy, that the interaction between the variables speed and sex was approaching significance $(f(1,8)=3.38, p=0.10)$. Figure 23 illustrates the interaction between theses two variables.

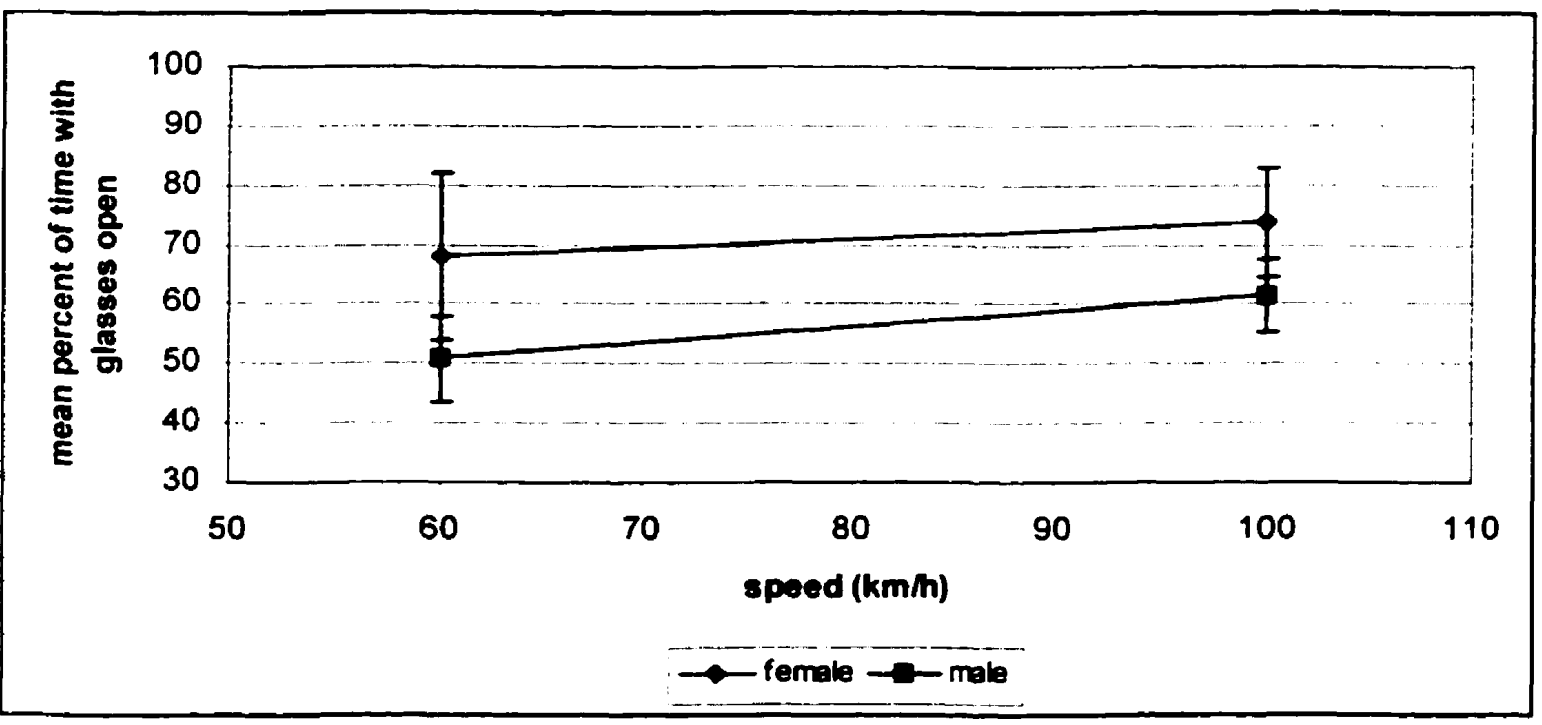

Figure 23. Mean percent of time with glasses open for the variables sex and speed.

Both males and females looked more often at the higher speed, but males looked less often than females for both speeds. However, it appears that the difference in looking between males and females was greater at the lower speed $(60 \mathrm{~km} / \mathrm{h})$ as 
compared to the higher speed $(100 \mathrm{~km} / \mathrm{h})$. Had more subjects been used perhaps this difference would have been significant.

No significant interactions were found for the percent of time with the glasses open (see Figure 24).

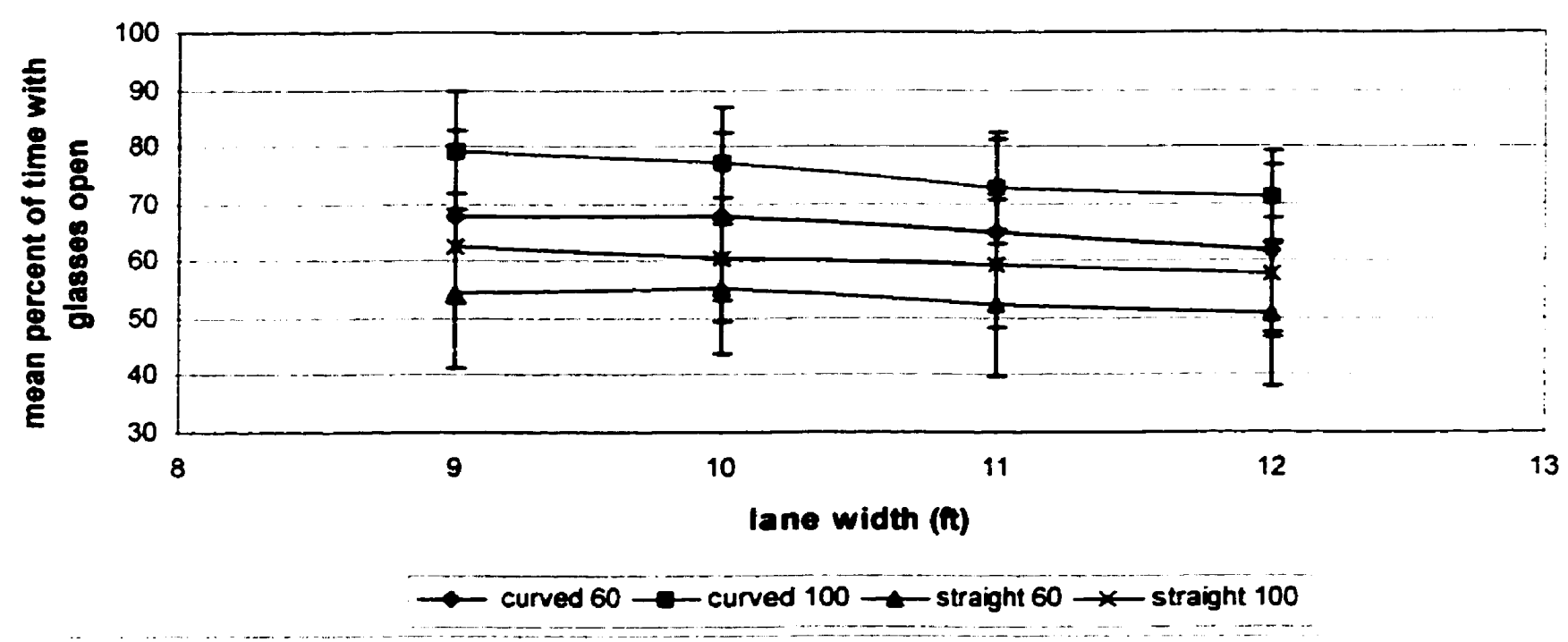

Figure 24. Mean percent of time with the glasses open ( +1 - the standard deviation) for each lane width, speed and curvature treatment.

\subsubsection{Differences between sexes}

As illustrated by Figures 17 and 22 significant differences were found between males and females for the Experiment 2 variables: mean number of seconds between looks and mean percent of time with the glasses open. In particular, it was found that males had a significantly longer mean time between glass opening requests and thus drove with the glasses open for a significantly smaller percent of time across all scenarios. These findings were not anticipated; therefore further analyses were carried out. Specifically, it was of interest to determine if the mean 
standard deviation of lane position also differed between males and females. This particular measure was examined as a presumed indication of whether a difference in primary driving performance existed between the sexes.

Firstly, the mean standard deviation of lane position was examined for the Experiment 2 scenarios. A between subjects ANOVA revealed no significant differences between males and females $(f(1,8)=1.64, p>.05)$. Table 13 and Figure 25 present the mean data.

\begin{tabular}{|c|c|c|}
\hline Sex & Mean & Std. Deviation \\
\hline Male & 0.88 & 0.21 \\
\hline Female & 1.04 & 0.27 \\
\hline
\end{tabular}

Table 13. Mean standard deviation of lane position and standard deviation for males and females across all Experiment 2 scenarios $(n=10)$.

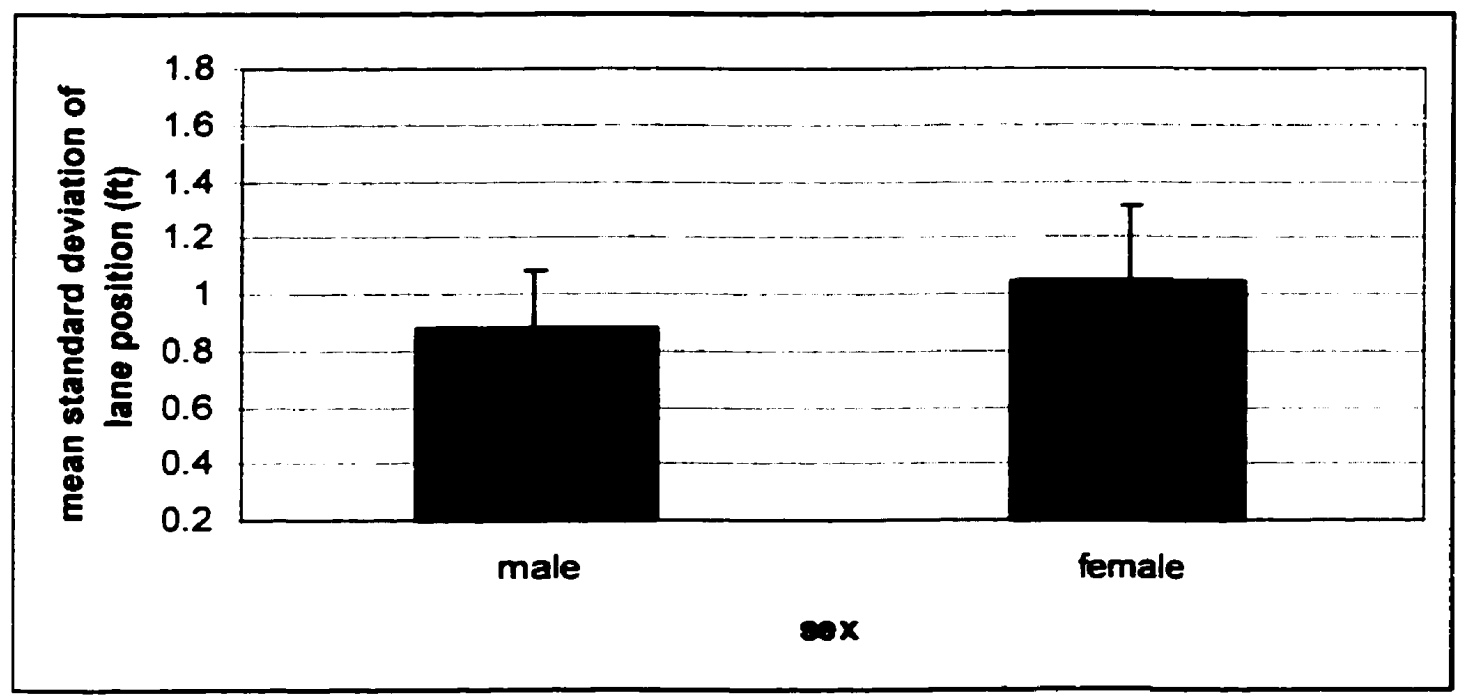

Figure 25. Mean standard deviation of lane position (+/- standard deviation) for males and females across all Experiment 2 scenarios $(n=10)$.

The standard deviations in lane position data were also examined for the original baseline drive, in which subjects did not wear the glasses. Once again, a between subjects one way ANOVA was carried out and revealed no significant differences between males and females for standard deviation of lane position for that scenario $(f(1,8)=.29, p>.05)$. Table 14 and Figure 26 illustrate these means. 


\begin{tabular}{|c|c|c|}
\hline Sex & Mean & Std. Deviation \\
\hline Male & 1.37 & 0.23 \\
\hline Female & 1.46 & 0.18 \\
\hline
\end{tabular}

Table 14. Mean standard deviation of lane position and standard deviation for males and females for the baseline scenario $(n=10)$.

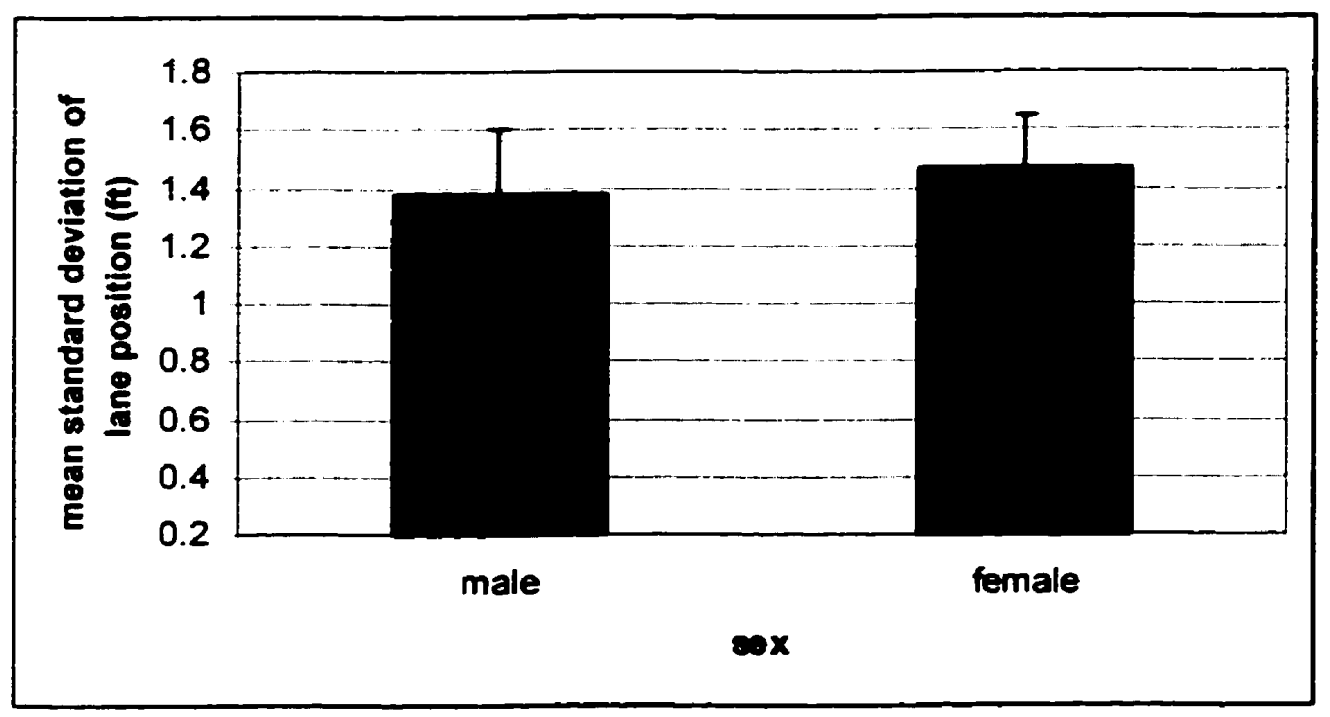

Figure 26. Mean standard deviation of lane position (+/-standard deviation) for males and females for the baseline scenario $(n=10)$.

\subsubsection{Mean standard deviation of lane position (SDLP)}

After examining the standard deviation of lane position (SDLP) for males and females across all Experiment 2 drives it was felt that it would be worthwhile to examine this dependent variable further for all conditions, to determine if sex interacted with any of the other variables. It would also allow us to examine if drivers' overall driving performance changed across the different driving conditions. Table 15 presents the results from the ANOVA for standard deviation of lane position. Unfortunately, due to limitations in the initial coding of the raw data for standard deviation of lane position, calculations were not possible for the variable road curvature 


\begin{tabular}{|c|c|c|c|c|c|}
\hline Source & $\begin{array}{c}\text { Sum of } \\
\text { Squares }\end{array}$ & df & $\begin{array}{c}\text { Mean } \\
\text { Square }\end{array}$ & $\bar{F}$ & $\begin{array}{l}\text { Sig. } \\
\text { Level }\end{array}$ \\
\hline SPEED & 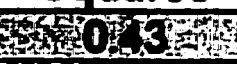 & 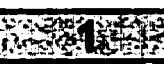 & 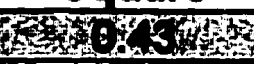 & 8099 & $0.0 \%$ \\
\hline SPEED * SEX & 0.05 & 1 & 0.05 & 0.65 & 0.44 \\
\hline Error(SPEED) & 0.56 & 8 & 0.07 & & \\
\hline 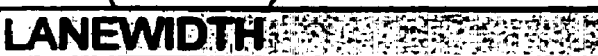 & $806 x^{2}$ & 3t & 0.21 & T1:00 & 0.00 \\
\hline LANEWIDTH * SEX & 0.00 & 3 & 0.00 & 0.08 & 0.97 \\
\hline Error(LANEWIDTH) & 0.43 & 24 & 0.02 & & \\
\hline SPEED * LANEWIDTH & 0.05 & 3 & 0.02 & 1.37 & 0.28 \\
\hline SPEED * LANEWIDTH * SEX & 0.04 & $\overline{3}$ & 0.01 & 1.12 & 0.36 \\
\hline Error(SPEED*LANEWIDTH) & 0.26 & 24 & 0.01 & & \\
\hline SEX & 0.53 & 1 & 0.53 & 1.64 & 0.24 \\
\hline Error & 2.61 & 8 & 0.33 & & \\
\hline
\end{tabular}

Table 15. Results from the ANOVA for standard deviation of lane position across all Experiment 2 conditions. (Calculations were not possible for the variable road curvature). Shaded areas represent $p<.05$.

A significant main effect was found for the variable lane width. Specifically, it was found that as lane width decreases so did the SDLP. Figure 27 displays these results.

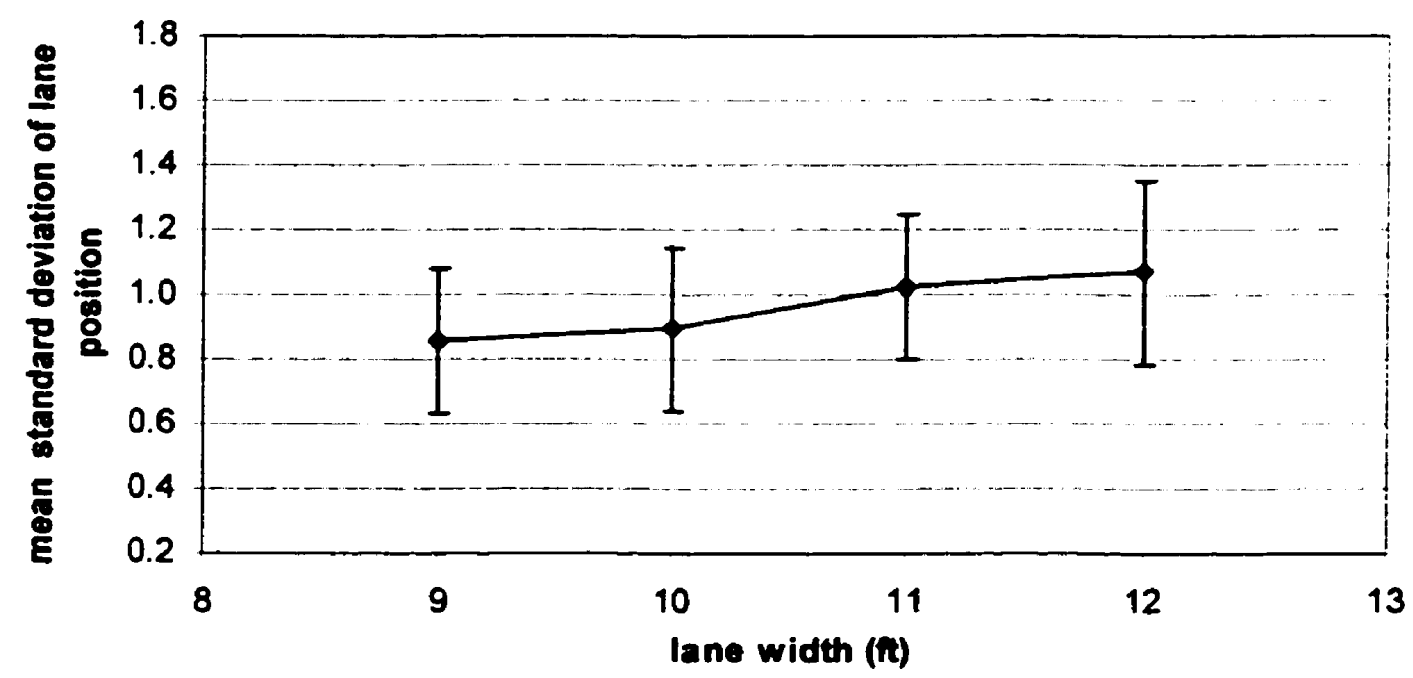

Figure 27. Mean standard deviation of lane position ( $+/$ - standard deviation) for lane width across all Experiment 2 drives $(n=10)$. 
Statistical comparisons revealed a number of significant differences between the SDLPs for different lane widths. Specifically, significant differences were found between SDLPs for each lane width pair with the exceptions of 9 and $10 \mathrm{ft}$ lanes and 11 and $12 \mathrm{ft}$ lanes. Table 16 presents the specific statistical findings.

\begin{tabular}{|c|c|c|c|c|c|c|}
\hline & $\begin{array}{l}\text { lane widths } \\
\text { (ft) }\end{array}$ & Mean & SD & $t$ & df & $\begin{array}{l}\text { Sig. } \\
\text { Level }\end{array}$ \\
\hline air 1 & $9 \& 10$ & 0.03 & 0.12 & 1.26 & 19 & 0.22 \\
\hline ?aif 2 & 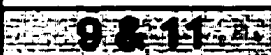 & 6ring & 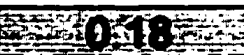 & CIOS) & 56 & $=000$ \\
\hline Pair 3 & 98 & xol & TNA0015 & 670 & tom & 0.00 \\
\hline Pair 4 & 100 & SEOKG & W & AEg & W & 10.00 \\
\hline Pair 5 & 10042 & 1016 & Costols A & 203600 & sing & 0000 \\
\hline Pair 6 & $11 \& 12$ & -0.05 & 0.20 & -1.06 & 19 & 0.30 \\
\hline
\end{tabular}

Table 16. Statistical comparison results for each lane width for the standard deviation of lane position. Shaded regions represent $p<.05$.

Statistical significance was also found for the variable speed. Figure 28 shows these means. It can be seen that, as the speed increases, the SDLP significantly increases. 


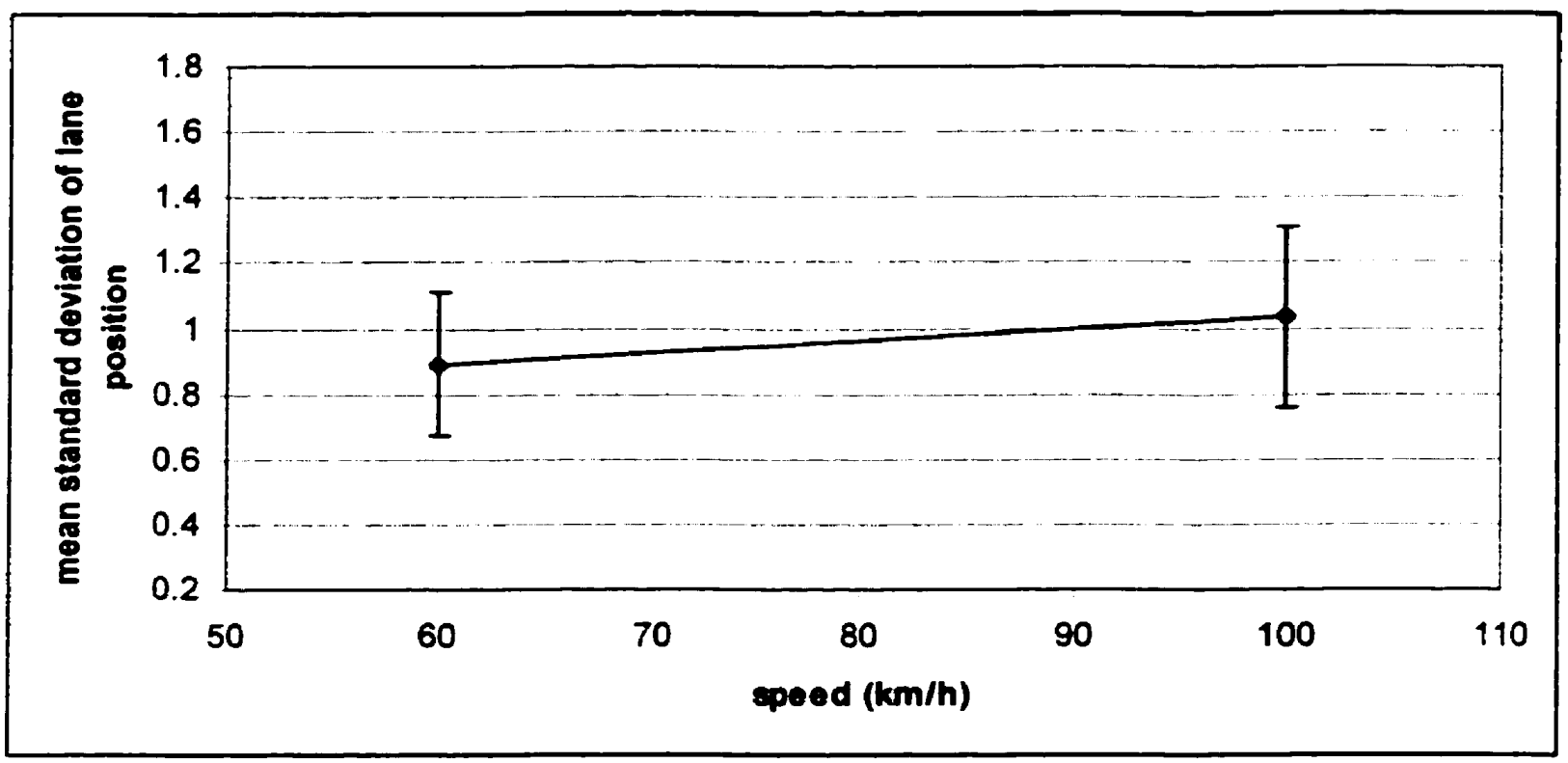

Figure 28. Mean SDLP (+/- standard deviation) for the variable speed $(n=10)$.

\subsubsection{Mean number of meters between spectacle openings}

As expected, the results of Experiment 2 indicated that attentional demand increased with increasing speed (see Figure 14 and Figure 19). As in Experiment 1, it was of interest to determine the number of meters between spectacle openings for Experiment 2. If the number of meters were equal for each of the speeds, this would imply that subjects perhaps had adopted a criterion of looking at the road as a function of distance travelled. If this were the case, this could be a very good explanation as to why attentional demand increases with speed. Table 17 presents the results from this calculation.

\begin{tabular}{|l|c|c|}
\hline Speed $(\mathrm{km} / \mathrm{h})$ & 60 & 100 \\
\hline \# of meters between looks & 6.55 & 7.41 \\
\hline
\end{tabular}

Table 17. Mean number of meters between looks at the road. 


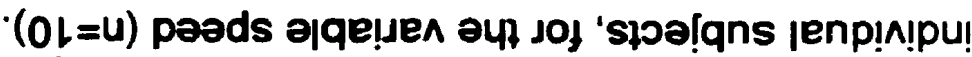

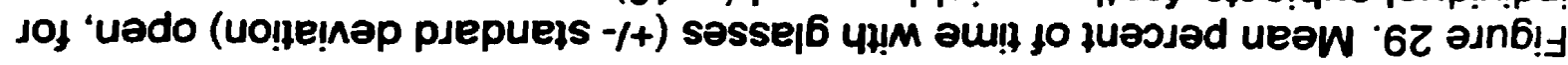

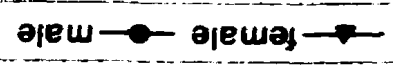

(4/uYy) poods

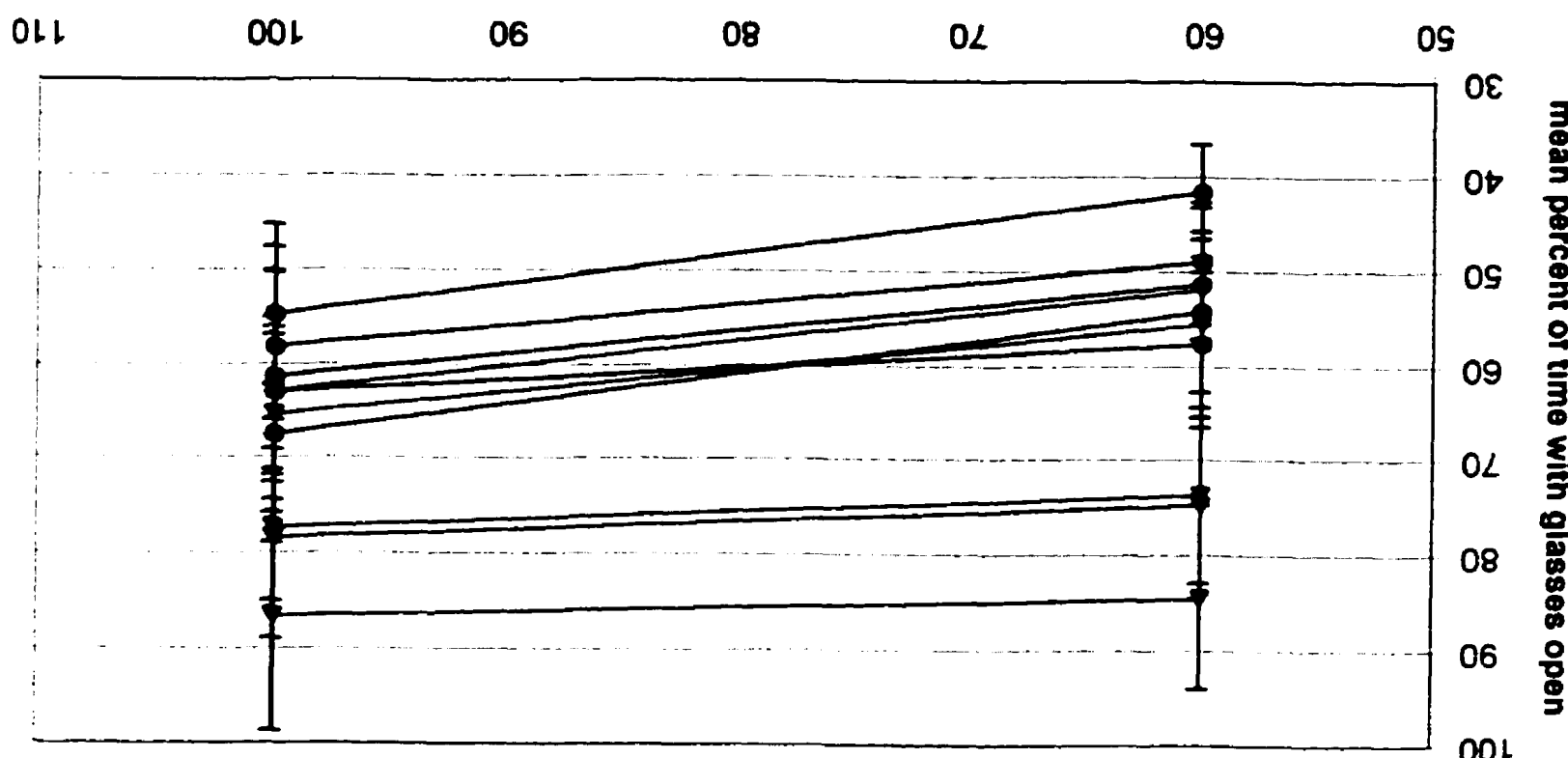

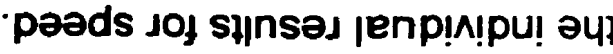

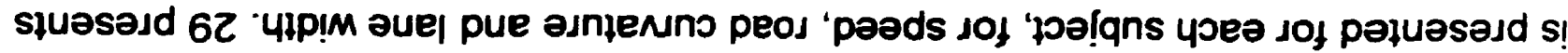

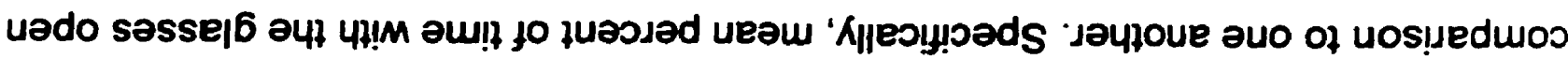

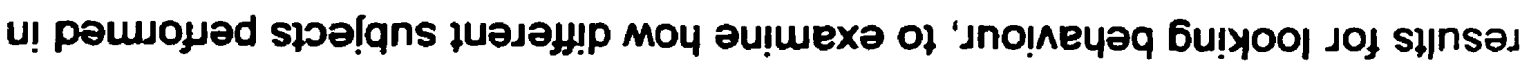

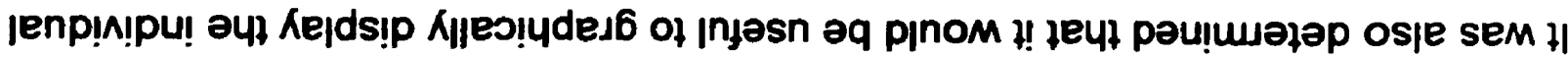
ø!nsey zoo!qns jenp!n!pul $9 \cdot 2 \cdot \varepsilon$

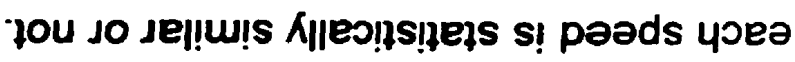

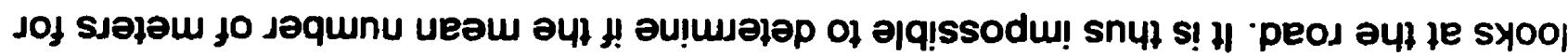

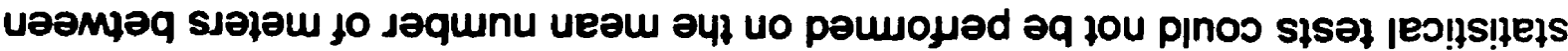

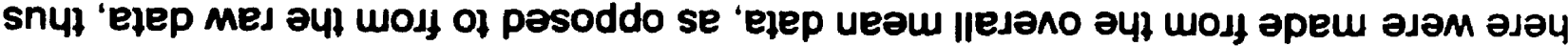

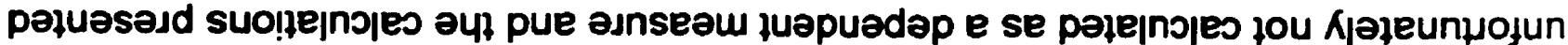

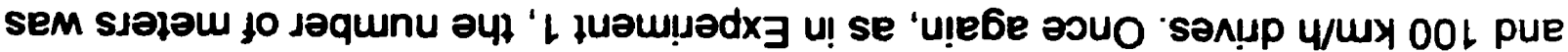

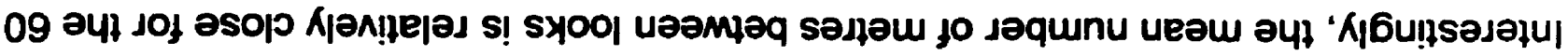


It can be seen from the graph that for each subject the mean percent of the time with the glasses open increases with speed. It can also be seen that this increase across speed is not as great for three of the female subjects. These same three female subjects also appear to have looked for a greater percentage of the drive for both speeds when compared to the other subjects.

Figure 30 illustrates the individual means for road curvature.

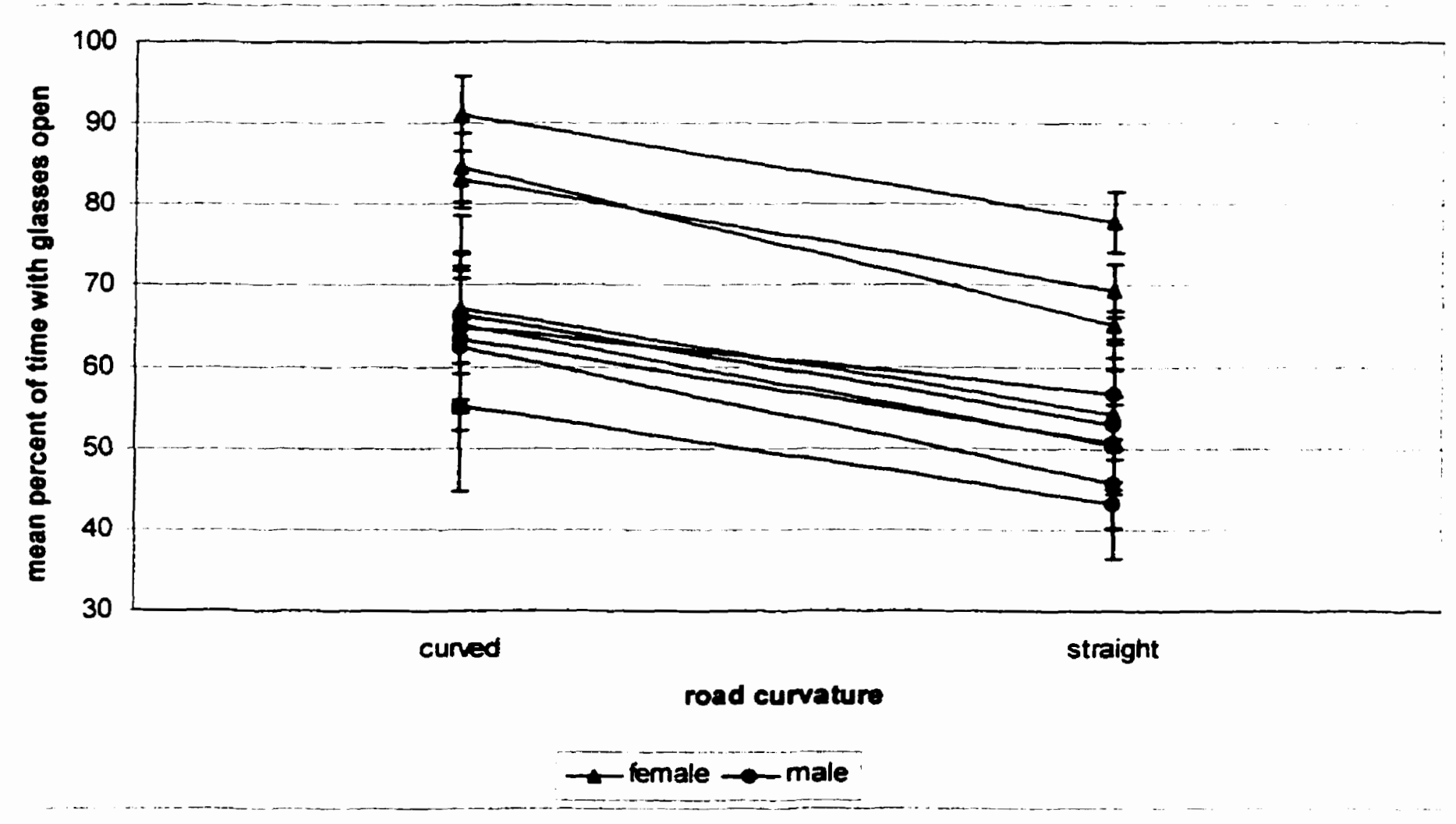

Figure 30. Mean percent of time with glasses (+/- standard deviation) open, for individual subjects, for the variable road curvature $(n=10)$.

An examination of Figure 30 illustrates that for each subject the mean percent of the time with the glasses open is greater for curved as compared to the straight segments of the road. It can also be seen that three of the five female subjects 
appear to have looked for a greater percentage of the drive for both straight and curved segments when compared to the other subjects.

Figure 31 illustrates the individual means for lane width.

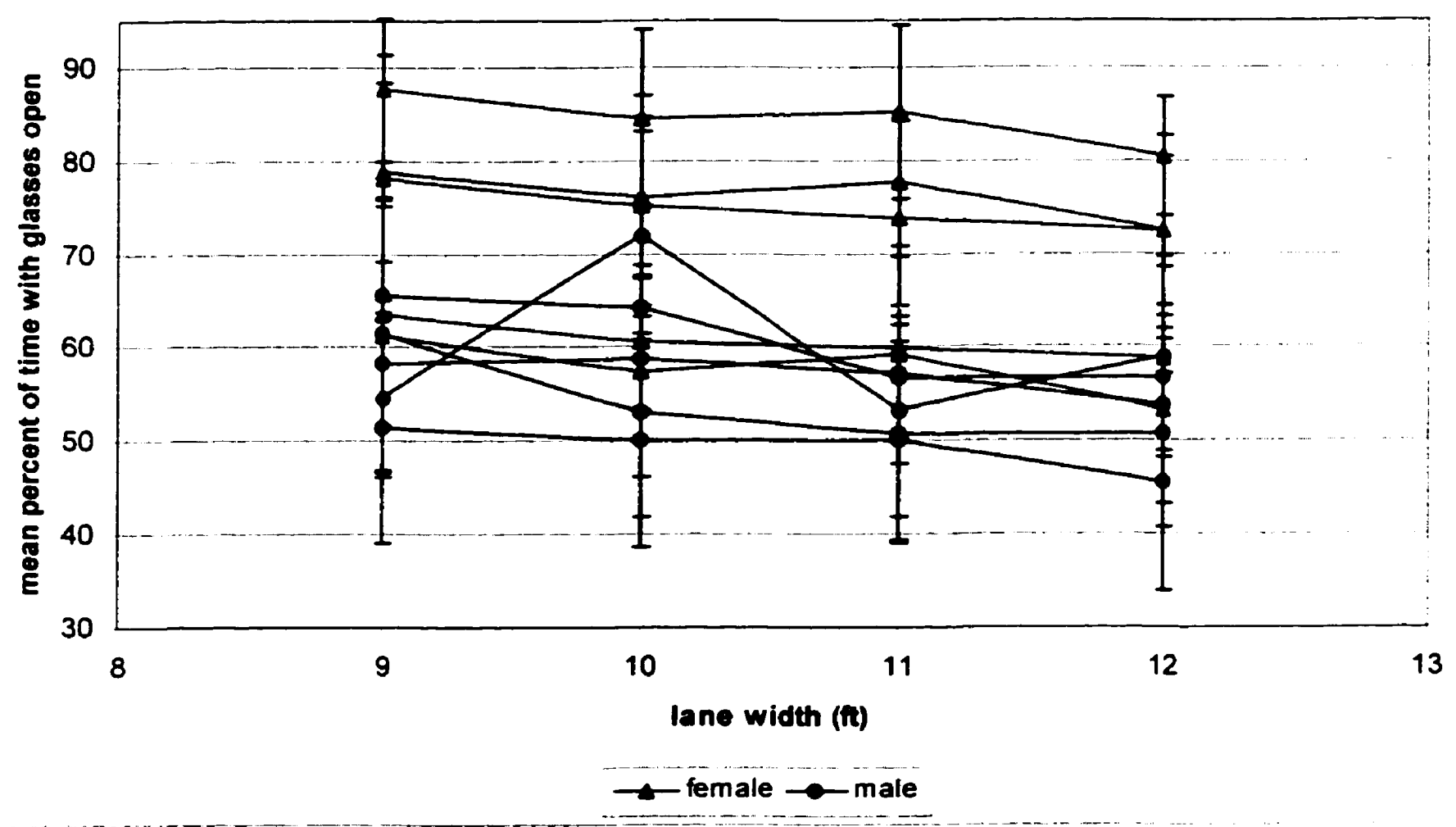

Figure 31. Mean percent of time with glasses (+/-standard deviation) open, for individual subjects, for the variable lane width $(n=10)$.

From examining the individual data in Figure 31 it can be seen that the trend for the majority of subjects is to look more as the lane with decreases. Once again for the variable lane width, as with the other two variables, it can be seen that three females appear to be looking more often than the other subjects. 


\subsection{Discussion}

\subsection{Experiment 1:}

The primary objective of Experiment 1 was to investigate the behavioural validity of a low cost, low fidelity Systems Technology Inc. simulator. More specifically, it was of interest to determine whether either of relative or absolute behavioural validity existed. This investigation was carried out by replicating an earlier on-the-road attentional demand study using visual occlusion carried out by Milgram et al. (1982). In Milgram et al.'s study, visual occlusion was the dependent variable measured to assess the attentional demand required by drivers for a variety of driving speeds. In general, it was found that, as speed increased, so did the attentional demand.

In Experiment 1 of the present study, Milgram et al.'s (1982) experimental design was replicated in a simulator. As in Milgram et al's study, visual occlusion was measured across different speeds $(20,60,100 \mathrm{~km} / \mathrm{h})$. In addition to speed, a second factor, viewing condition, was examined. This condition was examined to verify that drivers were performing the driving task as instructed. Specifically, drivers were instructed to look at the road as often as necessary in order to drive safely. To assess if drivers were in fact accomplishing this, subjects were required to drive each speed condition with and without the glasses. The standard deviation of lane position was computed and examined to determine if the subjects were "performing" equally well in conditions in which they were asked to wear the visual occlusion glasses as compared to those in which they were not. In this section the analysis of the lane position data are discussed, followed by a discussion of the visual occlusion data.

A $2 \times 3 \times 2$, mixed factorial ANOVA was performed to examine the standard deviation of lane position data. This analysis included the two sexes (male and female), the three levels of speed $(20,60,100 \mathrm{~km} / \mathrm{h})$ and the two viewing conditions. As expected, no significant main effects or interactions were found. This was actually a very important finding, because standard deviation of lane position was computed as 
a presumed measure of whether or not subjects were performing the task as instructed, that is, whether they were in fact driving "normally". The statistical results indicated that the subjects' standard deviation of lane position did not appear to be different, regardless of whether they were or were not wearing the goggles. This finding thus supports the assumption that the subjects were indeed opening the glasses as often as necessary in order to drive safely and maintain a safe position on the road. Specifically, it indicates that the subjects were not behaving in a risky manner and trying to look as seldom as possible because it is assumed that, if they were, their lane keeping performance probably would have suffered as a consequence.

Determining that subjects were carrying out the task as required was a very important first step in the analysis of the data collected from Experiment 1. It was of great importance because it provides strong support for our premise that subjects' visual looking behaviour was governed primarily by the attentional demands of the particular driving task, rather than some latent risk taking propensities. Note that a similar analysis was not performed for Experiment 2, because it was assumed unlikely that subjects would adopt a new risk taking attitude especially for that experiment after having carried out Experiment 1. Finally, in contradistinction to our suppositions about risk taking, it is important to note, on the other hand, that these data do not provide any insights at all into whether the subjects were in fact looking "more often than necessary".

Two more ANOVAs were carried out on the visual occlusion data collected from Experiment 1. The first examined the mean time between glass opening requests and the second examined the mean percent of time that the glasses were open. As previously mentioned, these dependent measures are essentially the same. It is advantageous to discuss both in that each allows the reader to view the data from a different vantage point. Each ANOVA involved a $2 \times 3$ mixed factorial design, comprising the two sexes (male and female) and the three levels of speed $(20,60$, $100 \mathrm{~km} / \mathrm{h}$ ). Each ANOVA revealed a significant main effect for the variable speed. 
No significant effect was found for either sex or the interaction between sex and speed. Planned comparisons for the speed variable revealed significant differences between each of the speeds relative to all of the others for both the dependent variables time between glasses openings and mean percent of time with the glasses open. Specifically, it was found that, as speed increased, the mean time between glasses openings decreased and the mean percent of time with the glasses open increased.

The findings that drivers sample the road more frequently and look at the road for a greater percentage of the drive as speed increases provide important support for the notion that attentional demand in driving increases with speed. To further examine this finding a calculation was carried out to examine the mean number of meters subjects drove between looks. Interestingly, it was found that, for the 60 and 100 $\mathrm{km} / \mathrm{h}$ speeds, drivers looked on average every 9.3 meters. Thus, it seems plausible that drivers' "need to look" may be based on the distance travelled since the previous look, and could explain why they look more often at greater speeds. Statistical tests could not be performed on the data for this variable, so further testing would be required to determine if statistical significance exists.

In addition to Experiment 1's speed findings, the fact that the same pattern of results was demonstrated in an on-the-road and a simulator study with essentially identical experimental designs provides supports for the behavioural validity of the low cost, low fidelity STI driving simulator. In conclusion, Experiment 1showed, in a very global sense, that Milgram et al.'s (1982) on-the-road study could be replicated on the STI simulator.

The second question of great importance to answer was whether the results from the simulator study had relative or absolute validity when compared to the on-theroad results. When a comparison was made between the two sets of results, relative validity was found to exist. Interestingly, the absolute numbers that resulted from each study differed dramatically. Specifically, it was found that in Milgram et al.'s 
(1982) study drivers sampled the road less frequently and looked at the road for a smaller percentage of time across all speeds when compared to Experiment 1 of the present study. This result was somewhat surprising because it was initially thought that, if relative validity were to exist between the on-the-road and simulator study, it would likely be found that the attentional demand exhibited by drivers would be greater on the road, not less.

The expectation that increased attentional demand would exist on-the-road when compared to the simulator resulted from consideration of the "real risk" that visual occlusion ostensibly presents when driving on a real road. This lead us to believe that drivers would adopt a lower threshold of uncertainty and thus look more often on the real road. When the results were in fact the reverse, this theory had to be reconsidered. In the on-the-road study a safety driver who had the ability to operate a safety brake travelled with the subjects at all times, so it is possible that this safety feature greatly reduced feelings of risk during the study. Conversely, a possible reason why the attentional demand was greater in the simulator as compared to the on-the-road study may relate to the lack of motion feedback provided by the simulator. An external disturbance function created by wind, was incorporated into each scenario. This wind caused the vehicle to drift, which in turn forced the subjects to continually attempt to maintain the vehicle's heading angle by controlling the steering. Due to the lack of motion feedback, however, the drivers could detect the gusts only by observing the drift of the vehicle on the roadway. It is quite possible, in other words, that the complete absence of motion feedback may have contributed to an increased level of uncertainty about position on the road, which compelled subjects to sample the visual information more often.

Another point to consider when examining the differences in the means for the two studies is that there appeared to be some large differences between individual subjects in the present study. Specifically, two of the ten subjects appeared to be looking much more often that the others across each of the three speeds. These two subjects obviously inflated the means for mean percent of time between looks and 
means percent of time with glasses open. Had more subjects been tested we might have been able to better assess if these two subjects were in fact exceptions to the rule.

To summarise, Experiment 1 revealed some very interesting findings. Firstly, it revealed that relative behavioural validity can exist between a low cost, low fidelity driving simulator and an on-the-road study with respect to at teast one subset of driving behaviour parameters. In other words, the study indicated that a low cost , low fidelity simulator can be a useful tool for examining trends, but that the absolute values that result can not necessarily be translated directly to the real world. One likely reason for this is the lack of motion feedback provided by such low cost simulators. (Experiment 1's findings also prompt an important caveat: When relying on the data generated by such driving research simulators for forensic and/or litigation purposes, one must not assume absolute validity between simulation results and on-the-road results.) Nevertheless, the obvious advantage of demonstrating the behavioural validity of such a simulator, even if only relative validity, is its potential for further driving behaviour research at relatively low cost and great flexibility.

Experiment 1 also helped accomplish a second experimental objective. Specifically, it provided support for visual occlusion as a measure of attentional demand by demonstrating the transferability, reliability, diagnosticity, and sensitivity of the visual occlusion measure. Firstly, transferability of visual occlusion was demonstrated, in that it was shown that visual occlusion can be used in both on-the-road and simulator studies and the same trend of results can be expected to result.

Secondly, the replication of Milgram et al.'s (1982) on-the-road study also supported the reliability of the measure. As previously discussed, it is also important that experimental results can be replicated to ensure the reliability of the method. Experiment 1 replicated Milgram et al.'s experimental design and found the same results, that is, that attentional demand increases with increasing speed. The 
replication of this finding lends support to visual occlusion as a reliable measure of attentional demand.

Experiment 1 also helped demonstrate both the diagnosticity and sensitivity of visual occlusion as a measure of attentional demand. Using this measure attentional demand was found to vary in driving conditions with different demands. This supports the sensitivity of the measure. In addition, the differences in attentional demand could be attributed to the different speeds that the drivers were driving. The ability to determine what caused the changes in attentional demand supports the diagnosticity of visual occlusion as a measure of attentional demand.

\subsection{Experiment 2:}

Experiment 2 of the present study had two main objectives. The first objective was to provide further support for visual occlusion as a measure of attentional demand. The second objective was to investigate how speed, curvature of the road and lane width affect the level of attentional demand in a simulated driving environment. Both objectives were accomplished and will be discussed in this section.

Experiment 2 was a $2 \times 2 \times 2 \times 4$ mixed factorial design, with the variables sex, speed, road curvature and lane width being examined. With the exception of sex, all variables were within subjects. The two dependent variables time between glasses opening requests and percent of time with the glasses open, were examined as presumed indices of the attentional demand of the different driving conditions. As previously mentioned, these dependent measures are essentially the same. It is advantageous to discus both in that each allows the reader to view the data from a different vantage point. An ANOVA was performed on each of the dependent variables to determine where significant differences lay. The specific findings for each variable and their relationship to the hypothesised findings are discussed in the following. 
Two speeds were examined in Experiment 2 (60 and $100 \mathrm{~km} / \mathrm{h}$ ). As in Experiment 1 and in previous studies (Milgram et al., 1982; Senders et al., 1967) it was found that as speed increased the time between glass openings decreased and the percent of time with the glasses opened increased. Specifically, there was a $15 \%$ increase in attentional demand from 60 to $100 \mathrm{~km} / \mathrm{h}$. This finding that both measures of attentional demand increase with increases in speed had been hypothesised, as previous researchers had made similar findings.

As in Experiment 1, additional calculations were made because the results brought new issues to light and/or it was felt that some results required further examination. The first of these calculations involved the number of meters between looks. This was done to explore if distance dictated when subjects felt they needed to look. The mean distances between looks were similar for the $60 \mathrm{~km} / \mathrm{h}$ and $100 \mathrm{~km} / \mathrm{h}$ speeds (6.55 and $7.41 \mathrm{~m}$ respectively). As to whether these distances were statistically similar or different, we cannot comment as statistical tests could not be performed. But it is felt that further research should examine this more closely.

In addition, the standard deviation of lane position for the variable speed was examined for Experiment 2. It was found that the SDLP was significantly greater for the $100 \mathrm{~km} / \mathrm{h}$ speed as compared to the $60 \mathrm{~km} / \mathrm{h}$ speed. Using this as a presumed measure of driving performance, this finding indicates that subjects were ostensibly not performing as well at the higher speed. Although subjects did look more often at the higher speeds, perhaps they should have been looking even more often.

In addition to speed, curvature of the road was also examined. Specifically, subjects drove on straight segments of road as well as curved segments (radius of curvature $=1.52 \mathrm{~km}$ ). Based on previous findings it was hypothesised that greater attentional demand would be required for the curved sections of road as compared to the straight segments of road (Mourant \& Ge, 1997; Fitzpatrick et al., 1999). This hypothesis was supported by the fact that subjects' time between glass openings was significantly smaller on the curved segments of the road, and the percent of 
time that they spent with the glasses open significantly greater, as compared to the straight sections of road. Specifically, the attentional demand required on the curved segments of the road was $10 \%$ greater than that required on the straight segments of road. Unfortunately, due to the initial coding of the variables, the standard deviation of lane position for the variable curvature could not be examined for Experiment 2. Such an examination would have proved useful in determining if the subjects' driving performance was equal for both straight and curved segments of the road.

A third variable, lane width, was also investigated. Specifically, the attentional demand across 9, 10,11 and $12 \mathrm{ft}$ lanes was examined. It was hypothesised that, as lane width decreased, the required attentional demand would increase. This hypothesis was supported. With the exception of the comparisons between the 9 and $10 \mathrm{ft}$ lanes (to be discussed later) it was found that as lane width increased, the time between looks at the road increased and the percentage of time with the glasses open decreased. In other words, as lane width decreases attentional demand increases. Specifically, a $6 \%$ increase in attentional demand was found as the lane width decreased from 12 to 9 feet. In addition, the standard deviation of lane position for the variable lane width was examined for Experiment 2, as a presumed measure of driving performance. Interestingly, the general trend for lane width was that, as the lane width increased, so did the SDLP. This in fact makes sense when one considers that, for a smaller lane width, one must adopt a smaller SDLP to maintain your position within the lane.

As previously discussed, no published study to date was found which has examined the relationship between lane width and attentional demand. These findings are thus of potentially great importance for road design. Often highway designers narrow lane widths so that additional lanes can be added to existing roads (Heimbach, Cribbins, \& Chang, 1983). This is done to help cope with increasing traffic volume. The findings of the current study demonstrate, however, that lane width has a significant potential impact on the attentional demand imposed upon the driver, in the sense 
that by narrowing lane widths the attentional load placed on the driver is likely to become significantly greater. Presumably, increased attentional demand increases the possibility of attentional overload, which can in turn result in driving errors or accidents. It has already been shown that roads with narrower lane widths have a higher percentage of accidents (Zegeer, Huang, Stewart, \& Williams, 1998). The present study illustrates why this may be the case.

As mentioned above, one unexpected finding regarding lane widths occurred. Specifically, it was found that significant differences did not exist between the 9 and $10 \mathrm{ft}$ lanes for the two dependent variables. However, it is believed that the lack of significant differences between the visual occlusion measures for the two lane widths does not in fact reflect that the attentional demand for 9 and $10 \mathrm{ft}$ lane widths is equal. The reasoning behind this thinking reflects the fact that the actual mean time between glasses openings for both the 9 and $10 \mathrm{ft}$ lane widths was very small, approximately 0.8 seconds. When the duration of time that the glasses were open, $0.5 \mathrm{~s}$, is subtracted from that mean, we are left with an average time between glances at the road of approximately 0.3 seconds. Based on the magnitude of this number, which is of approximately the same magnitude as human simple reaction time, it is probable that subjects were opening the glasses essentially as fast they were physically and mentally able for these lane widths. That is, to open the glasses subjects were required to activate the left turn signal. It is thus quite conceivable that it took subjects along the order of 0.3 seconds to accomplish this task. So despite the fact that in theory the glasses could be opened mechanically at a faster rate to allow the drivers to look more often (up to $100 \%$ of the time if they requested looks at the road while the glasses were still open) this behaviour was not seen, possibly because of the fatigue that would have resulted from continually opening the glasses at a very rapid rate for relatively long durations of time. Observations made during testing also support this line of thinking. It was observed that, when subjects were driving scenarios which contained the 9 and $10 \mathrm{ft}$ lane widths, that they were rapidly initiating left turn signals throughout the entire duration of the drive. It would be of interest to examine the attentional demand produced by these lane widths once 
again. This would require implementation of a method to open the glasses which is not as physically demanding or time consuming as the method used in the present study. If this were done, it would likely be seen that the attentional demand required for the $9 \mathrm{ft}$ lane widths is greater than that required for the $10 \mathrm{ft}$ lane widths.

The fourth variable which was examined was the between subjects variable, sex. This variable was not the focus of the present study, but in designing the experiment it was felt that it was important to examine sex, because differences in driving behaviour have been shown to exist between males and females (Mourant \& Rockwell, 1972; Shinar, 1978). Nevertheless, significant differences found to exist between males and females in Experiment 2 were somewhat unexpected. Specifically, it was found that for females the time between glass openings was smaller and that the percentage of time with the glasses open was larger when compared to males (12\% greater). Specifically, it appeared that the difference in looking behaviour between males and females was greater at the $60 \mathrm{~km} / \mathrm{h}$ speed when compared to the $100 \mathrm{~km} / \mathrm{h}$ speed. It is possible that, if more subjects had been used, this result might have been found statistically significant. Immediately, these findings gave rise to the question, "were males and females performing the task equivalently?", that is, were they both looking as often as necessary in order to drive safely? To investigate this, the standard deviation of lane position for males and females was also computed and examined across all of Experiment 2's driving scenarios, as a presumed measure of primary driving performance. No significant differences were found between male and female lane deviations, however, suggesting that both were performing the primary driving task as instructed.

The standard deviations of lane position for males and females were also compared in the baseline driving condition for which subjects drove without the visual occlusion glasses. This examination was done as a second check to see if males and females maintained similar lane deviations while driving the simulator. Specifically, if females had exhibited a larger standard deviation of lane position than males when driving without the glasses, but a similar standard deviation of lane position when driving 
with the glasses, this would indicate that females may have been driving more cautiously when wearing the glasses. This increased caution could then explain the increased percent of time with the glasses open and the decreased time between glasses openings. This was not the case, however, as once again no significant differences were found between males and females for standard deviations of lane position.

A possible explanation for the attentional demand differences between males and females is simply that females sample the road scene more often because they subjectively prefer a greater level of redundancy of information collected from the driving scene. By sampling the road more often they can obtain such high levels of redundancy. In Milgram et al's (1987) original study, mathematical modelling was used to indicate that subjects in their experiment adopted a criterion of constant redundancy in governing the looking behaviour in their visual occlusion experiment. That is, drivers continue to make estimates of the vehicle's position while their vision is occluded and, on the basis of these predictions, drivers make the decision to look again when their uncertainty reaches a comparable threshold level for each occlusion period. This looking behaviour is equivalent to the drivers' maintaining a constant level of redundancy in their subjectively acceptable estimates of the vehicle's position within the lane. Milgram et al did not look explicitly at sex differences, however. It would thus be of interest to examine such differences in attentional demand further in future studies. Had subjective measures been assessed in the present experiment, perhaps more insight could be offered at this time.

It is also worth mentioning that the individual subject performances were examined for each of the three variables (speed, road curvature, lane width) in Experiment 2. For each variable it was found that three of the female subjects looked what appears to be substantially more often than all of the other subjects. The results from these three subjects had strong implications on the data. That is, they increased the mean percent of time between looks and (equivalently) the mean percent of time with the 
glasses open. Due to the small subject population it is difficult to determine whether these three subjects were exceptions to the rule. This finding indicates, however, that it would be wise for researchers carrying out such examinations to use a greater sample of the population. By doing so, outlying subject data do not have as great an impact on the overall data.

Experiment 2, like Experiment 1, also helped accomplish a second experimental objective; that is, it provided support for visual occlusion as a measure of attentional demand. Specifically, it demonstrated the reliability, diagnosticity, and sensitivity of visual occlusion as a measure of attentional demand. Firstly, by replicating results found in previous studies, Experiment 2 demonstrated the reliability of visual occlusion as a measure of attentional demand. Specifically, it was found that attentional demand increases with speed and that greater attentional demand is required on curved roads as compared to straight roads. Both of these findings have been made previously using visual occlusion as a measure of attentional demand. Milgram et al (1982) and Senders et al. (1967) made the same findings for attentional demand as a function of speed, while Mourant \& Ge (1997) and Fitzpatrick et al. (1999) made the same findings for attentional demand as a function of road curvature.

Experiment 2 also illustrated the diagnosticity and sensitivity of visual occlusion as a measure of attentional demand. Using visual occlusion, attentional demand was found to vary in driving conditions with different demands, imposed by different speeds, road curvatures and lane widths. Such changes in visual occlusion with changing workload support the sensitivity of the measure. In addition, the differences in attentional demand could be attributed specifically to the different speed, road curvature and lane width conditions that the drivers were driving. The ability to determine what caused such changes in attentional demand thus supports the diagnosticity of visual occlusion as a measure of attentional demand. 


\subsection{CONCLUSION}

A number of important conclusions can be drawn from the present study. These conclusions pertain to the behavioural validity of low cost simulators, the power of visual occlusion as a technique for measuring attentional demand and how attentional demand in automobile driving changes as a function of speed, road curvature and lane width. The conclusions relating to each of these areas are discussed in further detail below.

Firstly, the present study demonstrated that behaviourally valid results can be obtained from a low-cost, low-level driving simulator. Specifically, results obtained from a low cost Systems Technology Inc. simulator were found to correspond with results obtained, under analogous conditions, from an on-the-road driving study. This finding has important implications for simulation research. As previously mentioned, the use of low cost low-level simulators is growing, yet an understanding of their behavioural validity is limited. Investigations which demonstrate the behavioural validity of results produced by such simulators have great importance because they support the power of this driving research tool. It is important to note that a simulator may possess behavioural validity, but this validity may not necessarily be absolute. This was the case in the present study. The same trend of results were found for the simulator and the on-the-road study, but the absolute values differed dramatically. It is very important that driving researchers who use low-level simulators be aware of such potential discrepancies. The present study illustrated, in other words, that low-level simulators are can be very useful for examining trends of results, but that one can not assume that the absolute values obtained can be applied directly to real road applications.

A second important issue worth discussing which arose from the present study is the value of the method of visual occlusion as a measure of attentional demand. As previously mentioned, it was found that attentional demand varies with speed and road curvature. These findings are not new; authors such as Senders et al. (1967), Milgram et al. (1982) and Mourant and Ge (1996) have made similar findings. 
Replication of such results using visual occlusion is nevertheless of great importance because it provides further support for the reliability of this method for assessing attentional demand. Additional support for the method in the present study came from the sensitivity and diagnosticity that it provided. The sensitivity, diagnosticity and reliability that visual occlusion provides make it an excellent tool for assessing attentional demand, potentially also beyond the realm of automobile driving.

A final very important finding of the present study pertains to how drivers adjust the allocation of their attention to meet different demands of the driving situation. The findings of the present study illustrated that drivers do indeed dynamically adjust their allocation of atteritional resources to meet the demands of the driving situation. In this study the driving elements: speed, road curvature and lane width were all found to have an impact on the allocation of attention. Specifically, it was found that, as speed increased, so did the attentional demand placed upon the driver. Attentional demand also was found to vary directly with road curvature; that is, drivers allocated more attention to the road when it was curved as opposed to straight. Finally, it was found that, as lane width decreased, drivers were again forced to pay more attention to the road. In summary, an understanding of the attentional demand imposed upon drivers by different driving conditions has very important implications for human factors professionals and highway designers. Specifically, such an understanding can help these professionals ensure that roadways which exceed drivers' capabilities are not created.

In the present experiments the attentional demand of fairly simplistic driving conditions was examined. In future experiments it would be of great interest to examine the attentional demand created by more complex driving conditions, such as conditions involving multiple lanes, traffic, and/or pedestrians. It would also be of interest to examine conditions in which the driver is dividing his/her attention between the driving task and in-vehicle technology, for example, driving while operating a cell phone or in-vehicle navigation device. The additional attentional demand introduced by such technological devices could be assessed, for example, 
by comparing the attentional demand required in those situations to the baseline measures of attentional demand collected in the present study. 


\subsection{REFERENCES}

Alexander, G. J. \& Lunenfeld, H. (1975). Positive guidance in traffic control. Federal Highway Administration, Washington, DC.

Allen, R.W., Rosenthal, T. J., \& Aponso, B.L. (1998). Low-cost simulation for safety research, prototyping and training. Intemational technical Conference on the Enhanced Safety of Vehicle (ESV) Conference.

Blaauw, G. (1982). Driving experience and task demands in simulator and instrumented car: a validation study. Human Factors, 24(4), 473-486

Blumenthal, M (1968). Dimensions of the traffic safety problem. Traffic Safety Research Review, 12, 7-12.

de Waard, D. \& Brookhuis, K. A., (1997). On the measurement of driver mental workload in T. Rothengatter \& E. Carbonell Vaya, Traffic and Transportation Psychology Theory and Application, New York: Pergamon

Dewar, R. (1993). Hazardous road signs ahead. Ergonomics in Design, July, 26-31.

Dewar, R. (1992). Driver and pedestrian characteristics in J. Pline (ed.), Traffic Engineering Handbook (4th ed). New Jersey: Englewood Cliffs, 1-28.

Fitzpatrick, K., Wooldridge, M. D., Tsimhoni, O., Collins, J. M., Green, P., Bauer, K. M., Parma, K. D., Koppa, R., Hanwood, D. W., Anderson, I, Krammes, R. A. \& Poggioli, B. (1999). Alternative Design consistency rating methods for twolane rural highways, Final Report for the U.S. Department of Transportation Federal Highway Administration by Texas Transportation Institute, University of Michigan Transportation Institute, and Midwest Research Institute. January. 
Ministry of Transportation (1985). Geometric Design Standards for Ontario Highways.

Gianutsos, R. (1994). Driving advisement with the elemental driving simulator (EDS): when less suffices. Behavior Research Methods, Instruments, \& Computers, $26(2), 183-186$.

Heimbach, C. L., Cribbins, P. D., \& Chang, M. (1983). Some partial consequences of reduced traffic lane widths on urban arterials. Transportation Research Record, 923, 69-72.

Kaptein, N. A., Theeuwes, J., \& van der Horst, R. (1996). Driving simulator validity: some considerations. Transportation Research Record 1550, 30-36.

McRuer, D. T., \& Klein, R. H. (1974). Automobile controllability: driver/vehicle response for steering control. Technical report for the Department of Transportation National Highway Traffic Safety Administration.

Milgram, P. (1987). A spectacle-mounted liquid-crystal tachistoscope. Behaviour Research Methods, Instruments and Computers, 19(5), 449-456.

Milgram, P., Godthelp, H., \& Blaauw, G. (1982). An investigation of decision-making criteria adopted by drivers while monitoring vehicle state in the temporary absence of visual input, Second European Annual Conference on Human Decision Making and Manual Control, Bonn, FRG, June.

Moskowitz, H., Burns, M., Fiorentino, D., Smiley, A., and Zador, P (1999). Driver characteristics and impairment at various BACs. Final report prepared for the National Highway Traffic Safety Administration, DTNH-22-95-C-05000 by Southern California Research Institute. June, 1999. 
Mourant, R. R. \& Ge, Z (1997). Measuring attentional demand in a virtual environment driving simulator. Proceedings of the Human Factors and Ergonomics Society $41^{\text {st }}$ Annual Meeting.

Mourant, R. R. and Rockwell, T. H. (1972). Strategies of visual search by novice and experienced drivers. Human Factors, 18, 325-335

Rolfe , J. M., Hammerton-Frase, A. M., Poulter, R. F., and Smith, E. M. B. (1970). Pilot response in flight and simulated flight. Ergonomics, 13, 761-768.

Senders, J. W., Kristofferson, A. B., Levison, W. H., Dietrich, C. W., \& Ward, J. L. (1967). The attentional demand of automobile driving. Highway Research Record, 195, 14-33.

Shinar, D. (1978). Psychology on the Road. New York: John Wiley \& Sons.

Smiley, A. (1989). Mental workload and information management. Vehicle Navigation and Information Systems Conference IEEE, New York, New York, September, 435-438.

Smiley, A. (1978). Vehicle steering control: a model of learning. Ph.D. Thesis, University of Waterloo.

van der Horst, R. \& Hoekstra, W. (1994). Testing speed reduction designs for 80 kilometre per hour roads with simulator. Transportation Research Record, 1464, 63-68.

Wierwille, W. W. \& Eggemeier, F. (1993). Recommendations for mental workload measurement in a test and evaluation environment. Human Factors, 35 (2), 263-281. 
Wierwille, W. W., Hulse, M. C., Fischer, T. J., and Dingus, T. A. (1988). Effects of variations in driving task attentional demand on in-car navigation system usage. Technical Report CR-88/02/OS. Warren, MI: General Motors Research Laboratories.

Wikman, A., S., Nieminen, T., \& Summala, H. (1998). Driving experience and timesharing during in-car tasks on roads of different widths. Ergonomics, 41(3),358-372.

www.systemstech.com

Zegeer, C. V., Huang, H. F., Stewart, J. R., \& Williams, C (1998). Investigation of national highway system roadways in the highway safety information system states. Transportation Research Record, 1635, 1-9. 


\section{APPENDIX A}

\section{Experimental Design}

\section{DAY 1: TRAINING}

\section{Baseline video game rating}

\begin{tabular}{|l|c|c|c|}
\hline \multicolumn{1}{|c|}{ Scenario } & \# of runs & Occlusion & $\begin{array}{c}\text { Time to complete } \\
\text { (min) }\end{array}$ \\
\hline $\begin{array}{l}\text { 1. baseline scenario: driver velocity } \\
\text { control, curves, traffic, buildings }\end{array}$ & 1 & no occlusion & approx. 3 \\
\hline \multicolumn{2}{|c|}{ Total time: 3.5 min } \\
\hline
\end{tabular}

\section{Training for Experiment 1}

\begin{tabular}{|l|c|c|c|}
\hline \multicolumn{1}{|c|}{ Scenario } & \# of runs & Occlusion & $\begin{array}{c}\text { Time to } \\
\text { complete (min) }\end{array}$ \\
\hline 1. straight road, $60 \mathrm{~km} / \mathrm{h}$ & 1 & no occlusion & 2.2 \\
\hline 2. straight road, $60 \mathrm{~km} / \mathrm{h}$ & 1 & Occlusion & 2.2 \\
\hline 3. straight road, $100 \mathrm{~km} / \mathrm{h}$ & $\begin{array}{c}\text { until criterion, } \\
\text { max.: } 3 \text { runs }\end{array}$ & Occlusion & $2.2-6.8$ \\
\hline
\end{tabular}

\section{Total time: $\quad 9-13 \mathrm{~min}$}

\section{Training for Experiment 2}

\begin{tabular}{|l|c|l|c|}
\hline \multicolumn{1}{|c|}{ Scenario } & \# of runs & Occlusion & $\begin{array}{c}\text { Time to complete } \\
\text { (min) }\end{array}$ \\
\hline 1. curved road, $60 \mathrm{~km} / \mathrm{h}, 11 \mathrm{ft} . \mathrm{road}$ & 1 & occlusion & 3.5 \\
\hline 2. curved road, $60 \mathrm{~km} / \mathrm{h}, 9 \mathrm{ft}$ road & 1 & occlusion & 3.5 \\
\hline 3. curved road, $100 \mathrm{~km} / \mathrm{h}, 11 \mathrm{ft}$ road & 1 & occlusion & 2.2 \\
\hline 4. curved road, $100 \mathrm{~km} / \mathrm{h}, 9 \mathrm{ft}$. road & $\begin{array}{c}\text { until criterion, } \\
\text { max.: } 6 \text { runs }\end{array}$ & occlusion & $2.2-13.2$ \\
\hline
\end{tabular}

Total completion time for Day 1 allowing 30 seconds between runs and including a 10 minute break between sessions $B$ and $C$ is estimated to be between 37 and 50 minutes

${ }^{*}$ criterion refers to the subject driving the scenario without going outside the lines of the roadway 
DAY 2 - TRAINING

A) Training for Experiment 1:

\begin{tabular}{|l|c|c|c|}
\hline \multicolumn{1}{|c|}{ Scenario } & \# of runs & Occlusion & Time to complete (min) \\
\hline 1. ${ }^{*}$ straight road, $100 \mathrm{~km} / \mathrm{h}$ & 1 & occlusion & 2.2 \\
\hline 2. straight road, $20 \mathrm{~km} / \mathrm{h}$ & 1 & occlusion & 2.2 \\
\hline 3.straight road, $60 \mathrm{~km} / \mathrm{h}$ & 1 & occlusion & 2.2 \\
\hline 4. straight road, $100 \mathrm{~km} / \mathrm{h}$ & 1 & occlusion & 2.2 \\
\hline 5. straight road, $20 \mathrm{~km} / \mathrm{h}$ & 1 & no occlusion & 2.2 \\
\hline 6. straight road, $60 \mathrm{~km} / \mathrm{h}$ & 1 & no occlusion & 2.2 \\
\hline 7. straight road, $100 \mathrm{~km} / \mathrm{h}$ & 1 & no occlusion & 2.2 \\
\hline \multicolumn{4}{|r}{} \\
\hline
\end{tabular}

B) Training for Experiment 2:

\begin{tabular}{|c|c|c|c|}
\hline Scenario & \# of runs & Occlusion & $\begin{array}{c}\text { Time to complete } \\
\text { (min) }\end{array}$ \\
\hline 1. ${ }^{*}$ curved road, $100 \mathrm{~km} / \mathrm{h}, 11 \mathrm{ft}$. road & 1 & occlusion & 2.2 \\
\hline 2. *curved road, $100 \mathrm{~km} / \mathrm{h}, 9 \mathrm{ft}$. road & 1 & occlusion & 2.2 \\
\hline 3. curved road, $60 \mathrm{~km} / \mathrm{h}, 9 \mathrm{ft}$. road & 1 & occlusion & 3.5 \\
\hline 4. curved road, $60 \mathrm{~km} / \mathrm{h}, 10 \mathrm{ft}$. road & 1 & occlusion & 3.5 \\
\hline 5. curved road, $60 \mathrm{~km} / \mathrm{h}, 11 \mathrm{ft}$. road & 1 & occlusion & 3.5 \\
\hline 6. curved road, $60 \mathrm{~km} / \mathrm{h}, 12 \mathrm{ft}$. road & $\mathrm{l}$ & occlusion & 3.5 \\
\hline 7. curved road, $100 \mathrm{~km} / \mathrm{h}, 9 \mathrm{ft}$. road & 1 & occlusion & 2.2 \\
\hline 8. curved road, $100 \mathrm{~km} / \mathrm{h}, 10 \mathrm{ft}$. road & 1 & occlusion & 2.2 \\
\hline 9. curved road, $100 \mathrm{~km} / \mathrm{h}, 11 \mathrm{ft}$. road & 1 & occlusion & 2.2 \\
\hline 10. curved road, $100 \mathrm{~km} / \mathrm{h}, 12 \mathrm{ft}$. road & 1 & occlusion & 2.2 \\
\hline
\end{tabular}

*warm up runs

With the exception of the first run of Experiment 1 and the first 2 runs of Experiment 2 (warm up runs) all runs will be randomised

Total completion time for Day 2 allowing 30 seconds between runs and including a 10 minute break between sessions $\mathrm{A}$ and $\mathrm{B}$, and an additional 5 minute break half way through session $B$ is estimated to be between 66 minutes 
Dav 3: DATA COLLECTION

B) Experiment 1:

\begin{tabular}{|c|c|c|c|}
\hline Scenario & \# of runs & Occlusion & Time to complete (min) \\
\hline 1. * straight road, $100 \mathrm{~km} / \mathrm{h}$ & 1 & occlusion & 2.2 \\
\hline 2. straight road, $20 \mathrm{~km} / \mathrm{h}$ & 1 & occlusion & 2.2 \\
\hline 3. straight road, $60 \mathrm{~km} / \mathrm{h}$ & 1 & occlusion & 2.2 \\
\hline 4. straight road, $100 \mathrm{~km} / \mathrm{h}$ & 1 & occlusion & 2.2 \\
\hline 5. straight road, $20 \mathrm{~km} / \mathrm{h}$ & 1 & no occlusion & 2.2 \\
\hline 6. straight road, $60 \mathrm{~km} / \mathrm{h}$ & 1 & no occlusion & 2.2 \\
\hline 7. straight road, $100 \mathrm{~km} / \mathrm{h}$ & 1 & no occlusion & 2.2 \\
\hline \multicolumn{4}{|r|}{ Total time: $18 \mathrm{~min}$} \\
\hline
\end{tabular}

\section{B) Experiment 2:}

\begin{tabular}{|l|c|l|c|}
\hline \multicolumn{1}{|c|}{ Scenario } & \# of runs & Occlusion & $\begin{array}{c}\text { Time to complete } \\
\text { (min) }\end{array}$ \\
\hline $1{ }^{*}$ curved road, $100 \mathrm{~km} / \mathrm{h}, 11 \mathrm{ft} . \mathrm{road}$ & 1 & occlusion & 2.2 \\
\hline $2{ }^{*}$ curved road, $100 \mathrm{~km} / \mathrm{h}, 9 \mathrm{ft} . \mathrm{road}$ & 1 & occlusion & 2.2 \\
\hline 3. curved road, $60 \mathrm{~km} / \mathrm{h}, 9 \mathrm{ft} . \mathrm{road}$ & 1 & occlusion & 3.5 \\
\hline 4. curved road, $60 \mathrm{~km} / \mathrm{h}, 10 \mathrm{ft} . \mathrm{road}$ & 1 & occlusion & 3.5 \\
\hline 5. curved road, $60 \mathrm{~km} / \mathrm{h}, 11 \mathrm{ft} . \mathrm{road}$ & 1 & occlusion & 3.5 \\
\hline 6. curved road, $60 \mathrm{~km} / \mathrm{h}, 12 \mathrm{ft} . \mathrm{road}$ & 1 & occlusion & 3.5 \\
\hline 7. curved road, $100 \mathrm{~km} / \mathrm{h}, 9 \mathrm{ft} . \mathrm{road}$ & 1 & occlusion & 2.2 \\
\hline 8. curved road, $100 \mathrm{~km} / \mathrm{h}, 10 \mathrm{ft} . \mathrm{road}$ & 1 & occlusion & 2.2 \\
\hline 9. curved road, $100 \mathrm{~km} / \mathrm{h}, 11 \mathrm{ft} . \mathrm{road}$ & 1 & occlusion & 2.2 \\
\hline 10. curved road, $100 \mathrm{~km} / \mathrm{h}, 12 \mathrm{ft} . \mathrm{road}$ & 1 & occlusion & 2.2 \\
\hline & & & Total time: $33 \mathrm{~min}$ \\
\hline
\end{tabular}

${ }^{*}$ no data will be collected (warm up runs)

With the exception of the first run of Experiment 1 and the first 2 runs of Experiment 2 (warm up runs) all runs will be randomised

Total completion time for Day 3 allowing 30 seconds between runs and including a 10 minute break between sessions $A$ and $B$, and an additional 5 minute break half way through session $B$ is estimated to be between 66 minutes 


\section{APPENDIX B}

\section{Consent Form \\ For participation in the experiment "An Investigation of Attentional Demand in a Simulated Driving Environment"

\author{
Investigators: Catherine Courage, Dr. Paul Milgram
}

I hereby consent to participate in the experiment "An Investigation of Attentional Demand in a Simulated Driving Environment". The objectives, methods, tasks and procedures have been thoroughly explained to me and all my questions and concerns about the apparatus used and other requirements of the experiment have been answered completely to my satisfaction.

I understand that, as a subject in this approximately three hour experiment, I will be required to drive a variety of simulated driving scenarios while wearing shuttering spectacles and I will also be required to answer a questionnaire. In addition, with the understanding that my identity will in no way be divulged to anyone other than the investigators, I consent to have the results of my participation in the experiment published as part of this research. I understand that I will be reimbursed $\$ 37$ for my participation at the conclusion of the experiment. I will have the right to withdraw from this experiment at any point of this experiment without any penalty, and to request that my data be destroyed.

Participant's Name:

Participant's Signature:

Date: 


\section{APPENDIX C}

Demographic Questionnaire

For participation in the experiment "An Investigation of Attentional Demand in a Simulated Driving Environment"

Subject No.

Date:

Time:

1. Age:

2. Gender: $\mathbf{M}$

3. Do you ordinarily wear corrective lenses of any kind?

Yes

No

- If yes, are you wearing prescribed lenses or contact lenses right now?

Yes

No

4. Please indicate the highest educational degree you have achieved to date:

5. Please indicate education beyond the highest educational degree you have achieved to date:

6. Do you hold a valid driver's license?

Yes

No

If yes:

- How many years have you held it?

- What class is the license?

In which province is the license held? 